\title{
Complications in obstructive jaundice: an experimental study in etiology and prevention
}

Citation for published version (APA):

Greve, J. W. M. (1990). Complications in obstructive jaundice: an experimental study in etiology and prevention. [Doctoral Thesis, Maastricht University]. Maastricht University. https://doi.org/10.26481/dis.19900420jg

Document status and date:

Published: 01/01/1990

DOI:

10.26481/dis.19900420jg

Document Version:

Publisher's PDF, also known as Version of record

\section{Please check the document version of this publication:}

- A submitted manuscript is the version of the article upon submission and before peer-review. There can be important differences between the submitted version and the official published version of record.

People interested in the research are advised to contact the author for the final version of the publication, or visit the DOI to the publisher's website.

- The final author version and the galley proof are versions of the publication after peer review.

- The final published version features the final layout of the paper including the volume, issue and page numbers.

Link to publication

\footnotetext{
General rights rights.

- You may freely distribute the URL identifying the publication in the public portal. please follow below link for the End User Agreement:

www.umlib.nl/taverne-license

Take down policy

If you believe that this document breaches copyright please contact us at:

repository@maastrichtuniversity.nl

providing details and we will investigate your claim.
}

Copyright and moral rights for the publications made accessible in the public portal are retained by the authors and/or other copyright owners and it is a condition of accessing publications that users recognise and abide by the legal requirements associated with these

- Users may download and print one copy of any publication from the public portal for the purpose of private study or research.

- You may not further distribute the material or use it for any profit-making activity or commercial gain

If the publication is distributed under the terms of Article $25 \mathrm{fa}$ of the Dutch Copyright Act, indicated by the "Taverne" license above, 


\section{COMPLICATIONS IN OBSTRUCTIVE JAUNDICE}

An experimental study on etiology and prevention 


\section{COMPLICATIONS IN OBSTRUCTIVE JAUNDICE}

\section{PROEFSCHRIFT}

ter verkrijging van de graad van doctor

aan de Rijksuniversiteit Limburg te Maastricht, op gezag van de Rector Magnificus, Prof. Dr. F.I.M. Bonke, volgens het besluit van het College van Dekanen, in het openbaar te verdedigen op vrijdag 20 April 1990 des namiddags om vier uur

door

Johannes Wilhelmus Maria Greve

geboren te Utrecht in 1956 
Promotores

Prof. Dr. J.M. Greep

Prof. Dr. P.B. Soeters

Co-promotores Dr. D.J. Gouma

Dr. W.A. Buurman

Beoordelingscommissie Prof. Dr. J.A. Flendrig (voorzitter)

Prof. Dr. J.W. Arends

Prof. Dr. P.J. Brombacher

Prof. Dr. H. Obertop

Prof. Dr. G.N.J. Tytgat

CIP-DATA KONINKLIJKE BIBLIOTHEEK, DEN HAAG

Greve, Johannes Wilhelmus Maria

Complications in obstructive jaundice : an experimental study on etiology and prevention / Johannes Wilhelmus Maria Greve. - Maastricht : Datawyse. - Ill.

Thesis Maastricht. - With ref. - With summary in Dutch.

ISBN 90-5291-022-7

SISO 605.19 UDC 616.94(043.3)

Subject headings: obstructive jaundice ; complications / obstructive jaundice ; prevention / endotoxins.

Produktie en layout: Datawyse Maastricht, Ruud Leliveld Druk: Krips Repro Meppel

De druk van dit proefschrift werd financieel mogelijk gemaakt door steun van Duphar Nederland B.V., Kabivitrum en Glaxo B.V. 
In memory of my father

To Chantal, Charlotte and......

To my mother 


\section{CONTENTS}

\section{Chapter 1}

INTRODUCTION 9

General introduction 9

$\begin{array}{lr}\text { Survey of the literature } & 10\end{array}$

$\begin{array}{ll}\text { Obstructive jaundice } & 10\end{array}$

$\begin{array}{ll}\text { Cause } & 10\end{array}$

Diagnosis 10

Histological changes $\quad 11$

Risk factors 11

Mortality rates after surgery in jaundiced patients $\quad 12$

Studies on the etiology of complications $\quad 12$

Hemorrhage 13

Wound healing 14

Septic complications $\quad 15$

Deterioration of renal function $\quad 16$

$\begin{array}{ll}\text { Prevention } & 18\end{array}$

General precautions 18

$\begin{array}{ll}\text { Preoperative biliary drainage } & 19\end{array}$

Anti-endotoxin treatment $\quad 19$

Conclusion 21

\section{Chapter 2}

INTRODUCTION TO THE EXPERIMENTS

Aim of the thesis 23

Endotoxins and tumor necrosis factor 25

Determination of endotoxins $\quad 25$

Tumor necrosis factor $\quad 25$

Introduction to the experiments 26

Role of endotoxins in obstructive jaundice $\quad 26$

Anti-endotoxin effects of bile salts and lactulose, mechanism of action $\quad 27$

Effect of endotoxin and TNF on renal function 28

Effect of preoperative intervention on postoperative morbidity and mortality in jaundiced rats $\quad 28$

References to chapters 1 and $2 \quad 30$ 


\section{Chapter 3}

SUPPRESSION OF CELLULAR IMMUNITY IN OBSTRUCTIVE

JAUNDICE IS CAUSED BY ENDOTOXINS. A study in germfree rats 39

Chapter 4

BILE ACIDS INHIBIT ENDOTOXIN INDUCED TUMOR NECROSIS

FACTOR PRODUCTION BY MONOCYTES. An in vitro study

\section{Chapter 5}

LACTULOSE INHIBITS ENDOTOXIN-INDUCED TUMOUR

NECROSIS FACTOR BY MONOCYTES. An in vitro study

\section{Chapter 6}

INCREASED SENSITIVITY TO ENDOTOXEMIA BY TISSUE

NECROSIS

\section{Chapter 7}

PREVENTION OF POSTOPERATIVE COMPLICATIONS IN

JAUNDICED RATS. Internal biliary drainage versus oral lactulose 101

\section{Chapter 8}

GENERAL CONCLUSION

\section{Chapter 9}

SUMMARY

SAMENVATTING

Acknowledgements

Curriculum vitae 



\section{Chapter 1}

\section{Introduction}

\section{GENERAL INTRODUCTION}

Despite improvements of modern perioperative care the complication rate after surgery in jaundiced patients remained virtually unaltered during the last decades (1). The complication rate is much higher than is found after similar surgery in not jaundiced patients.

The increased risk of surgery in jaundiced patients was recognized many years ago. In 1911 Clairmont described the occurrence of acute renal failure following surgery for obstructive jaundice with fatal outcome (2). To prevent complications Whipple proposed in 1935 a two staged procedure for surgery in deeply jaundiced patients with pancreatic carcinoma (3). The first stage consisted of a cholecystogastrostomy to decompress the biliary tract in order to restore normal liver function, followed 3-4 weeks later by radical resection of the tumor. Since then numerous experimental and clinical studies were performed to investigate the cause and possible preventive treatments of complications after surgery in patients with obstructive jaundice. Many of these supportive measures were ineffective or at least controversial despite initial hopeful results.

Obstructive jaundice may be caused by benign lesions of the biliary tract. The main causes of biliary obstructions, however, are malignancies. Despite general. advancements of chemo- and radiotherapy $(4,5)$, curative treatment of these malignancies can still only be offered by radical surgical resection. The treatment of these patients involves major surgical procedures with concomitant complications. Even palliative surgical treatment of obstructive jaundice is associated with a high morbidity and mortality.

The development of new techniques to drain the obstructed biliary tract via a percutaneous transhepatic route (PTD) (6) or by endoscopic retrograde canuulation of the common bile duct (ERCP) (7) has made the need for palliative surgical drainage less indicated. However, long-lasting biliary drainage with 
intemally placed drains is associated with many catheter related problems like displacement, clogging and recurrent cholangitis. In these cases a surgical biliodigestive bypass procedure may be the preferred treatment, also allowing a concomitant gastroenterostomy when indicated. Finally in nonmalignant obstructions of the biliary tract surgical bypass remains the therapy of choice in low risk patients.

In conclusion surgical treatment of biliary obstruction is still often required, and is in cases of malignant obstruction the only possible curative therapy. However these procedures are associated with considerable morbidity and mortality. It is therefore opportune to study the causes and possible preventive treatments of postoperative complications in jaundiced patients.

SURVEY OF THE LITERATURE

\section{Obstructive jaundice}

\section{Cause}

Obstructive jaundice can be caused by either extra- or intrahepatic occlusion of the bile ducts. This thesis will exclusively deal with the complications associated with the treatment of extra hepatic biliary obstruction which is sometimes called "surgical jaundice" $(8,9)$, although some of the pathophysiologic mechanisms described may also be applicable to intrahepatic cholestasis. Extrahepatic biliary obstruction may be due to either a malignant or a benign proces. Malignant obstructions are mainly caused by carcinoma of the pancreas, the bile ducts, the gallbladder or of the papilla of Vater and by metastases in the liver hilus and /or hepatoduodenal ligament. Benign causes are common bile duct stones, postsurgical sequelae, sclerosing cholangitis, chronic pancreatitis and choledochal cysts.

\section{Diagnosis}

The diagnosis of extra-hepatic biliary obstruction is mainly based on history, physical examination, liver enzyme and bilirubin plasma levels in combination with ultrasonography. ERCP and /or PTC are invaluable to determine the level and cause of the obstruction. Cytology obtained by aspiration of bile from the biliary tract or by direct puncture of the tumor can confirm the diagnosis of a suspected malignancy, in which case CT scanning and angiography are helpful to further evaluate operability and local vascular anatomy. 


\section{Histological changes}

Biliary obstruction causes an increased pressure in the biliary tree and hepatic bile secretion is inhibited when intrabiliary pressure exceeds $120-250 \mathrm{~mm} \mathrm{H} \mathrm{H}_{2} \mathrm{O}$ (10). Cholestasis will lead to cholangiolitic changes marked by distortion and swelling of the bile canaliculus. High concentrations of bile salts at the canalicular membrane are suggested to initiate these changes (11). Prolonged cholestasis results in deposition of reticulin fibers and finally of mature collagen the process of fibrosis and formation of scar tissue. The perilobular fibrotic changes can cause portal hypertension and are sometimes referred to as "secondary biliary cirrhosis". However, in contrast to true cirrhosis, the lobular architecture of the liver is usually well preserved and to a very late stage the fibrotic changes remain reversible (8). On a cellular level an increase of rough and smooth endoplasmatic reticulum and the number of lysosomes is observed. These changes are reported to be maximal at the biliary pole of the hepatocyte, and may be related to local concentrations of bile salts (12). The high bile acid concentration is suggested to be toxic to the hepatocytes causing necrosis and leucocyte infiltration around the portal tracts (biliary peacemeal necrosis) (11). These histological changes are largely reversible by decompression of the biliary tract.

\section{Risk factors}

Clinical review studies on the treatment of pancreatic carcinoma show that obstructive jaundice is a major risk factor related to postoperative complications $(2,3,13-15)$. A high bilirubin level not only predicts a higher mortality rate, but is also associated with an enhanced frequency of renal insufficiency, septic complications and postoperative hemorrhage (13-15).

In several studies risk factors have been identified which are specifically related to morbidity and mortality in jaundiced patients (16-20). Hunt found in a prospective study that serum bilirubin level $(>300 \mu \mathrm{mol} / \mathrm{l})$, glomerular filtration rate $\left(<50 \mathrm{ml} / \mathrm{min} / 1.73 \mathrm{~m}^{2}\right)$, the presence of fibrin degrading products and endotoxemia were related with an enhanced mortality rate (16). Pitt et al analyzed 155 patients undergoing biliary tract surgery and found 8 parameters (malignancy, age $>60$, hematocrit $<30 \%$, white blood cell count $>10.000$, albumin $<30 \mathrm{~g} / \mathrm{l}$, bilirubin $>170 \mu \mathrm{mol} / \mathrm{l}$, alkaline phosphatase $>100$ IU (normal 0-32 IU), and creatinine $>115 \mu \mathrm{mol} / \mathrm{l}$ ) that correlated highly with morbidity and mortality (17). In the latter study the number of risk factors present in each individual patient correlated significantly with postoperative mortality. Multivariant analysis in a retrospective study on 373 patients undergoing surgery for 
relief of biliary tract obstruction identified only three independent factors that were significantly associated with morbidity and mortality: hematocrit $<30 \%$, serum bilirubin $>200 \mu \mathrm{mol} / \mathrm{l}$ and malignancy $(18,21)$. These results were confirmed in a prospective study of the same group in which it was also shown that, in patients with benign biliary obstruction, only bilirubin levels correlated with mortality (20). In a similar group of patients studied retrospectively, serum creatinine, serum albumin and bilirubin levels appeared to significantly predict postoperative mortality (19). The value of risk factors was confirmed in a prospective study in which a computerprogram was used preoperatively to estimate the operation risk (22). Serum creatinine levels, serum albumin levels and a cholangitis score were used as parameters in the latter study.

It seems evident that the severity of jaundice correlates with the occurrence of complications. The observation that both serum albumin levels and hematocrit, in most of these studies, are associated with operative morbidity and mortality suggests that impairment of the nutritional status of these patients is in part responsible for the enhanced complication rate. Although the results of these studies on risk factors in patients with obstructive jaundice are difficult to compare they all confirm the high complication rate after surgery in these patients.

\section{Mortality rates after surgery in jaundiced patients}

Surgery of the biliary tract in non-jaundiced patients has a very low morbidity and mortality rate. Even more complicated procedures, including exploration of the common bile duct in elderly patients, are associated with mortality rates of less than $2.5 \%$ and renal insufficiency occurs in less than $0.1 \%$ of the cases (23-26). In contrast postoperative mortality rates in jaundiced patients reported since 1960 ranged from $3.3-42.8 \%$, with an average of $16.5 \%(15-20,22,27-45)$.

A major complication related to this high mortality rate is acute renal failure. Postoperative renal failure occurs in $4-18 \%(15,17-20,29,30,38,41,43,44,46$ 48) of jaundiced patients and the mortality rate in patients developing this complication is over $75 \%$ (1).

Postoperative hemorrhage, another major complication after surgery in jaundiced patients, is reported to occur in 4-21\% of the patients $(15-21,29-31,39,41$ $44,49)$. This complication is associated with high mortality rates of up to $48 \%$ $(17,18,20,21,44,49)$. 
Furthermore postoperative infectious complications, such as wound infections, intraabdominal sepsis and septic shock occur in $9-72 \%$ of the jaundiced patients and contribute largely to the reported high morbidity and mortality $(15-20,29,30,37-39,41-44,50,51)$.

Postoperative morbidity and mortality remain high even in more recent studies, although some authors did report low complication rates. Trede (31) reported a mortality rate of $3.3 \%$ in jaundiced patients undergoing pancreatic resection, however, most of the patients with obstructive jaundice had been treated preoperatively by internal biliary drainage and the morbidity in these patients was still $31 \%$. Others reported an overall mortality rate of $4.7 \%$ in treatment of biliary tract obstruction (44). In this study, the majority of the patients had low serum bilirubin levels and 81 of the 129 patients had a benign obstruction in which mainly limited surgical procedures had to be performed. These excellent results are exceptional and only applicable to selected patient groups. In patients with severe jaundice the complication rates are still high.

The variety of parameters observed and reported in the numerous publications on complications after surgery in jaundiced patients and the even greater variation in treatment protocols makes a thorough comparison of the results very complicated. However, as concluded from the studies on risk factors, the complication rates in this particular group of patients are high compared to non-jaundiced patients undergoing similar surgical procedures.

\section{Studies on the etiology of complications}

Postoperative complications in jaundiced patients can be divided in renal disorders, infectious complications, hemorrhage and impaired wound healing. The high complication rate initiated many studies to examine the cause of these complications and thus to find treatments to prevent them. A number of these studies investigated the effect of potential toxic substances as bilirubin and bile salts which accumulate due to cholestasis. Most studies however have been designed to analyze the cause of specific complications, therefore the literature will be discussed accordantly.

\section{Hemorrhage}

Hemorrhage is a serious complication occurring either per- or postoperatively in the afore mentioned frequency. In early studies massive bleeding in jaundiced patients was reported to be caused by vitamin $\mathrm{K}$ deficiency, as a result of impaired liver function (48). Despite normal coagulation some patients developed postoperative hemorrhage which was caused by gastric erosions 
(21). These gastric erosions were suggested to be caused by endotoxemia, which was based on studies in animals in which endotoxins induced similar lesions (53-55). Others reported hypercoagulability and decreased fibrinolytic activity in jaundiced patients $(56,57)$. This disseminated intravascular coagulation (DIC) was also suggested to be caused by endotoxins. Furthermore, increased fibrin degradation products in combination with endotoxemia were shown to be associated with increased mortality in jaundiced patients (58). Surprisingly, in the latter study, endotoxin levels in jaundiced patients were not different from control patients making an effect of endotoxins less certain. Finally in rats with experimental biliary obstruction normal clot formation was found, however fibrinolytic activity was increased (59). The latter could also explain the increased bleeding tendency seen in patients. These studies in obstructive jaundice offered two explanations for the cause of postoperative hemorrhage. First an increased fibrinolytic activity leading to insufficient coagulation and secondly occurrence of gastric erosions. Both phenomena were suggested to be caused by endotoxins.

\section{Wound healing}

Impaired wound healing is frequently observed in jaundiced patients resulting in incisional hernias in 10.3-12.5\% and wound dehiscence in $2-14.6 \%$ of the patients $(19,60,61)$. The presence of malignancy and subsequently poor nutritional status were considered to be related to delayed wound healing, wound healing was reported not to be related to bilirubin levels $(60,61)$. However, an inhibitory effect of both serum from jaundiced patients and of bilirubin on growth of cultured fibroblasts was reported (62), suggesting that bilirubin is responsible for impaired wound healing in jaundiced patients. Further explanations for impaired wound healing were the reduced migratory activity of reticuloendothelial cells and fibroblasts (63), and reduced prolyl hydroxylase levels (64). The latter reflects collagen turnover in the wounds and was shown to be reduced in both jaundiced patients and jaundiced rats $(64,65)$. These experimental studies did suggest a mechanism but not a cause through which the impaired wound healing can be explained. Further studies on burst strength of wounds in jaundiced rats showed controversial results. Two experiments confirmed the impaired wound healing and suggested a toxic effect of bilirubin or bile salts $(66,67)$. In contrast bursting strength of abdominal wounds was not significantly decreased in other studies $(68,69)$. Nevertheless, a significantly delayed collagen accumulation was found in the wounds and the investigators suggested that their techniques may have been insufficient to detect delayed wound healing (68). Snellen however, using similar techniques for assessment of bursting strength of abdominal wounds and duodenal anastomoses, did find 
significantly decreased wound healing (59). In this study a relation of wound healing and the impaired nutritional status was suggested. This was not substantiated because in an other study no difference was found between wound healing of jaundiced rats treated with preoperative parenteral nutrition and jaundiced rats treated with preoperative administration of saline (70). Moreover, the presence of an impaired nutritional status in jaundiced rats was seriously questioned (71).

The few studies on wound healing do not allow definite conclusions. Even the fact that impaired wound healing occurs in obstructive jaundiced has not been ascertained, and etiologic factors have not been identified. One might conclude that the observation by "experienced surgeons" $(65)$ that jaundiced patients tend to develop wound complications could not be confirmed by the results of experimental studies.

\section{Septic complications}

Septic complications are the most frequent complications in jaundiced patients. A major part of mortality is caused by these septic complications. In some studies a relation between the impaired nutritional status and the occurrence of septic complications was suggested $(17,18,50)$. This correlated well with studies in malnourished non-jaundiced patients, who were found to be more susceptible to infections (72-74). Other studies reported a relation between the preoperative infection of the biliary tract, specially after invasive diagnostic and preoperative drainage procedures $(75,76)$, and the occurrence of septic complications $(50,56,77)$.

Impairment of the function of the immune system was also suggested as a possible cause. This was based on the observation that jaundiced patients have reduced delayed-type hypersensitivity skin tests, suggesting an impaired cellular immunity $(78,79)$. The latter has important implications on the occurrence of infectious complications as was concluded in a review by Christou et al ( 80 ). Furthermore the reticuloendothelial system (RES) also appeared to be impaired in jaundiced patients $(81,82)$. Based on these findings a series of experimental studies were performed to identify causative factors.

A reduced specific cellular immunity in jaundiced patients was found by Newberry (83). Others did similar observations and suggested the presence of at plasma factor causing this suppression (84). Since then a number of different studies have confirmed these findings $(78,79,85-90)$. In search for a causative factor no relation of bilirubin levels and impaired cellular immunity was observed but a role for bile salts in this respect was suggested (83). In in vitro studies bile salts were actually found to cause suppression of cellular immunity $(79,86)$, however concentrations of the bile salts needed to induce suppression 
of a mitogen-induced lymphocyte response were well above those found in the clinical situation (12,91-93). Roughneen excluded the role of malnutrition as a cause of the impaired cellular immunity in a study with jaundiced rats and suggested that bile salts or bilirubin were involved (87,90). A suppression of cellular immunity was also observed in jaundiced rabbits, but appeared not to be related with bilirubin levels (90). Suppression of cellular immunity was not definite but appeared to be reversible after relief of biliary obstruction $(87,90)$.

Studies on the function of polymorphonuclear leukocytes (PMN) from jaundiced rats revealed an increased $P M N$ superoxide release, indicating activation of the cells $(94,95)$. However similar as lymphocyte function, phagocytic capacity of these PMN appeared to be significantly depressed (94).

Investigations concerning the impairment of the reticuloendothelial system were, in contrast to the studies on cellular immunity, less consistent in their results. Phagocytic activity of Kupffer cells was found to be increased in jaundiced patients (96), and in jaundiced rats (97). These data are in contrast to earlier mentioned clinical studies $(81,82)$ and experimental studies $(90,98,99)$ in which obstructive jaundice was related to a significantly decreased RES function (e.g. Kupffer cell activity). Others found a significantly reduced RES function after correction of RES function for the increased liver mass (100). This in contrast to the study of Snellen, who found increased phagocytic capacity and increased inactivation of endotoxin by the RES of jaundiced rats (59). In a study in dogs bile duct ligation appeared to have no adverse effects on RES function (101). In the latter study however RES measurements were performed after a very short duration of biliary obstruction. The different duration of biliary obstruction prior to the measurements of RES function could, at least in part, explain the controversial results.

It is obvious that the immune system is impaired in obstructive jaundice. Specific cellular immunity was negatively affected in all reported studies. Although the results were controversial, RES function also appears to be impaired as well as PMN phagocytosis. Apart from malnutrition, or the suggested toxic effects of bile salts or bilirubin no causative mechanism could be identified.

\section{Deterioration of renal function}

A number of etiologic factors of postoperative renal impairment in obstructive jaundice have been postulated based on clinical and experimental observations. These factors can be divided in circulation disorders, both systemic and renal, and those related to possible toxic agents, such as bile acids, bilirubin and endotoxin. 
Hypovolemia was suggested to play an important role in the occurrence of renal impairment in obstructive jaundice (102-105). Others could not confirm this but suggested that hypotension and insufficient renal perfusion was caused by an attenuated response to fluid loss (106). A reduced peripheral vascular resistance in combination with a decreased arterial pressure and an increased cardiac output was also proposed as a possible cause $(107,108)$. In contrast two other groups reported a reduced vascular response to noradrenalin although arterial blood pressure was normal $(109,110)$. The mechanisms described were suggested to cause a decreased renal perfusion and subsequently renal impairment. Other studies were directed to the effect of obstructive jaundice on renal blood vessels. Renal blood flow and glomerular filtration rates (GFR) remained normal in jaundiced dogs as reported by Dawson (111) and by Better et al (112). However other investigators found a decreased renal blood flow and GFR in similar experiments $(47,113,114)$. Further discrepancies were found in the vascular response of renal blood vessels to catecholamines. One group of investigators (115) observed an increased vascular sensitivity to catecholamines in baboons with biliary obstruction, whereas others (116) found a decreased vascular response to noradrenalin in kidneys from jaundiced rabbits. The results of these studies remain controversial. Altered renal blood flow and altered systemic vascular reactivity in jaundiced patients may be related to the occurrence of renal impairment, however this relation is not firmly established (1).

The toxic effects of compounds such as bilirubin and bile salts, which accumulate due to biliary obstruction, were also suggested to induce renal failure. Dawson found a significant correlation between bilirubin and creatinine clearance and concluded that bilirubin might be toxic to renal cells $(117,118)$. Bilirubin was also suggested to be responsible for impaired renal function in jaundiced rats $(119,120)$, and was shown to decrease mitochondrial function in in vitro experiments (121). Furthermore, it was demonstrated that jaundiced rats are more sensitive to renal ischemia than normal controls (122). After renal ischemia in Gunn rats, which cannot conjugate bilirubin, this difference was not found, again suggesting that conjugated bilirubin is responsible for renal impairment (119). However conflicting data were reported. In a choledochocaval shunt model isolated hypercholemia, which results in high plasma bilirubin and bile salt levels, did not affect renal function in the dog (123). Moreover, parenterally administered bilirubin did not increase renal ischemic damage whereas parenteral bile acids did, suggested a role for bile salts in the etiology of renal complications (124). The controversial results reported preclude at this moment a definitive conclusion. 
Other toxic substances observed in jaundiced patients are endotoxins. Endotoxins are lipopolysaccharides that form the outer cell wall of gram-negative bacteria. Increased absorption of endotoxins from the gut in jaundiced subjects is suggested to occur because bile salts which normally inactivate these endotoxins are absent in the bowel lumen. Endotoxemia in jaundiced patients was found to be significantly related to renal complications $(125,126)$. Experimental administration of endotoxins in rats affected renal blood flow and peripheral vascular resistance (127). Endotoxins can also cause DIC and renal fibrin deposition, all contributing to impaired renal function $(128,129)$. This suggested that endotoxemia must be considered as a major contributing factor in the development of postoperative renal failure in jaundiced patients (1).

In summary renal complications are suggested to be caused by insufficient blood supply to the kidney, in which hypovolemia, altered vascular reactivity or an attenuated response to fluid loss may play a role, however experimental data are confusing and conflicting. Toxic effects of bile salts and bilirubin on renal cells can also cause renal impairment, again experimental evidence is controversial. Endotoxemia may be a causative factor in the pathogenesis of renal impairment but further studies are necessary to confirm this hypothesis.

\section{Prevention}

\section{General precautions}

Prophylactic antibiotics are routinely used in jaundiced patients. Furthermore, per- and postoperatively patients are generously supported with intravenous fluids. It is even advocated by some groups to preoperatively correct the relative hypovolemia in order to prevent renal complications (103). Control and if necessary correction of coagulation disorders is as mentioned above a standard procedure.

Dawson reported in 1965 that intravenous administration of mannitol prevented postoperative renal impaiment in jaundiced patients (118). Since then mannitol is part of many treatment protocols. Mannitol is suggested to be effective by causing volume expansion, diuresis and natriuresis (osmotic diuretic), moreover it prevents endothelial cell swelling (130). However, its effect is incomplete since postoperative renal impairment still occurs $(47,131)$. Furthermore, recently the use of mannitol was disputed by Gubern et al (104) who even found an increased deterioration of renal function after use of mannitol. 


\section{Preoperative biliary drainage}

A two staged procedure for treatment of jaundiced patients was proposed by Whipple in 1935 (3). The first step of this procedure consisted of surgical drainage of the biliary tract to restore normal liver function. The second stage was performed three to four weeks later and consisted of a surgical resection of the tumor. Although the effect of drainage was positive, intraabdominal adhesions made the second operation (e.g. resection of the tumor) more conplicated and postoperative mortality was not significantly improved. Therefore this two staged procedure was generally abandoned.

Since the introduction of percutaneous drainage techniques by Molnar and Stockum in 1974 (132) a renewed interest in preoperative biliary drainage resulted in a series of clinical studies. The first reports on preoperative external biliary drainage were sensational. Takada et al (133) reported a reduction of postoperative mortality from $41 \%$ to $4 \%$. Similar results were reported by several other groups $(30,33,34,37,39,41,134)$. However in these studies the effect of preoperative drainage on postoperative outcome was compared to historical controls. More recent prospective randomized studies by others ( 40 , 42,43) did not confirm the remarkable benefit of preoperative external biliary drainage. Gouma and Moody (135) reviewed all reports on (external) preoperative biliary drainage from 1974 to 1984 and concluded that the hazards of this technique did outweigh the possible advantages. Internal biliary drainage may offer better results by preventing loss of fluids and electrolytes and by closing the enterohepatic cycle of bile salts. The positive effect of internal biliary drainage was confirmed in an experimental study, in which internal biliary drainage significantly reduced mortality after intraabdominal sepsis in jaundiced rats whereas external biliary drainage did not (136). Despite these promising results, until now only one prospective clinical study using internal biliary drainage via a percutaneously placed drain was reported (38). However when drainage related complications were included in the evaluation of this study no significant improvement was provided by preoperative biliary drainage.

Preoperative biliary drainage is a logical solution to prevent postoperative complications in jaundiced subjects. Data obtained indicate that a beneficial effect can be expected. So far, however, clinical results are disappointing. Further studies are needed to improve the used techniques and to substantiate the expected positive effect.

\section{Anti-endotoxin treatment}

As discussed endotoxins are lipopolysaccharides from the outer cell wall of Gram-negative bacteria. These lipopolysaccharides were shown to be extremely toxic and when administered in adequate dosage to animals will unleash a 
reaction which will lead to multiple organ failure and death $(137,138)$. In 1970 Levin (139) reported a technique to measure endotoxins in serum of septic patients. Using this test, significant amounts of endotoxin were found in blood. of jaundiced patients and this endotoxemia was shown to be related to acute renal failure $(125,126,128)$. Similar observations were reported by other investigators $(47,131,140-142)$. Furthermore a relation of endotoxemia with postoperative hemorrhage was suggested (58). Significant endotoxemia was also found in rats with experimental biliary obstruction (143). This endotoxemia decreased after internal but not after external biliary drainage.

Endotoxins are present in enormous amounts in the gastrointestinal tract. Under normal circumstances only minute amounts of these endotoxins are absorbed, and if absorbed are efficiently cleared by the reticuloendothelial system of the liver (144). Bile salts probably play an important role in the defence against endotoxins from the gut (145). In vitro studies have shown that bile salts disperse endotoxins into nontoxic subunits (146-148). In jaundiced rats oral administration of endotoxins led to a significantly increased mortality (140). However, when the rats were treated with oral bile salts prior to oral endotoxins mortality did not occur (140). Based on this observation clinical studies with oral bile salts were started, to prevent endotoxemia in jaundiced patients. Taurocholate significantly decreased occurrence of endotoxemia, and renal impairment was significantly reduced in treated patients (149). Similar results were found with sodium deoxycholate $(131,141)$. However, although both chenodeoxycholic acid and ursodeoxycholic acid did significantly reduce endotoxin levels, they did not improve renal function $(141,150)$. Further contradictory results were reported by Gawley et al (151), who confirmed that sodium deoxycholate prevented endotoxin absorption, but in contrast to the previously mentioned study with deoxycholic acid (141), they observed an impaired renal function in the treated patients.

Polymyxin B, an antibiotic with endotoxin binding properties, was also used to reduce endotoxin toxicity (152). It prevented endotoxin related complications in jaundiced rats (152). However, in jaundiced patients Polymyxin B had no effect on endotoxin levels nor on postoperative outcome (142). A great handicap in the use of Polymyxin B is its nephrotoxicity which does not allow the use of adequate high dosages in patients.

Lactulose, a synthetic non-toxic disaccharide, suggested to inactivate endotoxins was also used as an "anti-endotoxin drug" (153,154). Oral lactulose significantly reduced mortality in jaundiced rats after oral administration of endotoxins (153). In jaundiced patients postoperative renal impairment as well as endotoxin levels were significantly reduced by preoperative oral treatment with lactulose (153). 
A review of the treatments applied to prevent postoperative complications reveals that, although there are promising experimental results, most clinically used treatments remain controversial. In spite of this, the use of anti-endotoxin therapies seems justified. On theoretical grounds preoperative internal biliary drainage deserves great attention. However, as stated above the efficacy of internal biliary drainage in jaundiced patients has not been ascertained.

\section{Conclusion}

Postoperative complications still jeopardize the surgical treatment of jaundiced patients. So far the numerous studies addressing potential etiologic factors of the enhanced complication rates did not offer a clear solution to solve this problem. Endotoxins were indicated as a possible cause of renal impairment and were suggested to be related to postoperative hemorrhage and the enhanced mortality rates. Furthermore treatments directed against endotoxins (e.g. bile salts and lactulose) showed promising results, although the mechanism of action remained unclear. Controversial results were obtained with preoperative biliary drainage in patients, however results of experimental studies do justify further exploration. 


\section{Chapter 2}

\section{Introduction to the experiments}

\section{ATM OF THE THESIS}

The literature review revealed that many causative factors have been related to postoperative complications in jaundiced patients. These factors are thoroughly interlaced as depicted in figure A. In general, in obstructive jaundice, every etiologic factor, which is suggested to play a role in the development of a certain complication, is disputed by at least one other study on the same subject. No etiologic factor was identified which, without any doubt, is responsible for a specific complication, thus rational preventive treatments are difficult to develop. Apparently complications in obstructive jaundice are caused by more than one factor. One of these, not yet extensively examined, factors is endotoxin. Endotoxemia, as is shown in figure A, is suggested to be related to most complications that occur.

The exact role of endotoxins remains unclear. Moreover, measurements of endotoxins in clinical studies yielded controversial results $(126,142)$. Contradictory results were also reported in experimental studies. According to some investigators plasma from jaundiced rats contained considerable amounts of endotoxins (143), whereas in other studies no endotoxins could be detected (155).

Endotoxins are difficult to measure in plasma. However, recently the endotoxin assay, as will be described later was considerably improved. Furthermore the detection and cloning of tumor necrosis factor (TNF), the main mediator of endotoxin toxicity, led to a better understanding of the pathophysiologic phenomena underlying endotoxin induced complications. Plasma TNF levels can be used as a new parameter to study the presence of endotoxins. 


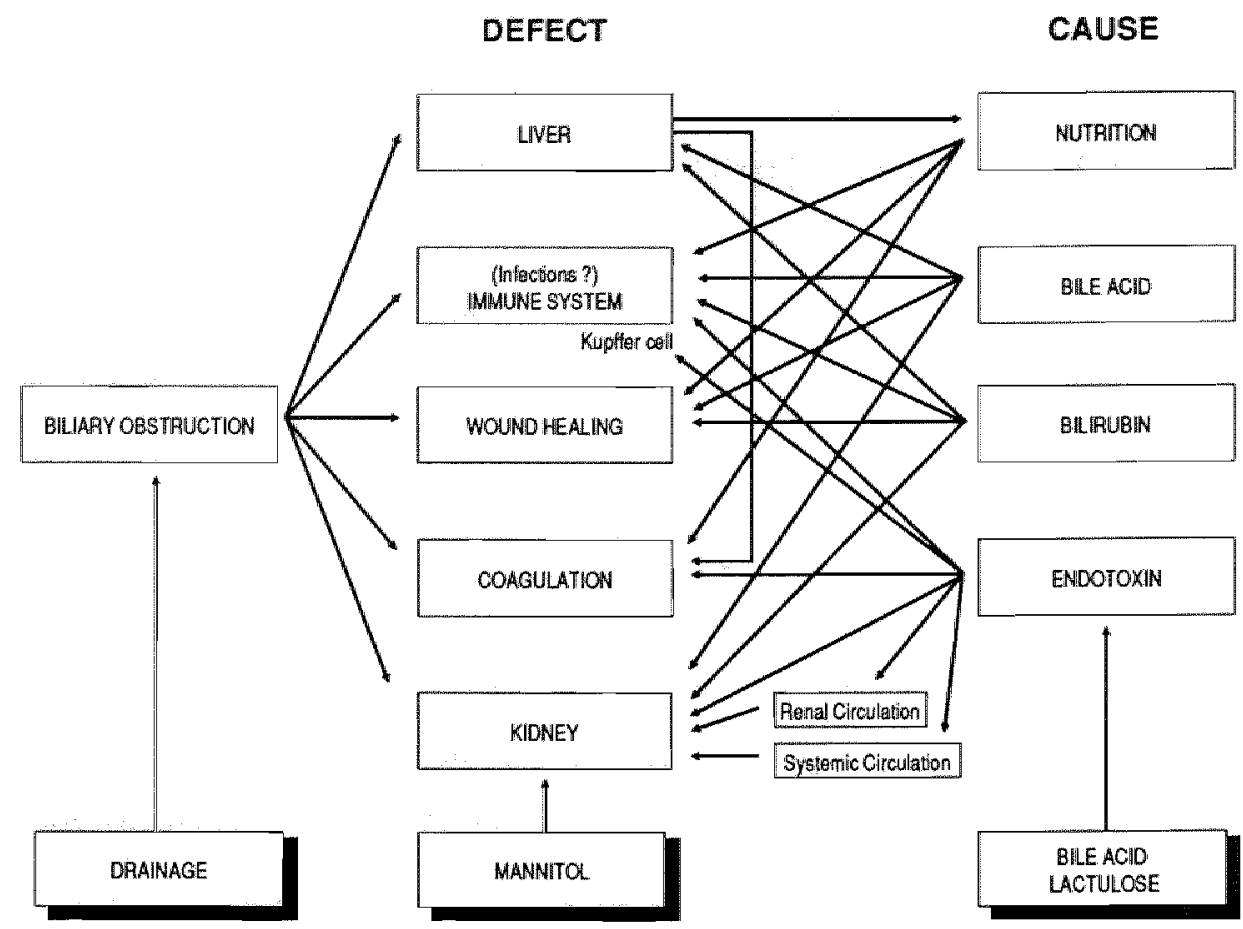

Figure A. Impaired organ functions related to postoperative complications in patients with biliary obstruction and suggested causative factors. Comelations are shown between impaired organ functions and possible etiologic factors as reported in the literature. The causative factors are shown on the right side of the figure, the affected organ systems in the middle. Suggested preventive treatments are shown in shadow-boxes.

\section{Aim of the thesis}

The presence and possible role of endotoxins in the development of complications, in obstructive jaundice, was studied in the experiments presented in this thesis. Based on both the literature survey and the availability of new techniques to determine endotoxin and TNF levels, several questions were posed.

1) Are endotoxins related to postoperative infectious complications in obstructive jaundice. Furthermore can the role of endotoxins be studied by determination of TNF.

2) By which mechanism do the alleged anti-endotoxin treatments prevent endotoxin related complications, and are they really active. 
3) What is the role of endotoxins in the deterioration of renall function in obstructive jaundice.

4) What is the effect of biliary drainage or anti-endotoxin treatments with respect to prevention of complications.

\section{ENDOTOXIN AND TUMOR NECROSIS FACTOR}

\section{Determination of endotoxins}

The test used to determine endotoxins is based on activation of an enzyme system. This enzyme system is derived from blood of the horseshoe crab (Limulus polyphemus), which coagulates in presence of low amounts of endotoxin. The early tests used were rather insensitive (detection limits from 1-5 $\mathrm{ng} / \mathrm{ml}$ ) and liable to alterations of experimental circumstances (156), which might explain its variable results. Besides the relatively primitive endotoxin assay used in the early studies on plasma endotoxin levels in jaundiced patients there were also potential problems with the determination of plasma samples. Test samples are easily contaminated during handling, and in addition plasma has a high capacity to inactivate endotoxins $(157,158)$. Therefore plasma samples have to be inactivated by heating and subsequently endotoxin levels have to be assessed immediately or samples must be stored at $-20^{\circ} \mathrm{C}(156,159)$. Recently the assay was drastically improved by using a chromogenic substrate that is converted by the activated enzyme system resulting in a color reaction (160). Further improvements were achieved by standardization $(\mathrm{pH}$, temperature, buffer solutions) of the assay $(156,159)$. The new chromogenic assay allows quantitative measurements with detection limits below $1.0 \mathrm{pg} / \mathrm{ml}$ in plasma and $1 \mathrm{pg} / \mathrm{ml}$ in water (159). However varying results of recent studies indicate that plasma kinetics of endotoxins during disease may be unpredictable $(155,161,162)$.

\section{Tumor necrosis factor}

Tumor necrosis factor (TNF) is a cytokine that is mainly produced by mononuclear phagocytes in response to endotoxins. Two different leads led to the discovery and cloning of TNF. One group studied the factor responsible for cachexia in animals with parasitic diseases (163). Another group isolated the factor responsible for tumor necrosis as observed after administration of en- 
dotoxins (164). A cytokine was isolated which was called cachectin by the first and TNF by the latter group. Further analysis revealed that this cytokine (TNF) also mediated the toxic effects of endotoxin (163). Administration of TNF caused a similar physiological response as endotoxins $(138,163,165)$. Moreover treatment of animals with an anti-TNF antibody could prevent most of the symptoms of endotoxin-induced shock $(137,166)$. Based on these data it seems justified to use TNF serum levels in order to estimate endotoxin effects.

In early studies TNF was detected with a bio-assay based on the sensitivity of cultured mouse fibroblasts (L929) for TNF (167). Recently a very sensitive and specific assay for determinations of human TNF became available. The assay consisted of a sandwich type enzyme-linked-immuno-sorbent-assay (ELISA) in which TNF specific anti-bodies were used that were raised in our laboratory. The ELISA is described in more detail in Chapter 4.

In the experiments, presented in this thesis, TNF measurements were performed to further elucidate the involvement of endotoxin in the pathogenesis of complications in obstructive jaundice. Furthermore, as will be described later, TNF measurements were used in an in vitro model to investigate the "anti-endotoxin" effect of different agents.

\section{INTRODUCTION TO THE EXPERIMENTS}

\section{Role of endotoxin in obstructive jaundice}

The experiments presented in Chapter 3 were performed to evaluate the role of endotoxins in obstructive jaundice. Previous studies by Gouma et al (143) had shown that experimental biliary obstruction in rats resulted in a significant endotoxemia. It was also shown that biliary obstruction results in an increased mortality after intraabdominal sepsis in rats (136). Intemal biliary drainage in rats did significantly reduce endotoxemia (143), and mortality (136). The significantly reduced cellular immunity observed after biliary obstruction in rats was also reversed by internal biliary drainage ( 87 ). This suggested that endotoxemia could be related to both increased mortality and decreased cellular immunity.

It is difficult to study the effect of one isolated factor, in a model in which the introduction of extrahepatic biliary obstruction causes a multiplicity of changes in metabolism. Therefore the role of endotoxin was studied in a model in which endotoxins were as low as possible. By comparing the differences after biliary obstruction in jaundiced rats with or without endotoxins it can be deduced if and 
which organ system is functionally impaired by endotoxins. Germ-firee endotoxin poor rats, which were kept on a special endotoxin free diet, were used. After bile duct ligation indicators of the nutritional status and the immune system were studied. Conventional rats were used as controls. Endotoxins were measured with the modified chromogenic limulus assay. To further study if endotoxins were involved peritoneal macrophages were harvested from the rats. The activation of these macrophages was determined by measuring the spontaneuos TNF production, as indicator for presence of endotoxins.

\section{Anti-endotoxin effects of bile salts and lactulose, and mechanism of action}

In clinical and experimental studies lactulose and bile salts were used to prevent endotoxin related complications $(141,153)$. The efficacy of the bile acids was related to their capacity to prevent the absorption of endotoxins from the bowel lumen (145). Taurocholate and deoxycholic acid did prevent endotoxemia and reduced renal complications $(131,149)$. However, chenodeoxycholic acid and ursodeoxycholic acid also reduced endotoxemia but did not protect renal function disputing the suggested relation $(141,150)$. Lactulose was also suggested to be effective by inactivation of endotoxins (153). The mechanism of action of the anti-endotoxin therapies remains unclear. Therefore, the effect of bile acids and lactulose on endotoxin toxicity was studied in an in vitro model (Chapters 4 and 5).

The toxicity of endotoxins is, as mentioned above, largely mediated by TNF which is mainly produced by mononuclear phagocytes (168). Based on this, an in vitro model was designed in which the effect of different agents on endotoxin toxicity could be tested. To this end, the influence of different agents on the endotoxin-induced TNF production by cultured monocytes was studied. TNF levels were assessed with the described ELISA. The modified chromogenic limulus assay was used to determine the direct effect of bile salts or lactulose on endotoxins (159).

\section{Effect of endotoxins and TNF on renal function}

In the first experiments it was shown that endotoxins, at least in part, are responsible for some complications in obstructive jaundice. Endotoxins may also be the etiologic agent responsible for the deterioration of renal function in jaundiced patients. Relevant to the issue are the data of Zager who reported that 
experimental ischemic renal injury is potentiated by endotoxins (169). Moreover it was shown that kidneys from jaundiced rats are more susceptible to ischemia (122).

The study presented in Chapter 6 was initiated to examine the putative harmful effect of endotoxins and TNF, the mediator of endotoxin toxicity, on renal function. Furthermore, the effect of the combination of tissue damage and endotoxiins on mortality was studied. In rats experimental renal tissue damage was induced by occlusion of the renal vessels. This was combined with administration of endotoxins or tumor necrosis factor.

\section{Effect of preoperative intervention on postoperative morbidity and mortality in jaundiced rats}

So far the present experiments provided evidence that endotoxins are involved in the reduced cellular immunity in jaundiced rats. Furthermore a relation was shown between renal impairment and endotoxins. It was also confirmed by the in vitro experiments that anti-endotoxin agents such as lactulose and deoxycholic acid can reduce endotoxin toxicity.

Subsequently a study was designed to determine the effect of an anti-endotoxin treatment (lactulose), which was compared with the effect of internal biliary drainage, on renal impairment and mortality in jaundiced rats. Internal biliary drainage is the most physiological preventive treatment. It restores natural flow of bile acids to the gut, thus preventing absorption of endotoxins, and also restores normal liver function. Lactulose theoretically only interferes with endotoxin related complications.

The clinical situation was simulated by introducing a severe surgical trauma in jaundiced rats. This trauma consisted of temporary bilateral renal ischemia, a model used in the previous experiments (Chapter 6). Parameters studied were nutritional status, plasma TNF levels, serum triglyceride levels, renal function and mortality. Serum triglyceride levels were determined because TNF levels, just as plasma endotoxin levels, are difficult to be measured reliably due to its not yet clearly understood kinetics in plasma (165). Serum triglycerides were shown to be related to TNF (163). TNF inhibits lipoprotein lipase activity $(170,171)$, as well as induces de novo synthesis of triglycerides in the liver $(172,173)$. Both phenomena will lead to enhanced plasma triglycerides. Since triglycerides have a half life time in plasma of about 17 hours, serum triglyceride levels may be a more functional indicator for plasma TNF levels.

The results of the experiments on the effect of preventive treatments are reported in Chapter 7 . 


\section{REFERENCES OF CHAPTER 1 AND 2}

1 Wait R.B., Kahng K.U. Renal failure complicating obstructive jaundice. Am I Surg $1989 ; 157: 256-263$.

2 Claimont P., Haberer v. H. Ueber Anurie nach Gallenstemoperationen. Mitt Grenzgeb Med Chir 1911;22:159-172.

3 Whipple A.O., Parsons W.B., Mullins C.R. Treatment of carcinoma of the ampula of vater. Ann Surg 1935;102:763-779.

4 Harvey J.H., Schein P.S. Chemotherapy of pancreatic carcinoma. World J Surg 1984; 8:935-939.

5 Dobelbower R.R., Milligan A.J. Treatment of pancreatic cancer by radiation therapy. World J Surg 1984;8:919-928.

6 Gouma D.J. Percutaneous transhepatic drainage in obstructive jaundice. Thesis 1984 , Maastricht, The Netherlands

7 Huibregtse K. Endoscopic biliary and pancreatic drainage. 1988 Georg Thieme Verlag, Stuttgart-New York

8 Benjamin I.S. Biliary tract obstruction. Surg Gastroenterol 1983;2:105-120.

9 Blumgart L.H., Biliary tract obstruction: new approaches to old problems. Am J Surg $1978 ; 135: 19-1$.

10 Lynn J.A.: Physiology of the extrahepatic billiary tree. In Liver and Biliary disease: Pathophysiology, Diagnosis, Management R. Wright, K.G.M.M. Alberti, S. Karran, and G.T.D. Milward-Sadler Eds. Saunders London 1969, p228

11 Schaffner F., Bacchin P.G., Hutterer F. et al. Mechanism of cholestasis: 4. Structural and biochemical changes in the liver and serum in rats after bile duct ligation. Gastroenterology 1971;60:888-892

12 Greim H., Trüzsch D., Czygan P., Rudick J., Hutterer F., Schaffner F., Popper H. Mechanism of cholestasis 6 . Bile acids in human livers with or without biliary obstruction. Gastroenterology 1972;63:846-850.

13 Andrén-Sandberg A., Ihse I. Factors influencing survival after total pancreatectomy in patients with pancreatic cancer. Ann Surg 1983;198:605-610.

14 Gilsdorf R.B., Spanos P. Factors influencing morbidity and mortality in pancreaticoduodenectomy. Ann Surg 1973;177:332-337.

15 Brasch J.W., Gray B.N. Considerations that Jower pancreatoduodenectomy mortality. Am J Surg 1977;133:480-484.

16 Hunt D.R. The identification of risk factors and their application to the management of obstructive jaundice. Aust N Z J Surg 1980,50:476-480.

17 Pitt H.A., Cameron J.L., Postier R.G., Gadacz T.R. Factors affecting mortality in biliatry tract surgery. Am J Surg 1981;141:66-71.

18 Dixon J.M., Armstrong C.P., Duffy S.W., Davies G.C. Factors affecting morbidity and mortality after surgery for obstructive jaundice: a review of 373 patients. Gut $1983 ; 24: 845$ 852.

19 Blamey S.L., Fearon K.C.H., Gilmour W.H., Osborne D.H., Carter D.C. Prediction of risk. in biliary surgery. Br J Surg 1983;70:535-538.

20 Armstrong C.P., Dixon J.M., Taylor T.V., Davies G.C. Surgical experience of deeply jaundiced patients with bile duct obstruction. Br J Surg 1984;71:234-238. 
21 Dixon I.M. Armstrong C.P., Duffy S.W., Elton R.A., Davies G.C. Upper gastrointestinal bleeding. significant complication after surgery for relief of obstructive jaundice. Ann Surg $1984: 199: 271-275$.

22 Little J.M. A prospective evaluation of computerized estimates of risk in the management of obstructive jaundice. Surgery 1987;102:473-476.

23 McSherry C.K., Glenn F. The incidence and causes of death following surgery for nommalignant biliary tract disease. Ann Surg 1980;191:271-275.

24 Crumplin M.K.H, Jenkinson L.R., Kassab J.Y., Whitaker C.M., Al-Boutiahi F.H. Management of gallstones in a district general hospital. Br J Surg 1985;72:428-432.

25 Roukema J.A., Carol EJ., Liem F., Jakimowicz J.J. A retrospective study of surgical common bile duct exploration: ten years experience. Neth J Surg 1986;138:11-15

26 Gouma D.J., Konsten J., Soeters P.B., von Meyenfeldt M., Obertop H. Long-term followup after choledochojejunostomy for bile stone with complex clearance of the bile duct. $\mathrm{Br}$ J Surg 1989;76:451-453

27 Evander A., Fredlund P., Hoevels J., Ihse I., Bengmark S. Evaluation of aggressive surgery for carcinoma of the extrahepatic bile ducts. Ann Surg 1980;191:23-29.

28 Gillen P., Peel A.L.G. Failure to improwe survival by improved diagnostic techniques in patients with malignant jaundice. Br J Surg 1986;73:631-633.

29 Thompson I.N., Edwards W.H., Winearls C.G., Benjamin I.S., Blumgart L.H. Renal impairment following biliary tract surgery. Br J Surg 1987;74:843-847.

30 Gundry S.R., Strodel W.E., Knol J.A., Eckhauser E., Thompson N.W. Efficacy of preoperative biliary tract decompression in patients with obstructive jaundice. Arch Surg $1984 ; 119: 703-708$.

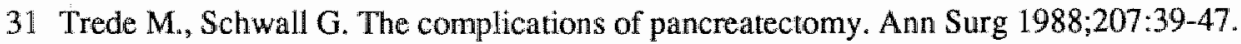

32 McPherson G.A.D., Benjamin I.S., Habib N.A., Bowley N.B., Blumgart L.H. Percutaneous transhepatic drainage in obstructive jaundice: advantages and problems. Br J Surg 1982;69:261-264.

33 Norlander A., Kalin B., Sundblad R. Effect of percutaneous transhepatic drainage upon liver function and postoperative mortality. Surg Gynecol Obstet 1982;155:161-166.

34 Nakayama T., Ikeda A., Okuda K. Percutaneous transhepatic drainage of the biliary tract. Technic and results in 104 cases. Gastroenterology 1978;74:554-559.

35 Dooley J.S., Olney J., Dick R., Sherlock S. Non-surgical treatment of biliary obstruction. Lancet 1979;ii: 1040-1043.

36 Dobbronte Z., Kagel K.O. Preoperative external biliary drainage. Endoscopy 1983;15:215218.

37 Ellison E. C., Van Aman M. E., Carey L.C. Preoperative transhepatic biliary decompression in pancreatic and periampullary cancer. World J Surg 1984;8:862-871.

38 Smith R.C., Pooley M., George C.R.P., Faithfull G.R. Preoperative percutaneous transhepatic internal drainage in obstructive jaundice: A randomized, controlled clinical trial examining renal function. Surgery 1985;97:641-647.

39 Gobien R.P., Stanley J.H., Soucek C.D., Anderson M.C., Vujic I., Gobien B.S. Routine preoperative biliary drainage: effect on management of obstructive jaundice. Radiology $1984 ; 152: 353-356$.

40 Hatfield A.R.W., Terblanche J., Fataar S., Kernoff L., Tobias R., Girdwood A.H., HarriesJones R., Marks I.N. Preoperative external biliary drainage in obstructive jaundice A prospective controlled clinical trial. Lancet 1982;11:896-899. 
41 Denning D.A., Ellison E.C., Carey L.C. Preoperative percutaneous transhepatic biliary decompression lowers operative morbidity in patients with obstractive jaundice. Am II Surg 1981:141:61-65.

42 Pitt H.A., Gomes A.S., Lois J.F., Mann L.L., Deutsch L.S., Longmire W.P. Does preoperative percutaneous biliary drainage reduce operative risk or increase hospital cost?. Ann Surg 1985;201:545-553.

43 McPherson G.A.D., Benjamin I.S., Hodgson H.J.F., Bowley N.B., Allison D.J., Blumgart L.H. Pre-operative percutaneous transhepatic biliary drainage:the results of a controlled clinical trial. Br J Surg 1984;71:371-375.

44 Greig J.D., Krukowski Z.H., Matheson N.A. Surgical morbidity and mortality in one hundred and twenty-nine patients with obstructive jaundice. Br J Surg 1988;75:216-219.

45 Husemann B. Preoperative drainage of common bile duct obstruction. Endoscopy 1983; 15:219-220.

46 Dawson J.L. The incidence of postoperative renal failure in obstructive jaundice. Br J Surg $1965 ; 52: 663-665$.

47 Allison M.E.M., Prentice C.R.M., Kennedy A.C., Blumgart L.H. Renal function and other factors in obstructive jaundice. Br J Surg 1979;66:392-397.

48 Wittenstein B.H., Giacchino J.L., Pickleman J.R., et al. Obstructive jaundice: the necessity for improwed management. Am Surg 1981;47:116-120

49 Pain J.A., Cahill C.J., Bailey M.E. Perioperative complications in obstructive jaundice:therapeutic considerations. Br J Surg 1985;72:942-945.

50 Holman J.M., Rikkers L.F., Moody F.G. Sepsis in the management of complicated biliary disorders. Am J Surg 1979;138:809m813.

51 Lygidakis N.J., van der Heyde M.N., Lubbers M.J. Evaluation of preoperative biliary drainage in the surgical management of pancreatic head carcinoma. Acta Chir Scand $1987 ; 153: 665-668$.

52 Dawson J.L. Acute post-operative renal failure in obstructive jaundice. Ann R Coll Surg Engl 1968;42:163-81.

53 Rosoff C.B., Goldman H. Effect of the intestinal bacterial on acute gastric stress ulceration. Gastroenterology $1968 ; 55: 212-222$

54 Greisman S.E., Woodward C.L. In vivo studies on the role of liver in endotoxin fever and tolerance. I Clin Invest 1970;49:A37

55 Margaretten W., McKay D.G. Thrombotic ulcerations of the gastro-intestinal tract Arch Intern Med 1971;127:250-253

56 Takeda S., Takaki A., Ohsato K. Occurrence of disseminated intravascular coagulation (DIC) in obstructive jaundice and its relation to billary tract infection. Jap J Surg 1977;7:8289.

57 Wardle E.N. Fibrinogen in liver disease. Arch Surg 1974;109:741-746.

58 Hunt D.R., Allison M.E.M., Prentice C.R.M., Blumgart L.H. Endotoxemia, disturbance of coagulation, and obstructive jaundice. Am J Surg 1982;144:325-329.

59 Snellen J.P. Biliary obstruction and... Thesis 1984 Rotterdam

60 Irvin T.T., Vassilakis J.S., Chattopadhyay D.K., Greany M.G. Abdominal wound healing in jaundiced patients. Br J Surg 1978;65:521-522.

61 Armstrong C.P., Dixon J.M., Duffy S.W., Elton R.A., Davies G.C. Wound healing in obstructive jaundice. Br J Surg 1984;71:267-270. 
62 Taube M. Elliot P. Ellis H. Jaundice and wound healing: a tissue-culture study. Br J Exp Path 1981:62:227:231.

63 Lee $\mathbb{E}$. The effecl of abstructive jaundice on the migration of reticulo-endothelial cells and fibroblasts into early experimental granulomata. Br J Surg 1972;59:875-877.

64 Than Than, McGee J.OD., Sokhi G.S., Patrick R.S, Blumgart L.H. Skin prolyl hydroxylase in patients with obstructive jaundice. Lancet 1974;ii:807-808.

65 Than Than MeGee J.O'D. Blumgart L.H. Prolyl hydroxylase in the skin of patients with obstructive jaundice. I Clin Inwest $1977 ; 30: 1044-1047$.

66 Bayer I., Ellis H. Jaundice and wound healing: an experimental study. Br J Surg 1976; $63: 392-396$

67 Amaud. J.P. Humbert W., Eloy M.-R., Adloff M. Effect of obstructive jaundice on wound healing. An experimental study in rats. Am J Surg 1981;141:593-596.

68 Greany M.G., van Noort R., Smythe A., Irvin T.T. Does obstructive jaundice adversely affect wound healing?. Br ISurg 1979;66:478-481.

69 Than T., Evans J.H., Ryan C.J., Smith D.A., Harper A.M., Blumgart L.H. Rupture strength of skin wounds in jaundiced rats. Br J Exp Path 1979;60:107-110.

70 Vree R. Preoperative parenterale voeding en galdrainage. Thesis 1985 Leiden

71 Gouma D.J., Roughneen P.T., Kumar S., Moody F.G., Rowlands B.J. Changes in nutritional status associated with obstructive jaundice and biliary drainage in rats. Am J Clin Nutr 1986;44:362-369

72 Buzby G.B., Mullen J.L., Matthews D.C., Hobbs C.L., Rosato E.F. Prognostic nutritional index in gastrointestinal surgery. Am J Surg 1980;139:160-167.

73 Halliday A.W., Flannigan G.M. Pre- and postoperative nutrition in hepatobiliary surgery. In: Surgery of the liver and biliary tract. L.H. Blumgart Ed. Churchill Livingstone Edinburgh 1987, p 423-433

74 Kahan B.D. Nutrition and host defense mechanisms. Surg Clin North Am 1981;61:557570.

75 Blenkharn J.I., McPherson G.A.D., Blumgart L.H. An improved system for external biliary drainage. Lancet 1981;ii:781-782

76 Blenkharn J.I., McPherson G.A.D., Blumgart L.H. Septic complications of percutaneous transhepatic biliary drainage. Evaluation of a new closed drainage system. Am J Surg $1984 ; 147: 318-321$

77 Keighley M.R.B., Flinn R., Alexander-Williams J. Multivariate analysis of clinical and operative findings associated with biliary sepsis. Br J Surg 1976;63:528-531.

78 Maggiore G., De Giacomo C., Scotta M.S., Siena S., Maccario R., Vitiello A. Cell-mediated immunity in children with chronic cholestasis. J Pediatr Gastroenterol Nutr 1982; 1:385388.

79 Gianni $\mathbb{L}_{\text {, }}$ Di Padova F., Zuin M.., Podda M. Bile acid-induced inhibition of the lymphoproliferative response to phytohemagglutinin and pokeweed mitogen. An in vitro study. Gastroenterology 1980;78:231-235.

80 Christou N.V., Mannick J.A., West M.A., Kasper D.L. Lymphocyte- macrophage interactions in the response to surgical infections. Arch Surg 1987;122:239-251.

81 Drivas $\mathrm{G}$. , James O., Wardle N. Study of reticuloendothelial phagocytic capacity in patients with cholestasis. Br Med J 1976;1:1568-1569.

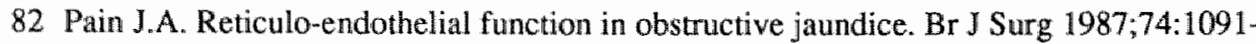
1094. 
83 Newberry W.M., Shorey J.W., Sanford J.P., Combes B. Depression of lymphocyte reactivity to phytohemagglutinin by serum from patients with liver disease. Cell Immunol $1973 ; 6: 87-97$.

84 Fargion S.R., Cappellini M.D., Podda M., Fiorelli G. Immunità cellulare nelle colestasi intra ed extramepatiche. Min Gastr 1976;22:261-265.

85 Pinto M., Kaplun A. Immune status in mice with experimental biliary obstruction. Clin Immunol Immunopathol $1980 ; 16: 396-405$.

86 Keane R.M., Gadacz T.R., Munster A.M., Birmingham W., Winchurch R.A. Impairment of human lymphocyte function by bile salts. Surgery $1984 ; 95: 439-443$.

87 Roughneen P.T., Gouma D.J., Kulkarni A.D., Fanslow W.F., Rowlands B.J. Impaired specific cell-mediated immunity in experimental biliary obstruction and its reversibility by internal biliary drainage. J Surg Res 1986;41:113-125.

88 Roughneen P.T.Kulkarni A.D.Gouma D.J.Fanslow B.J.Rowlands B.J. Suppression of host-versus-graft response in experimental biliary obstruction. Transplantation 1986; 42:687-689.

89 Roughneen P.T., Didlake R., Kumar S.C., Kahan B.D., Rowlands B.J. Enhancement of heterotopic cardiac allograft survival by experimental biliary ligation. Transplantation $1987 ; 43: 437-438$.

90 Vane D.W., Redlich P., Weber T., Leapman S., Siddiqui A.R., Grosfeld J.L. Impaired immune function in obstructive jaundice. J Surg Res 1988;45:287-293.

91 Pennington C.R., Ross P.E., Bouchier A.D. Serum bile acids in the diagnosis of hepatobiliary disease. Gut 1977;18:903-908.

92 Neale G., Lewis B., Weawer V., Panveliwalla D. Serum bile acids in liver disease. Gut $1971 ; 12: 145-152$.

93 Makino I., Nakagawa S., Mashimo K. Conjugated and unconjugated serum bile acid levels in patients with hepatobiliary diseases. Gastroenterology 1969;56:1033-1039.

94 Roughneen P.T., Drath D.B., Kulkarni A.D., Rowlands B.J. Impaired nonspecific cellular immunity in experimental cholestasis. Ann Surg 1987;206:578-582.

95 Wardle E.N., Williams R. Polymorph leucocyte function in uraemia and jaundice. Acta Haemat 1980;64:157-164.

96 Halpern B.N., Biozzi G., Nicol T., Bilbey D.L.J. Effect of experimental biliary obstruction on the phagocytic activity of the reticulomendothelial system. Nature 1957;180:503-504.

97 Arii S., Shibagaki M., Takahashi S., Uozumi T., Tanaka J., Takasan H., Tobe T. Differemt response of reticuloendothelial system to endotoxin in obstructive-jaundiced and cirrhotic rats. Eur Surg Res 1983;15:107-108.

98 Holman J.M., Rikkers L.F. Reticuloendothelial function and biliary obstruction. Curr Surg $1980 ; 37: 366-367$.

99 Holman J.M. Rikkers L.F. Biliary obstruction and host defense failure. J Surg Res 1982;32:208-213.

100 Tanaka N., Ryden S., Christensen P., Bengmark S. Reticulo-endothelial function in rats with obstructive jaundice. Br J Surg 1985;72:946-949.

101 O'Connor Allen M., Wilton P.B., Barke R.A., Gerding D.N., Forstrom L.A., Shafer R.B., Vennes J.A. Effects of biliary obstruction on hepatic clearance of bacteria. Arch Surg $1989 ; 124: 973-977$.

102 Williams R.D., Elliot D.W., Zollinger R.M. The effect of hypotension in obstructive jaundice. Arch Surg 1960;81:334-340. 
103 McPherson G.A.D., Benjamin I.S., Blumgart L.H. Improwing renal function in obstructive jaundice without preoperative drainage. Lancet 1984;i:511-512.

104 Gubern J.M., Sancho J.J., Simo J., Sitges-Serra A. A randomized trial on the effect of mannitol on postoperative renal function in patients with obstructive jaundice. Surgery $1988 ; 103: 39-44$.

105 Martínes-Ródenas F. Oms L.M., Carulla X., Sancho J. J., Piera C., Fernández-Espina M.R., Stiges-Serra A. Measurement of body water compartments after ligation of the common bile duct in the rabbit. Br J Surg 1989;76:461-464

106 Cattell W.R. Blood-volume and hypotension in obstructive jaundice. Br J Surg 1967; 54:272-278.

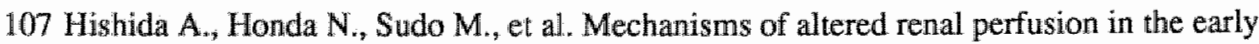
stage of obstructive jaundice Kidney Int 1980;17:223-230

108 Shasha S.M., Better O.S., Chaimovitz C., Doman J, Kishon Y. Hemodynamic studies in dogs with chronic bile-duct ligation. Clin Sci 1976,50:533-537.

109 Bomzon L., Kew M.C. Renal blood flow in experimental obstructive jaundice. In: The kidney in liver disease. Epstein M. Ed. Elsevier Scientific Publishing Co. 1983 p 313-326

110 Finberg J.P.M., Syrop H.A., Better O.S. Blunted pressor response to angiotensin and sympathomimetic amines in bile-duct ligated dogs. Clin Sci 1981;61:535-539.

111 Dawson J.L. The effect of hemorrhage on renal function in obstructive jaundice. Brit J Surg $1966 ; 53: 979-985$

112 Better O.S., Massry S.G. Effect of chronic bile duct obstruction on renal handling of salt and water. J Clin Invest 1972;51:402-411.

113 Yarger W.E. Intrarenal mechanism of salt retention after bile duct ligation in rats. J Clin Invest 1976;57:408-418.

114 Aylward T.D., Schowengerdt C.G., Bove K. Experimental hyperbilirubinemia: effect on glomerular filtration. J Surg Res 1973;15:1-3.

115 Bloom d., McCalden T.A., Rosendorff C. Effects of jaundiced plasma on vascular sensitivity to noradrenalin. Kidney Int 1975;8;149-157

116 Cioffi W.G., DeMeules J.E., Kahng K.U., Wait R.B. Renal vascular reactivity in jaundice. Surgery $1986 ; 100: 356-362$.

117 Dawson J.L. Renal failure in obstructive jaundice - clinical aspects. Postgrad Med J 1975;51:510-511.

118 Dawson J.L. Post-operative renal function in obstructive jaundice: effect of a mannitol diuresis. Br Med J 1965;1:82-86.

119 Baum M., Stirling G.A., Dawson J.L. Further study into obstructive jaundice and ischemic renal damage. Br Med J 1969;2:229-231.

120 Masumoto T., Masuoka $S$. Kidney function in the severely jaundiced dog. Am J Surg $1980 ; 140: 426-430$.

121 Israeli B.A., Bogin E. Biochemical changes in liver, kidney and blood associated with common bile duct ligation. Clin Chim Acta 1986;160:211-221.

122 Dawson I.L. Jaundice and anoxic renal damage: protective effect of mannitol. Br Med J 1964;1:810-811.

123 Alon U., Berant M., Mordechovitz D., et al. Effect of isolated cholemia on systemic hemodynamics and kidney function in conscious dogs. Clin Sci 1982;63:59-64

124 Aoyagi $T$., Lowenstein $L$.M. The effect of bile acids and renal ischemia on renal function. J Lab Clin Med 1968;71:686-692. 
125 Wilkinson S.P., Moody H., Stamatakis J.D., Kakkar V.V., Williams R. Endotoxaemia and renal failure in cirrhosis and obstructive jaundice: Br Med J 1976,2:1415-1418.

126 Wardle E.N. Endotoxinaemia and the pathogenesis of acute renal failure. Q J Med $1975 ;$ XLV: $389-398$.

127 Gillenwater J.Y., Dooley E.S., Frohlich E.D. Effects of endotoxin on renal function and hemodynamics. Am J Physiol 1963;205:293-297

128 Wardle E.N., Wright N.A. Endotoxin and acute renal failure associated with obstructive jaundice. Br Med J 1970;4:472-474.

129 Fletcher M.S., Westwick J., Kakkar V.V. Endotoxin, prostaglandins and renal fibrin deposition in obstructive jaundice. Br J Surg 1982;69:625-629.

130 Flores J., DiBonna D.R., Beck C.A., Leaf A. The role of cell swelling in ischaemic renal damage and the protective effect of hypertonic solute. J Clin Invest 1972;51:118-26

131 Cahill C.J. Prevention of postoperative renal failure in patients with obstructive jaundicethe role of bile salts. Br J Surg 1983;70:590-595.

132 Molnar W., Stockum A.E. Relief of obstructive jaundice through percutaneous transhepatic catheter a new therapeutic method. AJR 1974;122:356-367

133 Takada T., Hanyu F., Kobayashi S., Uchida Y. Percutaneous transhepatic cholangial drainage: direct approach under fluoroscopic control. J Surg Oncol 1976;8:83-97.

134 Gouma D.J., Wesdorp R.I.C., Oostenbroek R.J., Soeters P.B., Greep J.M. Percutaneous transhepatic drainage and insertion of an endoprosthesis for obstructive jaundice. Am J Surg 1983;145:763-767.

135 Gouma D.J., Moody F.G. Preoperative percutaneous biliary drainage: use or abuse. Surg Gastroenterol 1984;3:74-80.

136 Gouma D.J., Coelho J.C.U., Schegel J.F, Li Y.F., Moody F.G. The effect of preoperative internal and external biliary drainage on mortality of jaundiced rats. Arch Surg 1987; 122:731-734..

137 Beutler B., Milsark I.W., Cerami A.C. Passive immunization against cachectin/tumor necrosis factor protects mice from lethal effect of endotoxin. Science 1985;229;869-871.

138 Tracey K.J., Beutler B., Lowry S.F., Merryweather J., Wolpe S., Milsark I.W., Hariri R.J., Fahey T.J., Zentella A., Albert J.D., Shires G.T., Cerami A. Shock and tissue injury induced by recombinant human cachectin. Science 1986;234:470-474.

139 Levin J., Poore T.E., Zauber N.P., Oser R.S. Detection of endotoxin in the blood of patients with sepsis due to gram-negative bacteria, $N$ Engl J Med 1970;283:1313-1316.

140 Bailey M.E. Endotoxin, bile salts and renal function in obstructive jaundice. Br J Surg 1976;63:774-778.

141 Cahill C.J., Pain J.A., Bailey M.E. Bile salts, endlotoxin and renal function in obstructive jaundice. Surg Gynecol Obstet 1987;165:519-522.

142 Ingoldby C.J., McPherson G.A.D., Blumgart L.H. Endotoxemia in human obstructive jaundice. Effect of Polymyxin B. Am J Surg 1984;147:766-771.

143 Gouma D.J., Coelho J.C.U., Fisher J.D., Schlegel J.F., Li Y.F., Moody F.G. Endotoxemia after relief of biliary obstruction by internal and external drainage in rats. Am J Surg $1986 ; 151: 476-479$.

144 Nolan J.P. Endotoxin,reticuloendothelial function, and liver injury. Hepatology 1981; 1:458-465.

145 Bertók L. Physico-chemical defense of vertebrate organisms: the role of bile acids in defense against bacterial endotoxins. Perspect Biol Med 1977;:70-76. 
146 Ribi E., Aracker R.L., Brown R., Haskins W.T., Malmgren B., Milner K.C., Rudbach J.A. Reaction of endotoxin and surfactants 1 . Physical and biological properties of endotoxin treated with sodium deoxycholate. J Bacteriol 1966;92:1493-1509.

147 Tarmina D.F., Miner K.C., Ribi E., Rudbach J.A. Reaction of endotoxins and surfactants Immunologic properties of endotoxins treated with sodium deoxycholate. J Immunol $1968,100: 444-450$.

148 Shands J.W., Chun P.W. The dispersion of gram-negative lipopolysaccharide by deoxycholate. J Biol Chem 1980;255:1221-1226.

149 Evans H.J.R., Torrealba V., Hudd C., Knight M. The effect of preoperative bile salt administration on postoperative renal function in patients with obstructive jaundice. $\mathrm{Br} J$ Surg 1982;69:706-708.

150 Thompson J.N., Cohen J., Blenkharn J.I., McConnell J.S., Barr J., Blumgart L.H. A randomized clinical trial of oral ursodeoxycholic acid in obstructive jaundice. Br J Surg $1986 ; 73: 634-636$.

151 Gawley W.F., Gorey T.F., Johnson A.H., Collins P.B., Osbome D.H., Lane B.E., Collins P.G. The effect of oral bile salts on serum endotoxin and renal function in obstructive jaundice. Br J Surg 1988;75:600.

152 Ingoldby C.I.H. The value of polymyxin B in endotoxaemia due to experimental obstructive jaundice and mesenteric ischaemia. Br J Surg 1980;67:565-567.

153 Pain J.A., Bailey M.E. Experimental and clinical study of lactulose in obstructive jaundice. Br IS Surg 1986:73:775-778.

154 Litehr H., Englisch G., Rasenack U. Lactulose-A drug with antiendotoxin effect. Hepatogastroenterology 1980;27:356-360.

155 Roughneen P.T., Kumar S.C., Pellis N.R., Rowlands B.J. Endotoxemia and cholestasis. Surg Gynecol Obstet 1988;167:205-210.

156 Sturk A., Joop K., ten Cate J.W. Thomas L.L.M. Optimalization of a chromogenic assay for endotoxin in blood. In: Bacterial endotoxins: structure, biomedical significance, and detection with the limulus amoebocyte lysate test. Alan R. Liss, Inc. 1985 p1 17-136

157 Olofsson P., Olofsson C., Nylander G., Olsson P. Endotoxin inactivation in plasma from septic patients:An in vitro study. World J Surg 1986;10:318-323.

158 Yamaguchi Y., Billing P.A., Babb J.L., Mori K., Akagi M. Endotoxin inactivating activity of rat serum. Proc Soc Exp Biol Med 1986;181:163-168.

159 Olofsson P. Application of a quantitative spectrophotometric endotoxin assay on lymph and plasma from the rat. Eur Surg Res 1986;18:112-121.

160 Friberger P., Sörskog L., Nilsson K., Knős M. The use of a quantitative assay in endotoxin resting. Prog Clin Biol Res 1987;231:149-169.

161 Triger D.R., Boyer T.D., Levin J. Portal and systemic bacteraemia in liwer disease. Gut 1978; $19: 95-939$

162 Pain J.A., Bailey M.E. Measurements of operative plasma endotoxin levels in jaundiced and non-jaundiced patients. Eur Surg Res 1987;19:207-216

163 Beutler B., Cerami A. Cachectin: More than a tumor necrosis factor. N Engl J Med $1987 ; 316: 379-385$.

164 Aggarwal B.B., Kohr W.J., Hass P.E., et al Human tumor necrosis factor: production, purification, and characterization. J Biol Chem 1985;260:2345-2354 
165 Michie H.R., Spriggs D.R., Manogue K.R., Sherman M.L., Revhang A., O'Dwyer S.T., Arthur K., Dinarello C.A., Cerami A., Wolff S.M., Kufe D.W., Wilmore D.W. Tumor necrosis factor and endotoxin induce similar metabolic responses in human beings. Surgery $1988 ; 104: 280-286$.

166 Tracey K.J., Fong Y., Hesse D.G., Manogue K.R., Lee A.T., Kuo G.C., Lowry S.F., Cerami A. Anti-cachectin/TNF monoclonal antibodies prevent septic shock during lethal bacteraemia. Nature 1987;330:662-664.

167 Spofford B.T., Daynes R.A., Granger G.A. Cell-mediated immunity in vitro: a highly sensitive assay for human lymphotoxin. J Immunol 1974;112:2111-2116

168 Beutler B., Krochin N., Milsark I.W., Luedke C., Cerami A. Control of cachectin (tumor necrosis factor) synthesis: Mechanisms of endotoxin resistance. Science 1986;232:977980.

169 Zager R.A. Escherichia coli endotoxin injections potentiate experimental ischemic renal injury. Am J Physiol 1986;251:F988-F994

170 Mahoney J.R., Beutler B.A., Le Trang N., Vine W., Ikeda Y., Kawakami m., Cerami A. Lipopolysaccharide-treated raw 264.7 cells produce a mediator that inhibits lipoprotein lipase in 3T3-L1 cells. J Immunol 1985;134:1673-1675.

171 Beutler B., Mahony J., Le Trang N., Pekala P., Cerami A. Purification of cachectin, at lipoprotein lipase-suppressing homone secreted by endotoxin induced raw 264.7 cells. J Exp Med 1985;161:984-995.

172 Feingold K.R., Grunfeld C. Tumor necrosis factor-alpha stimulates hepatic lipogenesis in the rat in vivo. J Clin Invest 1987;80:184-190.

173 Feingold K.R., Serio M.K., Adi S., Moser A.H., Grunfeld C. Tumor necrosis factor stimulates hepatic lipid synthesis and secretion. Endocrinology 1989;124:2336-2342. 



\section{Chapter 3}

\section{Suppression of cellular immunity in obstructive jaundice is caused by endotoxins}

\section{A study with germfree rats}

J.W. Greve, D.J. Gouma, P.B. Soeters, W.A. Buurman.

Gastroenterology 1990;98:478-485

\section{ABSTRACT}

The increased susceptibility to infections after surgery in jaundiced patients is considered to be caused by an impairment of cellular immunity and/or nutritional status. Endotoxins are suggested to play a role in the pathogenesis. The mechanism of action is however unknown.

Germfree rats were used to study the effect of biliary obstruction in a model with negligible amounts of endotoxin. Cellular immunity, production of tumor necrosis factor (TNF) (as a mediator of endotoxin toxicity) by peritoneal macrophages and the nutritional status were assessed.

Significant suppression of cellular immunity was found in conventional rats with obstructive jaundice. In contrast ${ }_{\text {, }}$ cellular immunity was not suppressed in jaundiced germfree rats. Large amounts of TNF were spontaneously secreted by peritoneal macrophages of jaundiced conventional rats, whereas macrophages from jaundiced germfree rats did not. Moreover macrophage activation (expressed in TNF production) was significantly related to suppression of cellular immunity. Weight changes and depression of albumin levels were not different in germfree and conventional rats after bile duct ligation. The data presented indicate that suppression of cellular immunity in obstructive jaundice is caused by endotoxins, whereas the impaired nutritional status seems not to be affected by the presence of endotoxins. 


\section{NTTRODUCTION}

Surgical treatment of patients with obstructive jaundice is associated with a high morbidity and mortality (1). Of all complications, infective complications are the most frequent $(2-4)$.

The cause of the increased susceptibility to infections is still unclear, but an impairment of the immune system is suggested to play an important role in the pathogenesis of these complications. Experimental bile duct ligation in animals resulted in a suppression of cellular immunity (5-7). In patients with obstructive jaundice, a similar reduction of cellular immunity was found $(8,9)$. This impairment of cellu lar immunity is considered to be caused directly by biliary obstruction and subsequent liver function abnormalities. However, the nutritional status may also influence cellular immunity, because cellular immunity appeared to be impaired in patients with protein-calorie malnutrition (10).

Besides affecting the immune system, malnutrition by itself has been associated with a high postoperative complication rate (11). Moreover, malnutrition is frequently observed in jaundiced patients, and the serum albumin level has prognostic significance regarding the operation risk of these patients (12, 13). Deterioration of the nutritional status was also found after experimental biliary obstruction in rats (14).

Another factor, suggested to play an important role in the pathogenesis of the enhanced morbidity and mortality, is the systemic and/or portal endotoxemia frequently observed in jaundiced patients (15-18). The endotoxemia in obstructive jaundice is considered to result from an increased absorption of gut-derived endotoxins (19). The mechanism by which endotoxins negatively influence the postoperative outcome of jaundiced patients is unknown. Because endotoxemia disappeared after internal biliary drainage in rats and because it was found in another study that cellular immunity recovered after internal drainage, it has been suggested that endotoxins affect the immune system $(7,20)$. Impairment of the nutritional status by endotoxins is another possibility. However, it is difficult, to assess selectively the role of endotoxins in jaundice because of the multiple biochemical and pathological changes in a model with experimental billiary obstruction.

This problem can be solved by using germfree rats, which have a very low endotoxin level in the bowel lumen, to study the effects of biliary obstruction with little or no interference of endotoxins. The aim of this study was to evaluate the influence of endotoxins on the immune system and the nutritional status. We also studied the effect of bile duct ligation on the production of tumor necrosis factor (TNF) by peritoneal macrophages, because recent studies showed conflicting data with respect to the existence of endotoxemia, which in part 
may be caused by difficulties associated with the endotoxin assay. TNF is a cytokine, produced by mononuclear phagocytes when stimulated with endotoxins (21). Moreover TNF is an important mediator of endotoxin toxicity and plays a major role in the pathogenesis of septic and endotoxin shock (22-24).

\section{MATERIALS AND METHODS}

\section{Animals}

Conventional male Wistar rats (Winkelmann, Borchen, FRG) weighing approximately $200 \mathrm{~g}$ were housed under controlled conditions with a constant day-night rhythm, and were allowed free access to food and water.

Male germfree rats (Centralized Animal Facilities, Catholic University of Nijmegen, The Netherlands) were housed in a pressurized stainless steel isolator in cages with mesh wire bottoms. Incoming air was filtered through glasswool and subsequently through bacteria filters (Miller-filters, Millipore Corp., Bedford, Mass.). The germfree rats were kept on irradiated rat diet (SRM-A120, Hope Farms, Woerden, The Netherlands) until one week before experiments. From then on, an endotoxin free diet was supplied, consisting of equal volumes of a glucose $45 \%$ solution (NPBI, Emmer-Compascuum, The Netherlands) and Synthamin 14 (Travenol, Utrecht, The Netherlands) an amino acid solution, supplemented with electrolytes and vitamins. The rats were allowed free access to water. Mixed grains, which were extensively washed in pyrogen free water and baked in oil at $180^{\circ} \mathrm{C}$ for $3 \mathrm{~min}$ to minimize endotoxin contamination, served as a source of nutritional fiber. All supplies were brought into the isolator after steam sterilization in special cylinders. Sterility was checked by culturing feces on a weekly basis and by culturing the cecal contents of all the rats after the experiments.

\section{Chemicals}

Concanavalin A (ConA) was obtained from Pharmacia (Uppsala, Sweden), phytohemagglutinin 15 (PHA) from Wellcome (Dartford, U.K.), $\left[{ }^{3} \mathrm{H}\right]$ thymidine from Amersham (Amersham, U.K.), Mitomycin C and lipopolysaccharide E. coli O111:B4 (LPS) from Sigma co. (St Louis, MO). Culture medium (CM) consisted of RPMI 1640 (Gibco, Paisley, Scotland) supplemented with 10\% 
bovine calf serum (Hyclone, Logan, Utah), penicillin $100 \mathrm{U} / \mathrm{ml}$ and streptomycin $100 \mu \mathrm{g} / \mathrm{ml}$ (Flow, Irvine, U.K.). Recombinant human tumor necrosis factor $(\mathrm{TNN})$ was a kind gift of BASF/Knoll AG (Ludwigshaven, FRG).

\section{Surgical procedures}

Both conventional and germfree rats were divided in two groups, a sham operated control group (SHAM) and a bile duct ligation (BDL) group. Bile duct ligation or the sham operation in conventional Wistar rats were performed under a light ether anesthesia. Germfree rats were operated upon under strict sterile conditions in the isolator using pentobarbital, at a dose of $6 \mathrm{mg} / 100 \mathrm{~g}$ body wt i.p., as anesthetic. A $2 \mathrm{~cm}$ mid-abdominal incision was made and the common bile duct was ligated and divided as described by Lee (25). In SHAM rats the bile duct was dissected, ligatures were placed but not tied and removed again. The abdominal wall was closed in two layers. Before operation $0.7 \mathrm{ml}$ blood was obtained by puncture of the retrobulbar venous plexus.

After two weeks the rats were killed for analysis. Both the conventional and germfree rats were operated upon under ether anaesthesia. An abdominal lavage was performed with ice-cold $\mathrm{CM}$ to harvest peritoneal macrophages. Subsequently the abdomen was opened by a long mid line incision. One milliliter of portal blood was drawn, after which the aorta was cannulated to obtain systemic blood samples. The spleen was removed and kept on ice in $\mathrm{CM}$. The ceca of the germfree rats were aseptically removed for bacterial culture of their contents.

\section{Blood analysis}

Blood collected on day 1 and 14 was analyzed by standard laboratory techniques for total bilirubin, glutamic pyruvic transaminase (SGPT), alkaline phosphatase (AP) and albumin. Hemoglobin (Hb) and hematocrit (Ht) levels were measured, peripheral white blood cells were counted and peripheral blood smears stained with May Grünwald and Giemsa were used for differential white cell counting. 


\section{Endotoxin assay}

Endotoxins in portal and systemic blood were measured with an modified chromogenic limulus amoebocyte lysate test (LAL) (Coatest ${ }^{\text {endotoxin, Ka- }}$ bivitrum, Stockholm, Sweden) $(26,27)$. The test had a lower detection limit of $1 \mathrm{pg} / \mathrm{ml}$ in water and approximately $10 \mathrm{pg} / \mathrm{ml}$ in plasma. To determine recovery of endotoxin, plasma samples of normal and jaundiced rats were spiked with 50 pg LPS prior to storage at $-70^{\circ} \mathrm{C}$ or prior to heat inactivation of the plasma as required by the LAL assay. The recovery of the spiked endotoxin was more than $90 \%$.

One $\mathrm{ml}$ blood samples were collected on ice in endotoxin-free polypropylene tubes (Greiner, Nürtingen, FRG) containing $10 \mathrm{U}$ heparin (Organon, Boxtel, The Netherlands). Only heparin from a tested endotoxin free batch was used. Within 10 minutes platelet poor plasma was prepared by centrifugation, at $3,000 \mathrm{x} \mathrm{g}$ for $5 \mathrm{~min}$ at $4^{\circ} \mathrm{C}$. Plasma was collected in polypropylene tubes and stored at $-70^{\circ} \mathrm{C}$ until analysis.

Endotoxin levels in feces were measured by making a suspension of 50 $\mathrm{mg} / \mathrm{ml}$ wet cecal contents in endotoxin free water (NPBI). The suspensions were spun and the supernatants were collected. Seriall dilutions of the supernatants were made until the endotoxin concentration was in the measurable range of the endotoxin assay. In cecal contents of conventional rats endotoxin levels were at least $30 \mu \mathrm{g} / \mathrm{g}$ wet feces. Endotoxin levels in feces of germfree rats on an endotoxin poor diet were, on average, thousand times lower than in feces of conventional rats on a normal diet ( $30 \mathrm{ng} / \mathrm{g}$ wet feces).

\section{Bacterial cultures}

For sterility control bacterial cultures of the cecal contents of the germfree rats were performed in GLC broth supplemented with meat granules (London Analytical and Bacteriological Media Ltd, Salford, UK) and Brain Heart Infusion broth (Oxoid Ltd, Basingstoke, UK). The results of the cultures were assessed after 48 hours and after 7 days. Sterility control of germfree rats in the isolators was performed as described previously (28).

During the experiments all cultures obtained from the isolator, in which the germfree rats were housed, remained sterile. Neither aerobic nor anaerobic bacteria were cultured from any of the cecal feces samples taken from the germfree rats after the experiments. 


\section{Body weight}

Body weight of the rats in both groups were recorded on day 1,7 and 14 . In the isolator the rats were weighed with a spring balance (Pesola ${ }^{\text {e }}$, Switzerland).

\section{Cellular immunity}

Specific cellular immunity was tested by an in vitro mitogen assay using the mitogens PHA and ConA as stimulants. Lymphocytes were harvested by crushing the rat spleens through an infusion system filter (NPBI) and flushing the filter with $\mathrm{CM}$. The cells were thereafter gently passed through a sieve. Red blood cells were removed by treatment with tris ammonium chloride. The cell suspensions were washed twice in RPMI. Finally a suspension of $5 \times 10^{6}$ cells $/ \mathrm{ml}$ in $\mathrm{CM}$ was made. The cells were dispersed in a u-bottom microtiter plate (Greiner) at $5 \times 10^{5}$ cells/well. PHA in concentrations of $0.25,0.5$ and $1.0 \%$ and Con $A$ in concentrations of $0.9,1.8$ and $3.7 \mu \mathrm{g} / \mathrm{ml}$ were added to quadruplicate wells. Unstimulated lymphocytes of each spleen served as control. The volume per well was adjusted to $200 \mu \mathrm{l}$ with culture medium. Cells were incubated for 72 hours at $37^{\circ} \mathrm{C}$ in a humidified $8 \% \mathrm{CO}_{2}$ air mixture. Following incubation, cells were pulse labeled with $\left[{ }^{3} \mathrm{H}\right]$ thymidine $(0.5 \mu \mathrm{Ci} /$ well) for 4 hours. The cells were then harvested on a Titertek cell harvester (Skatron AS, Lier, Norway). Filter disks were transferred to vials and $1 \mathrm{ml}$ of Atomlight (NEN research products, Boston, Mass) was added. $\left.\int^{3} \mathrm{H}\right]$ thymidine incorporation into the cells was measured with a liquid scintillation counter. The optimum concentrations of ConA and PHA were found to be $1.8 \mu \mathrm{g} / \mathrm{ml}$ and $0.5 \%$ respectively for lymphocytes cultures from both germfree and conventional rats.

\section{Culture of peritoneal macrophages and assessment of Tumor Necrosis Factor (TNF) production}

From each rat the CM containing the peritoneal macrophages was dispersed in aliquots of $1 \mathrm{ml}$ in 24 well tissue culture plates (Greiner). In two wells LPS was added at a concentration of $1 \mu \mathrm{g} / \mathrm{ml}, 4$ wells were left untreated. The macrophages were cultured in a moist atmosphere with $8 \% \mathrm{CO}_{2}$ at $37^{\circ} \mathrm{C}$. To measure spontaneous TNF production by the peritoneal macrophages samples of the cell culture supernatant were taken from the untreated wells after 16 hours. Similar samples were obtained from the macrophages stimulated with LPS. 
TNF production by the peritoneal macrophages was measured with a cytotoxicity assay with L929 mouse cells as described by Spofford et al (29). In short, L929 cells were cultured and brought on 96 well tissue culture plates (Greiner) in $100 \mu \mathrm{l} \mathrm{CM}$ at $1 \times 10^{4}$ cells/well. After $11 / 2$ hours Mitomycin $\mathrm{C}$ was added at a concentration of $0.75 \mu \mathrm{g} / \mathrm{ml}$. The $L 929$ cells were allowed to settle for 16 hours after which serial dilutions of the samples were added. After 48 hours incubation at $37^{\circ} \mathrm{C}$ the remaining cells were stained with crystal violet and optic density of the wells was measured with a Titertek microplate autoreader at 595 $\mathrm{nm}$. The cytolytic effect of the samples was compared with the cytolytic effect of a serial dilution of human rTNF. Cells in CM and cells treated with $4 \mathrm{M}$ blood urea nitrogen served as no cell lysis and $100 \%$ cell lysis controls respectively. In the average assay $40 \mathrm{pg}$ human rTNF represented approximately 1 unit (1 unit $=50 \%$ cell 1 ysis).

\section{Statistical analysis}

The Student T test was used for analysis of all hematological and chemical data. Data from cellular immunity tests were analyzed with the Kruskal Wallis test. Probability (p) values below 0.05 were considered to be statistically significant.

\section{RESULTS}

\section{Blood chemistry and hematology after bile duct ligation}

Basal values were largely the same in germfree and in conventional rats. Only AP levels were significantly lower and bilirubin levels were significantly higher in germfree compared with conventional rats (Table 1). Despite these initial differences, changes of blood chemistry and hematology were similar in both conventional and germfree rats after bile duct ligation.

On day 14 both germfree and conventional BDL rats were deeply jaundiced, as was confirmed by the high serum bilirubin levels (Table 2). AP levels were also significantly elevated in both germfree and conventional BDL rats, whereas SGPT levels were not significantly higher in the germfree BDL rats in contrast to conventional BDL rats. Bilirubin and AP levels remained statistically different between conventional SHAM and BDL rats and their germfree counterparts (bilirubin conventional SHAM vs germfree SHAM p $<0.001$; AP 
Table 1. Basal chemicall blood values of germfree and conventional Wistar rats

\begin{tabular}{lllll}
\hline & $\begin{array}{l}\text { bilirubin } \\
\text { Umol/ }\end{array}$ & $\begin{array}{l}\text { SGPT } \\
\mathrm{U} / 1\end{array}$ & $\begin{array}{l}\text { AP } \\
\text { U/ }\end{array}$ & $\begin{array}{l}\text { albumin } \\
\mathrm{g} / 1\end{array}$ \\
\hline CONVENT & $3.4 \pm 0.36^{*}$ & $61 \pm 12.8$ & $316 \pm 46^{*}$ & $28 \pm 0.7$ \\
GERMFREE & $4.3 \pm 0.6$ & $70 \pm 26.6$ & $149 \pm 78$ & $28 \pm 2.0$ \\
\hline
\end{tabular}

Preoperative serum values of germfree $(n=14)$ and conventionall Wistar rats $(n=14)$.

* p<0.001; NS if not marked

Table 2. Chemical blood analysis of BDL and SHAM rats on day 14

\begin{tabular}{lcccc}
\hline & $\begin{array}{c}\text { bilirubin } \\
\mu \text { mol/ }\end{array}$ & $\begin{array}{c}\text { SGPT } \\
\mathrm{U} / 1\end{array}$ & $\begin{array}{l}\text { AP } \\
\mathrm{U} /\end{array}$ & $\begin{array}{c}\text { albumin } \\
\mathrm{g} / \mathrm{l}\end{array}$ \\
\hline $\begin{array}{l}\text { conventional } \\
\text { SHAM } \mathrm{n}=7\end{array}$ & $3 \pm 0.4^{*}$ & $64 \pm 16^{*}$ & $281 \pm 70^{*}$ & $27 \pm 1.5^{*}$ \\
BDL $\mathrm{n}=7$ & $135 \pm 52$ & $121 \pm 32$ & $632 \pm 80$ & $22 \pm 2.7$ \\
& & & & \\
germfree & & & & \\
SHAMn=7 & $4 \pm 0.3^{*}$ & $51 \pm 16$ & $104 \pm 16^{*}$ & $33 \pm 1.7^{*}$ \\
BDL $\mathrm{n}=6$ & $187 \pm 24$ & $64 \pm 12$ & $390 \pm 77$ & $23 \pm 1.3$ \\
\hline
\end{tabular}

Systemic blood samples were obtained on day 14 by aortic puncture. Conventional Wistar SHAM $(n=7), B D L(n=7)$ and germfree SHAM $(n=7)$ and BDL $(n=6)$ blood samples were analyzed with standard laboratory tests. * $p<0.001$; $\#<0.01$; NS not marked

conventional BDL and SHAM vs germfree BDL and SHAM $\mathrm{p}<0.001$; bilirubin conventional $B D L$ vs germfree $B D L p<0.05$ ). Albumin level was significantly lower in conventional SHAM compared to germfree SHAM ( $<<0.001)$.

Hemoglobin and Hct levels were only significantly depressed in the germfree BDL rats. Despite the absence of bacteria and endotoxins in the germfree rats a highly significant increase of the WBC count was found in BDL rats compared with SHAM (Table 3). A similar increase of the WBC count was observed in conventional BDL rats. A shift of lymphocytes to monocytes and polymorphonuclear cells was found in peripheral blood of both conventional and germfree (endotoxin "free") BDL rats. 
Table 3. Hematology of blood samples taken on day 14

\begin{tabular}{|c|c|c|c|c|c|c|c|}
\hline & \multirow{2}{*}{$\begin{array}{l}\mathrm{Hb} \\
\mathrm{mmol} / \mathrm{l}\end{array}$} & \multirow{2}{*}{$\begin{array}{l}\mathrm{Ht} \\
\%\end{array}$} & \multirow{2}{*}{$\begin{array}{l}\text { total WBC } \\
\times 10^{9} / 1\end{array}$} & \multicolumn{4}{|c|}{ differentiation in $\%$} \\
\hline & & & & lymph & pmnc & mono & other \\
\hline \multicolumn{8}{|l|}{ convent } \\
\hline SHAM $n=5$ & $8.2 \pm 0.5$ & $44 \pm 2.9$ & $5.2 \pm 1.7^{*}$ & $75 \pm 8^{*}$ & $16 \pm 8$ & $8 \pm 4^{\# t}$ & 1 \\
\hline BDL $n=7$ & $8.7 \pm 0.7$ & $46 \pm 4.2$ & $19.6 \pm 3.4$ & $46 \pm 9$ & $35 \pm 7$ & $17 \pm 7$ & 2 \\
\hline \multicolumn{8}{|l|}{ germfree } \\
\hline SHAM $n=7$ & $8.9 \pm 0.8^{\#}$ & $42 \pm 4.4^{\circ}$ & $2.4 \pm 0.7^{*}$ & $80 \pm 7^{*}$ & $15 \pm 7^{*}$ & $4 \pm 2^{*}$ & $\mathbb{1}$ \\
\hline BDL $n=6$ & $7.5 \pm 0.8$ & $36 \pm 3.9$ & $20.3 \pm 9.6$ & $27 \pm 8$ & $53 \pm 8$ & $19 \pm 4$ & 1 \\
\hline
\end{tabular}

Systemic blood was sampled by aortic puncture on day 14. Hematologic analysis was performed with an automatic analyzer. WBC differentiation was assessed on peripheral blood smears. Lymphocytes (lymph), polymorphonuclear cells (pmnc) and monocytes (mono) were expressed as percentage of the total count. Values are mean $\pm S D$.

* $\mathrm{p}<0.001 ; \# \mathrm{p}<0.01$; o $\mathrm{p}<0.05$; not marked NS

\section{Endotoxin levels in serum of conventional and germfree rats, effect of bile duct ligation}

Endotoxin levels in both portal and systemic blood of conventional rats on day 14 amounted to maximally $20 \mathrm{pg} / \mathrm{ml}$. Most samples were close to the detection limit of $10 \mathrm{pg} / \mathrm{ml}$ (Figure 1). No correlation was found between obstructive jaundice and endotoxemia. All portal and systemic blood samples of germfree rats were negative for endotoxin.

As a positive control for the endotoxin assay in serum, blood taken from rats repeatedly injected with endotoxin (as will be described) was assayed. Approximately 4 hours after the last subcutaneous injection of LPS, systemic blood contained an average of more than $2 \mathrm{ng} / \mathrm{ml}$ of endotoxin. In sham treated rats endotoxin levels were less than $10 \mathrm{pg} / \mathrm{ml}$. 


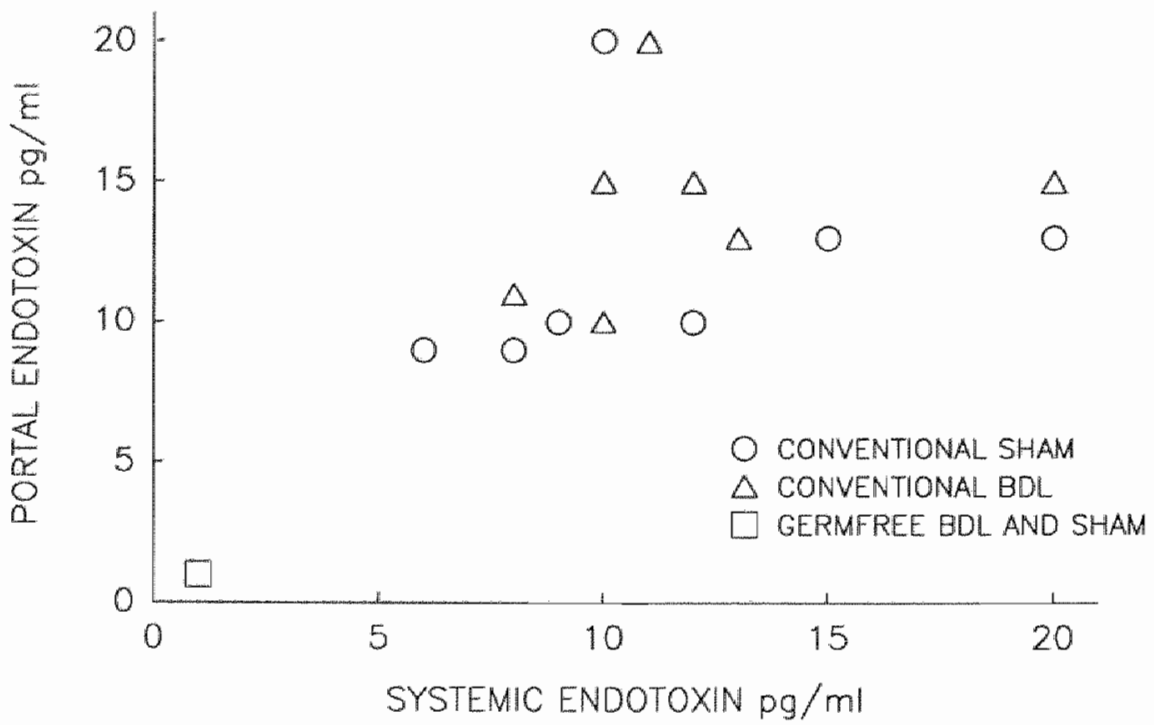

Figure 1. Endotoxin levels in portal and systemic blood of BDL and SHAM rats Endotoxin levels (expressed in pg LPS/ml) measured in portal blood were plotted against endotoxin levels measured in systemic blood of the same rat. Endotoxins were measured with a modified chromogenic LAL assay. Endotoxin levels of both SHAM and BDL germfree rats were all below the detection limit of the assay.

\section{Changes of nutritional parameters after bile duct ligation with or without endotoxins}

Both weight and albumin levels were evaluated in BDL and SHAM rats of both groups. One week after bile duct ligation a significant weight loss was found in the germfree and conventional group, compared to the SHAM animals. In the second week, weight gain of conventional or germfree BDL rats was not significantly less compared to the SHAM animals (Figure 2).

In conventional BDL rats a significant decrease of albumin levels was found. Although the germfree rats were virtually endotoxin free, biliary obstruction resulted in a decrease of albumin levels identical to that of the conventional BDL rats (Table 2). 


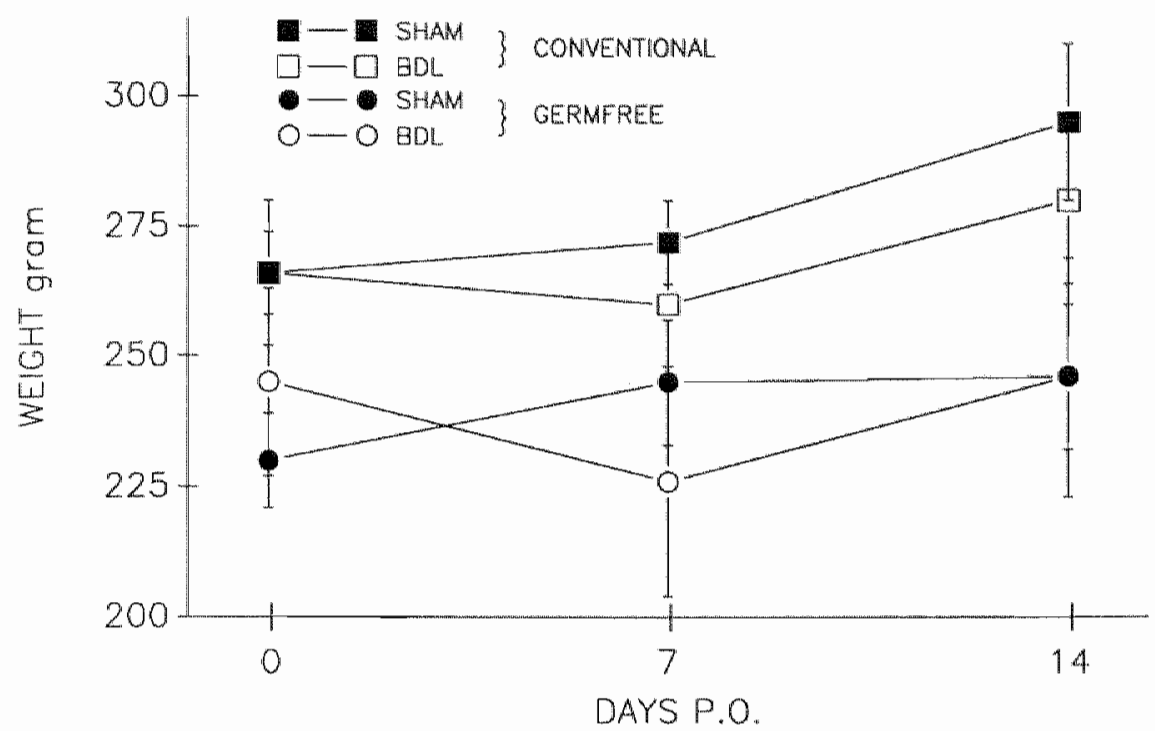

Figure 2. Weight change of germfree and conventional rats after bile duct ligation and sham operation. Weight change is expressed in grams and represents the mean \pm SD of all animals in each group, conventional BDL $(n=7)$, conventional SHAM $(n=7)$, germfree BDL $(n=6)$ and germfree SHAM ( $n=7)$.

\section{Influence of endotoxin on cellular immunity in germfree and conventional BDL rats}

Specific cellular immunity, as measured by the lymphocyte response to the mitogens ConA and PHA, did show a statistically significant difference between conventional and germfree BDL rats.

$\left[{ }^{3} \mathrm{H}\right]$ thymidine uptake was significantly decreased in lymphocytes from conventional $B D L$ rats compared with SHAM rats after stimulation with PHA (Figure 3 ) or ConA (BDL vs SHAM, cpm 7,223 $\pm 5,494$ vs $39,570 \pm 19,530$, $\mathrm{p}<0.01$ ). In contrast cellular immunity was not suppressed after bile duct ligation in the germfree, endotoxin "free" rats (PHA values Figure 3; ConA values BDL vs SHAM, cpm $11,900 \pm 5,870$ vs $16,540 \pm 8,217 \mathrm{NS}$ ).

To evaluate if this difference in effect of bile duct ligation on cellular immunity of germfree and conventional rats was caused by the absence of endotoxins in the germfree rats a supplementary experiment was performed.

Conventional Wistar rats and germfree rats were treated with a chronic low dose of endotoxin. For 3 days a non lethal dose of $250 \mu \mathrm{g} \mathrm{LPS} / 100 \mathrm{~g}$ body wt was injected subcutaneously (sc) every 8 hours. Sham treated rats (CONTROL) were injected with a similar volume of a saline solution. Four hours after the last 


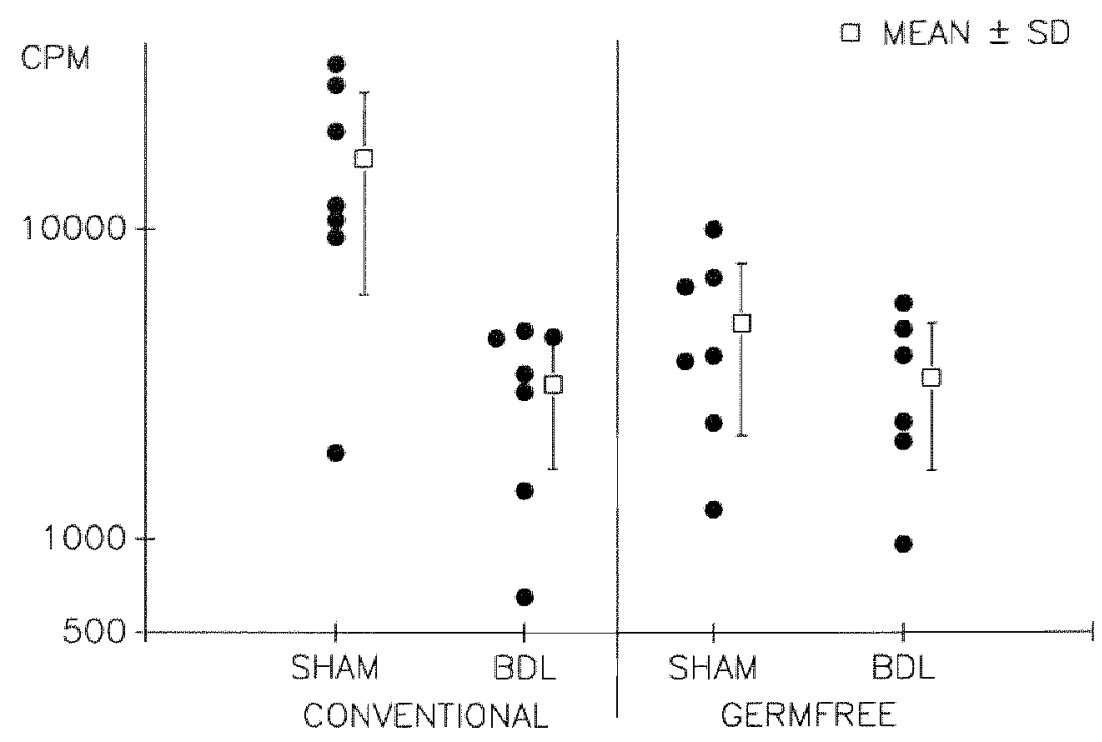

Figure 3. Effect of bile duct ligation on the cellular immunity in the conventional and germfree rat.. Cellular immunity, tested by stimulation of spleen cell cultures with the mitogen PHA and measured by uptake of ${ }^{3} \mathrm{H}$ TThymidine, is expressed in counts per minute. Data points represent the median of 4 values. Statistical analysis BDL versus SHAM, for conventional rats $p<0.02$, for germfree rats NS.

injection blood samples were taken for endotoxin measurements (only the conventional group results see above) and the spleen was removed to test cellular immunity. A significantly reduced $\left[{ }^{3} \mathrm{H}\right]$ thymidine uptake was found in conventional rats treated with LPS sc (PHA values Figure 4; ConA values LPS vs CONTROL, cpm 3,404 $\pm 1,1.19$ vs $14,670 \pm 4,551 \mathrm{p}<0.01)$. This correlated well with the immunosuppression observed in the conventional rats after bile duct ligation.

In contrast to bile duct ligation, LPS treatment of germfree rats resulted in a suppression of cellular immunity similar to the reduction of cellular immunity in LPS treated conventional rats (PHA values Figure 4; ConA values LPS vs CONTROL, cpm 47,849 $\pm 7,211$ vs $65,143 \pm 7,221 \mathrm{p}<0.01$ ). 


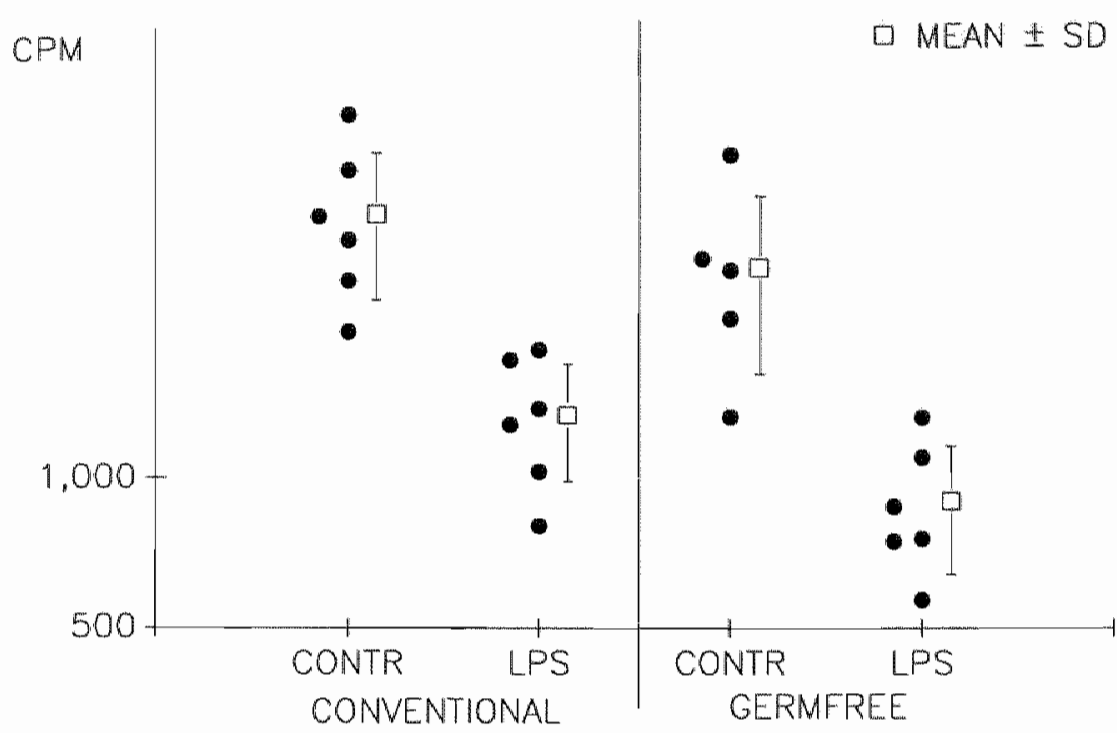

Figure 4. Effect of low dose endotoxin treatment on the cellular immunity in conventional and germfree rats. Rats were treated for 3 days with LPS or saline (CONTROL) sc. Cellular immunity, tested by stimulation of spleen cell cultures with the mitogen PHA and measured by uptake of $\left[{ }^{3} \mathrm{H}\right]$ Thymidine, is expressed in counts per minute. Data points represent the median of 4 values. Statistical analysis LPS versus CONTROL; for conventional rats $\mathrm{p}<0.005$, for germfree rats $\mathrm{p}<0.01$.

\section{TNF production by peritoneal macrophages from conventional and germfree rats, effect of bile duct ligation}

TNF is an important mediator of endotoxin toxicity. Therefore, to study if endotoxins were present in the peritoneal cavity, the TNF production by peritoneal macrophages from SHAM and BDL rats was compared. Supernatants, taken after 16 hours from cultures of untreated macrophages from conventional BDL rats contained a level of TNF which was significantly higher compared with the TNF levels in supernatants from SHAM rats (Figure 5). No significant spontaneous TNF production was found after 16 hours in the supernatants of macrophages from bile duct ligated and sham treated germfree, endotoxin "free", rats. Stimulation of macrophage cultures with $1 \mu \mathrm{g}$ LPS $/ \mathrm{ml}$ resulted in high TNF levels. In this respect macrophages of all groups behaved similar (data not shown).

Further analysis of a relation between endotoxin and suppression of cellular immunity, as suggested by the results of our experiments, was performed by studying the correlation between spontaneous TNF production of peritoneal 


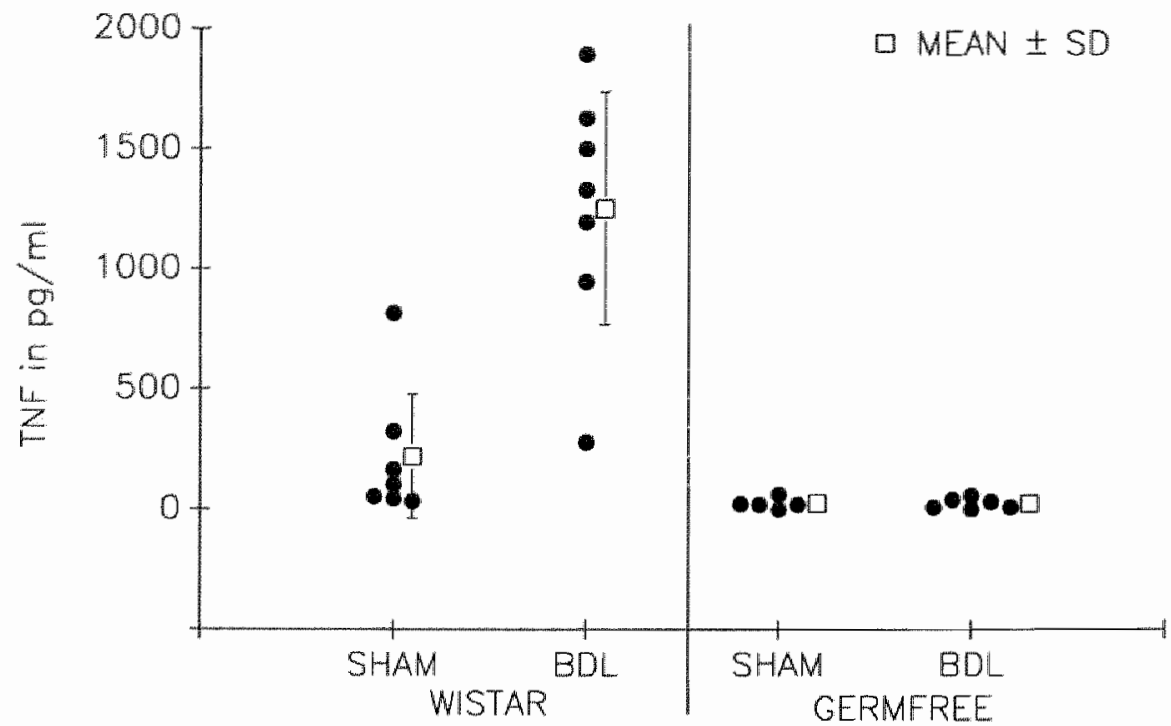

Figure 5. Spontaneous TNF release of peritoneal macrophages after bile duct ligation in germfree and conwentional rats. Peritoneal macrophages were obtained by peritoneal lavage, and cultured in CM. After 16 hours TNF production was measured with a L929 cytotoxicity assay. Results are expressed as equivalents of human rTNF.

macrophages and changes of cellular immunity. As is shown in Figure 6 a statistically significant relation was found between TNF production (indicative for activation of peritoneal macrophages) and the reduced mitogen-induced proliferation of lymphocytes from conventional rats. High TNF productions (found in BDL rats) correlated clearly with a reduced mitogen-induced lymphocyte responses.

\section{DISCUSSION}

The impaired capacity of lymphocytes from jaundiced patients to respond to specific mitogens gives evidence for immuno-suppression in these patients $(8,9)$. Moreover in rats and mice, experimental biliary obstruction reduced the immune response to allografts and suppressed specific cellular immunity $(5,6,7)$. An inhibitory factor was found in serum from patients with liver disease (30). Several factors such as hyperbilirubinemia and high bile acid levels were considered to be responsible $(5,30)$. Bile acids inhibited the lymphocyte response to PHA in vitro, however the concentrations of bile acids used in these studies were far above those present in vivo $(31,32)$. 


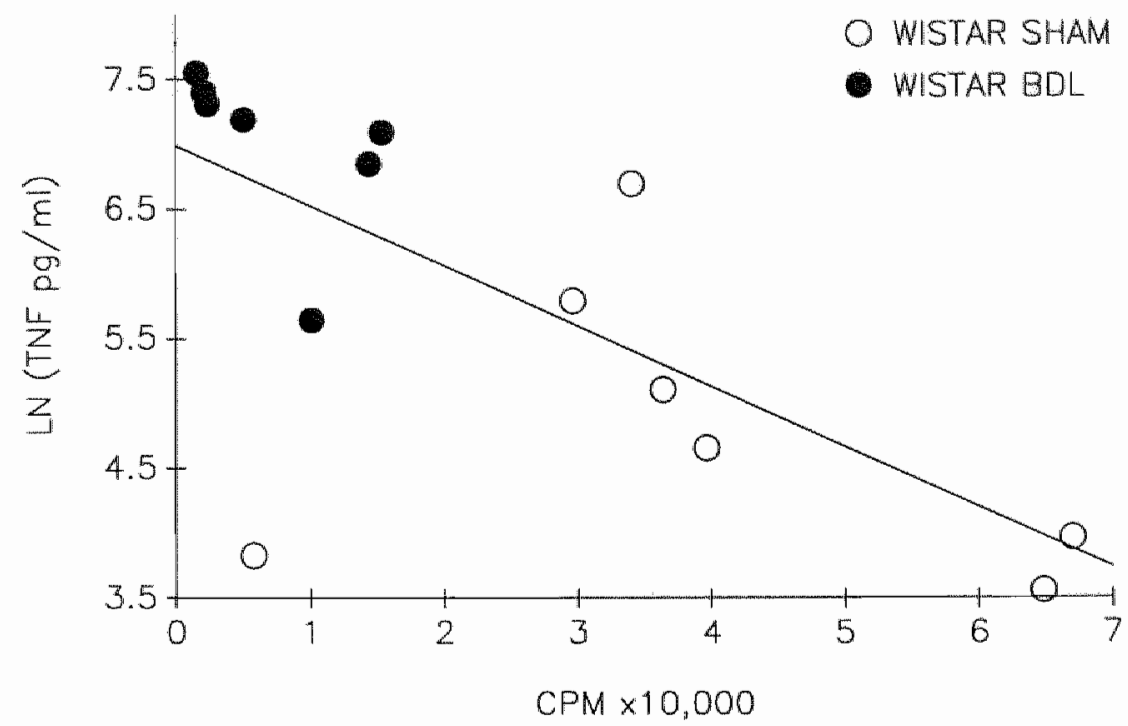

Figure 6. Correlation of macrophage activation and cellular immunity in conventional rats. Spontaneous TNF production of peritoneal macrophages (measured with a L929 cytotoxicity assay) from each individual conventional rat was plotted against the Con $\mathrm{A}$-induced proliferation of lymphocytes from the spleen. Macrophage activation is expressed as the natural logarithm of the spontaneous TNF production and cellular immunity is expressed in counts per minute. Correlation analysis exponential model: $\ln \mathrm{y}=6.987-\left(4.63^{*} 10^{-5}\right) \mathrm{x} \mathrm{r}=-0.717 \mathrm{p}<0.004$.

Our study confirmed the suppression of cellular immunity after bile duct ligation in rats. However, it seemed that cellular immunity was not impaired in jaundiced germfree rats. These data strongly suggest that factors such as hyperbilirubinemia and elevated plasma bile acids do not contribute to immunosuppression since bilirubin levels in both conventional and germfree bile duct ligated rats were identical. Furthermore changes of weight and plasma albumin in jaundiced conventional and germfree rats were similar, excluding an essential role for nutrition in the suppression of cellular immunity. However our results indicate that endotoxins are involved.

Several clinical and experimental studies have shown a clear relation between systemic and/or portal endotoxemia and postoperative complications. More than $50 \%$ of the blood samples of jaundiced patients were found to be positive when the classical LAL test was used (15-17). Furthermore, the beneficial effect of preoperative treatment with oral bile salts or lactulose in obstructive jaundice was explained by inactivation of endotoxins (33-35). However the data with regarding the level of endotoxins measured in serum of jaundiced patients are controversial. In a recent study, using the new and much more 
sensitive chromogenic LAL assay, maximum endotoxin levels in jaundiced patients were found to be below the detection limit of the classical LAL test used in previous studies (19).

Our data indicate that gut derived endotoxins play a crucial role in the suppression of cellular immunity in obstructive jaundice despite the fact that serum endotoxin levels in conventional BDL rats were not different from those in conventional SHAM rats. The latter is in agreement with data of Roughneen (36). The very low endotoxin content (more than a thousand times lower) and the absence of bacteria in the gastrointestinal tract of germfree rats are the main differences with conventional rats. Furthermore it is shown that treatment of conventional rats with a chronic low dose of endotoxins results in a suppression of cellular immunity, similar to the suppression found after bile duct ligation. Moreover sc administration of endotoxin to germfree rats resulted in a suppression of cellular immunity similar to the impairment of cellular immunity in conventional BDL rats and conventional LPS treated rats.

An important mediator of endotoxin toxicity is TNF, a cytokine that is mainly produced by macrophages (22-24). Therefore, to further substantiate the role of endotoxin in obstructive jaundice, we determined the spontaneous TNF production of macrophages from BDL and sham treated rats of both groups. It seemed that macrophages from conventional BDL rats produced significant amounts of $\mathrm{TNF}$, indicative for an activation of the cells. In contrast macrophages of germfree BDL and SHAM rats produced amounts of TNF similar to macrophages of conventional sham treated rats. These data confirm that endotoxins, responsible for activation of the macrophages, are present in jaundiced conventional rats. Furthermore a statistically significant relation was found between macrophage activation (expressed in $\mathrm{pg} / \mathrm{ml} \mathrm{TNF}$ ) and the reduced cellular immunity in conventional rats. These data suggest that endotoxins affect the cellular immunity by activating macrophages that release TNF and a number of other cytokines.

The poor nutritional status, frequently observed in jaundiced patients, is another cause of a high postoperative morbidity and mortality $(11,37)$. Analysis of risk factors in jaundiced patients showed that hypoalbuminemia correlates with a high postoperative complication rate $(3,12,13)$. Low albumin levels were found after experimental biliary obstruction in rats but anorexia or malnutrition were absent (14). In the latter study changes of the liver metabolism were held responsible. Furthermore hypoalbuminemia has been found to coincide with an impairment of the immune system and has therefore been suggested to play a role in the high susceptibility to infections (10). 
In our study, nutritional parameters such as albumin levels and weight changes were similar in conventional and germfree rats after bile duct ligation. The clear impairment of these parameters did not seem to be related to the presence of endotoxins in the gastrointestinal tract. This suggests that in contrast to cellular immunity the nutritional status, in jaundiced but otherwise healthy rats, is not affected by endotoxins. Impairment of the nutritionall state is probably caused by other effects of biliary obstruction on liver metabolism.

In summary it was found that the impaired nutritional state is not related to suppression of cellular immunity. Apparently bile acids and bilirubin are not involved in this aspect. Clear evidence is given that suppression of cellular immunity is caused by endotoxins from the gastrointestinal tract, whereas impairment of the nutritional status is not related to endotoxins. Furthermore a significant correlation was found between macrophage activation and suppression of cellular immunity. The results of this study suggest that one of the aims of preoperative supportive therapy in jaundiced patients should be prevention of the toxic effect of endotoxins from the bowel lumen. The role of the nutritional status remains to be further elucidated. 


\section{REFERENCES}

1 Pain J.A., Cahill C.J., Bailey M.E. Perioperative complications in obstructive jaundice:therapeutic considerations. Br J Surg $1985 ; 72: 942-945$.

2 Armstrong C.P., Dixon J.M., Taylor T.V., Davies G.C. Surgical experience of deeply jaundiced patients with bille duct obstruction. Br J Surg 1984;71:234-238.

3 Blamey S.L. Fearon K.C.H., Gilmour W.H., Osborne D.H., Carter D.C. Prediction of rísk in biliary surgery. Br J Surg 1983;70:535-538.

4 Holman J.M., Rikkers L.F., Moody F.G. Sepsis in the management of complicated biliary disorders. Am J Surg 1979;138:809-813.

5 Pinto M., Kaplun A. Immune status in mice with experimental biliary obstruction. Clin Immunit Immunopathol 1980;16:396-405.

6 Roughneen P.T., Didlake R., Kumar S.C., Kahan B.D., Rowlands B.J Enhancement of heterotopic cardiac allograft survival by experimental biliary ligation. Transplantation $1987 ; 43: 437-438$.

7 Roughneen P.T., Gouma D.J., Kulkarni A.D., Fanslow W.F., Rowlands B.J. Impaired specific cell-mediated irmmunty in experimental biliary obstruction and its reversibility by internal biliary drainage. J Surg Res 1986;41:113-125.

8 Maggiore G., De Giacomo C., Scotta M.S., Siena S., Maccario R., Vitiello A. Cell-mediated immunity in children with chronic cholestasis. J Pediatr Gastroenteroll Nutr 1982; 1:385388.

9 Fargion S.R., Cappellini M.D., Podda M., Fiorelli G. Immunità cellulare nelle colestasi intra ed extra-epatiche. Min Gastr 1976;22:261-265.

10 Law D.K., Dudrick S.J., Abdou N.I. Immunocompetence of patients with protein-callorie malnutrition. Ann Intern Med 1973;79:545-550.

11 Buzby G.B., Mullen J.L., Matthews D.C., Hobbs C.L., Rosato E.F. Prognostic nutritional index in gastrointestinal surgery. Am J Surg 1980;139:160-167.

12 Little J.M. A Prospective evaluation of computerized estimates of risk in the management of obstructive jaundice. Surgery 1987;102:473-476.

13. Pitt H.A., Cameron J.L., Postier R.G., Gadacz T.R. Factors affecting mortality in biliary tract surgery. Am J Surg 1981;141:66-71.

14 Gouma D.J., Roughneen P.T., Kumar S., Moody F.G., Rowlands B.J. Changes in nutritional status associated with obstructive jaundice and biliary drainage in rats. Am J Clin Nutr 1986;44:362-369.

15 Wardle E.N., Wright N.A. Endotoxin and acute renal failure associated with obstructive jaundice. Br Med J 1970;4:472-474.

16 Wilkinson S.P., Moody H., Stamatakis J.D., Kakkar V.V., Williams R. Endotoxaemia and renal failure in cirrhosis and obstructive jaundice. Br Med J 1976;2:1415-1418.

17 Hunt D.R., Allison M.E.M., Prentice C.R.M., Blumgart L.H. Endotoxemia, disturbance of coagulation ${ }_{4, y}$ and obstructive jaundice. Am J Surg 1982;144;325-329.

18 Pain J.A., Bailey M.E.Measurement of operative plasma endotoxin levels in jaundiced and non-jaundiced patients. Eur Surg Res 1987;19:207-216.

19 Deventer v. S.J.H., Cate t. J.W., Tytgat G.N.J. Intestinal endotoxemia. Gastroenterology $1988 ; 94: 825-831$. 
20 Gouma D.J., Coelho J.C.U., Fisher J.D., Schlegel J.F., Li Y.F, Moody F.G. Endotoxemia after relief of biliary obstruction by internal and external drainage in rats. Am I Surg $1986 ; 151: 476-479$.

21 Beutler B., Cerami A. Cachectin: More than a tumor necrosis factor. N Engl I Med 1987;316:379-385.

22 Lehman V., Freudenberg M.A., Galanos C. Lethal toxicity of lipopolysaccharide and tumor necrosis factor in normal and d-galactosamine-treated mice. J Exp Med 1987; 165:657-663.

23 Beutler B., Mulsark I.W., Cerami A.C. Passive immunization against cachectin/tumor necrosis factor protects mice from lethal effect of endotoxin. Science 1985;229:869-871.

24 Tracey K.J., Fong Y., Hesse D.G., Manogue K.R., Lee A.T., Kuo G.C., Lowry S.F., Cerami A. Anti-cachectin/TNF monoclonal antibodies prevent septic shock during lethal bacteriaemia. Nature 1987;330:662-664.

25 Lee E. The effect of obstructive jaundice on the migration of reticulo-endothelial cells and fibroblasts into early experimental granulomata. Br J Surg 1972;59:875-877

26 Friberger P., Sörskog L., Nilsson $\mathbb{K}$., Knös M. The use of a quantitative assay in endotoxin testing. Prog Clin Biol Res 1987;231:149-169.

27 Olofsson P. Application of a quantitative spectrophotometric endotoxin assay on lymph and plasma from the rat. Eur Surg Res 1986;18:112-121.

28 Berlo v. C.L.H., Jonge d. H.R., Bogaard v.d. A.E.J.M., Eijk v. H.M.H., Janssen M.A., Soeters P.B. Gamma-aminobutyric acid production in small and large intestine of nomal and germfree wistar rats. Influence of food intake and intestinal flora. Gastroenterology 1987;93:472-479.

29 Spofford B.T.,Daynes R.A.,Granger G.A. Cell-mediated immunity in vitro: a highly sensitive assay for human Iymphotoxin. J Immunol 1974;112:2111-2116.

30 Newberry W.M.,Shorey J.W.,Sanford J.P., Combes B. Depression of lymphocyte reactivity to phy tohemagglutinin by serum from patients with liver disease. Cell Immunol 1973;6:87 97.

31 Gianni L.,Di Padova F.,Zuin M.,Podda M. Bile acid-induced inhibition of the lymphoproliferative response to phytohemagglutinin and pokeweed mitogen: An in vitro study. Gastroenterology 1980;78:231-235.

32 Keane R.M., Gadacz T.R., Munster A.M., Birmingham W., Winchurch R.A. Impairment of human lymphocyte function by bile salts. Surgery 1984;95:439-443.

33 Bailey M.E. Endotoxin, bile salts and renal function in obstructive jaundice. Br J Surg 1976;63:774-778.

34 Cahill C.J., Pain J.A., Bailey M.E. Bile salts, endotoxin and renal function in obstructive jaundice. Surg Gynecol Obstet 1987;165:519-522.

35 Pain J.A., Bailey M.E. Experimental and clinical study of lactulose in obstructive jaundice. Br J Surg 1986;73:775-778.

36 Roughneen P.T., Pellis N.R., Kumar S., Rowlands B.J. Does lack of bile salt flow into the gastrointestinal tract increase portal absorption of gut-derived endotoxin? Gastroenterology $1986 ; 90: 1763$.

37 Reinhard! G.F., Myscofski J.W., Wilkens D.B., Dobrin P.B., Mangan J.E., Stannard R.T. Incidence and mortality of hypoalbuminemic patients in hospitalized veterans. J Parent Ent Nutr $1980 ; 4: 357-359$. 



\section{Chapter 4}

\section{Bile acids inhibit endotoxin induced release of tumor necrosis factor by monocytes}

\section{An in vitro study}

J.W. Greve, D.J. Gouma, W.A. Buurman

Hepatology 1989;10:454-458

\section{ABSTRACT}

Endotoxins play an important role in the pathogenesis of complications of surgery in obstructive jaundice. Preoperative treatment with orally administered deoxycholic acid prevented endotoxin-related complications, such as renal malfunction. Other bile acids, however, were less effective, and the mechanism of action is not known.

Endotoxin toxicity is considered to be largely mediated by tumor necrosis factor/cachectin (TNF), a cytokine released by mononuclear phagocytes. Therefore we studied the influence of different bile acids on endotoxin-induced TNF production by monocytes in vitro.

Bile acids inhibit TNF production through a direct inhibitory effect on the monocytes. Deoxycholic acid was the most effective, chenodeoxycholic acid was less effective and ursodeoxycholic acid was ineffective in the concentrations used. Bile acids did not inactivate endotoxin as measured in a chromogenic Limulus amoebocyte lysate assay.

The therapeutic effect of bile acids in obstructive jaundice can be explained by an inhibition of endotoxin-induced TNF release by mononuclear phagocytes. 


\section{INTRODUCTION}

Surgery in patients with biliary obstruction is associated with increased morbidity and mortality $(1,2)$. In jaundiced patients a high incidence of endotoxemia was found that correlated with the high complication rate in these patients (3-7). Therefore, endotoxins are considered to play an important role in the pathogenesis of several complications $(1,2,8)$. A possible cause for endotoxemia in jaundiced patients is the absence of bile acids in the bowel lumen, resulting in an enhanced absorption of endotoxins $(1,9,10)$.

Preoperative treatment with orally administered bile acids prevented renal complications in jaundiced patients (1,1 1-13). Furthermore, bile acids reduced mortality in rats, with experimental biliary obstruction, challenged with a high dose of oral endotoxin (1). The beneficial effect of bile acids was suggested to be an inactivation, or a prevention of the absorption, of gut-derived endotoxins. However, whereas deoxycholic acid and taurocholate were used successfully, other bile acids such as chenodeoxycholic acid and ursodeoxycholic acid did not have a beneficial effect $(1,11-14)$. The mechanism by which bile acids reduce endotoxin toxicity remains unknown.

It was recently shown that tumor necrosis factor (TNF) is an important mediator of endotoxin toxicity (15-19). The main source of TNF production, in response to endotoxins, are mononuclear phagocytes (20). We developed an in vitro model, using human peripheral blood monocytes, to study the effect of different agents on the production of the mediator of endotoxin toxicity.

The aim of this study was to determine by which mechanism bile acids reduce endotoxin toxicity. A modified chromogenic limulus amoebocyte lysate assay was used to measure the direct effect of bile acids on endotoxins. The effect of bile acids on the production of TNF, the mediator of endotoxin toxicity, was tested in the in vitro model.

\section{MATERIALS AND METHODS}

\section{Materials and antibodies}

Endotoxin Escherichia Coli O111:B4 chromatographically purified lipopolysaccharide (LPS), phorbol myristate acid (PMA), deoxycholic acid Grade II (DCA), chenodeoxycholic acid Grade II (CDCA), ursodeoxycholic acid approximately 99\% pure (UDCA), bovine serum albumin Type A9647 (BSA), o-phenylenediamine and latex beads $(1.091 \mu \mathrm{m}$ diameter) were obtained from 
Sigma Chemical Co. (St.Louis, MO). Human recombinant tumor necrosis factor (rTNF) was kindly provided by BASF/Knoll AG (Ludwigshaven, FRG). Monoclonal antibodies against TNF were derived from hybridomas obtained by a standard cell fusion procedure. Mouse spleen cells from BALB/c mice immunized with highly purified rTNF were used for the cell fusions. Rabbit polyclonal antibodies against TNF were raised by immunizing rabbits with rTNF. Peroxidase-conjugated goat anti-rabbit IgG was purchased from Jackson Immunoresearch Laboratories (West Grove, PA). Rabbit anti-sheep red blood cell antibody (anti-SRBC antibody) was obtained from the RIVM (Bilthoven, The Netherlands)

\section{Isolation of mononuclear cells from human peripheral blood}

Peripheral blood mononuclear cells (PBMC) from buffy coats of healthy blood donors (kindly provided by the local blood bank) were purified by buoyant density centrifugation on Lymphoprep (Nycomed AS, Oslo, Norway). The interface layer was collected and washed twice in RPMI 1640 (Gibco, Paisley, Scotland). The PBMC were resuspended in culture medium (CM), consisting of RPMI supplemented with $10 \%$ fetal calf serum (Boehringer, Mannheim, FRG), streptomycin $100 \mu \mathrm{g} / \mathrm{ml}$ and penicillin $100 \mathrm{IU} / \mathrm{ml}$ (Flow, Irvine, UK), at a concentration of $5 \times 10^{7} / \mathrm{ml}$. The suspension was spun in polypropylene tubes at $20 \mathrm{rpm}, 4^{\circ} \mathrm{C}$ to induce monocyte clumping. The clumped monocytes were separated from lymphocytes by sedimentation on ice cold fetal calf serum for $20 \mathrm{~min}$ (21). Monocytes were resuspended in CM at a concentration of $1 \times 10^{5} / \mathrm{ml}$ and transferred to a 96-well tissue culture plate (Costar, Cambridge,MA) $100 \mu \mathrm{l} /$ well. The remaining cells consisted of more than $90 \%$ monocytes as evaluated by phagocytosis and indirect immunofluorescence (data not shown).

\section{TNF enzyme-linked immunosorbent assay (ELISA)}

TNF concentrations in the cell free supernatants of the cell cultures were determined with a TNF-specific ELISA as described previously (22). In brief, 96 well immunoassay plates (Greiner, Nürtingen, FRG) were coated with a monoclonal anti-TNF antibody. Test samples were added to the plate and incubated for 3 hours at room temperature. A standard titration curve was obtained by making serial dilutions of a known sample of rTNF. Next the plates were washed and sequentially incubated with rabbit anti-TNF immune serum 


\section{RESULTS}

\section{Effect of bile acids on LPS-induced TNF production by monocytes}

Incubation of cultured monocytes with endotoxin results in a high TNF release. In the first experiment, the effects of DCA, CDCA and UDCA on this LPS-induced TNF production by monocytes were compared. The bile acids at a concentration of $125 \mu \mathrm{M}$ were incubated with serial dilutions of LPS (Figure 1). DCA in the concentration used appeared to be a strong inhibitor of TNF release, whereas CDCA is less effective and UDCA is not effective (respectively, $p<0.001, p<0.001$ and NS vs. control). Viability of the monocytes tested after the experiment, by trypan blue exclusion, was greater than $95 \%$, excluding a cytolytic effect of the bile acids in the concentration used. The viability of the cells was further confirmed by phagocytosis of latex beads as described later.

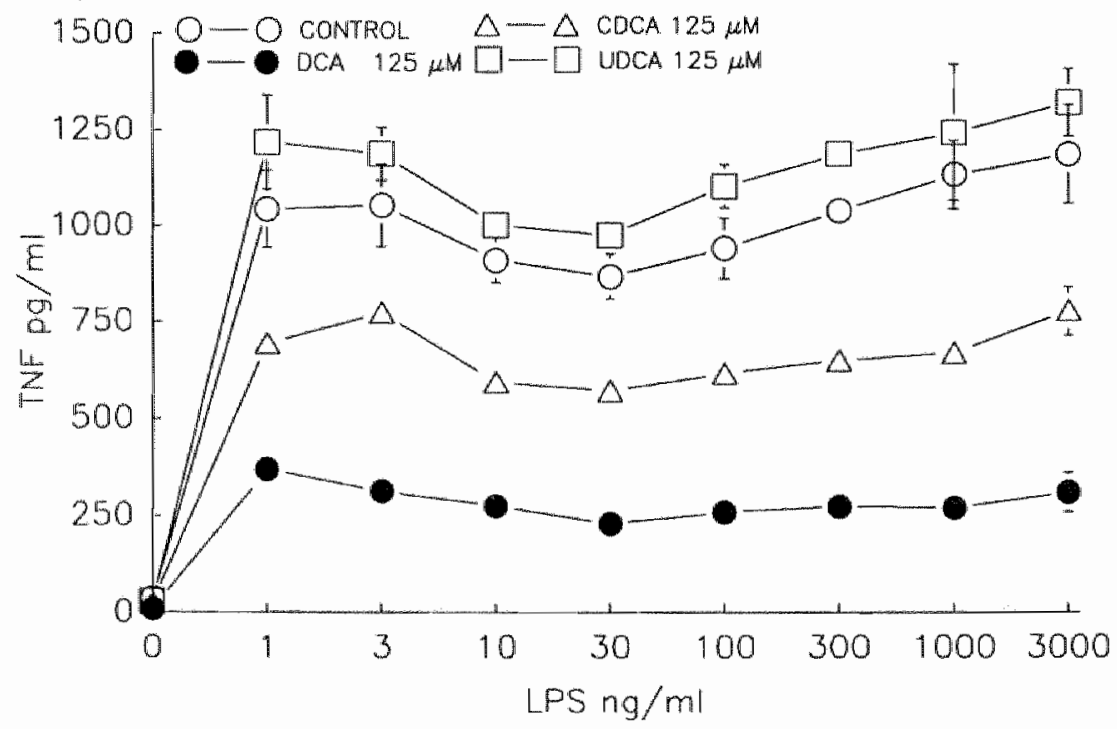

Figure 1. Effect of bile acids on LPS-mediated TNF production by monocytes.

LPS in concentrations given was preincubated 1 hour with DCA, CDCA, UDCA (concentration $125 \mu \mathrm{M})$ or culture medium and then added to monocytes. After 18 hours culture TNF production was measured in cell free supernatants. Data are expressed as mean \pm S.D. (bars) of four values. 


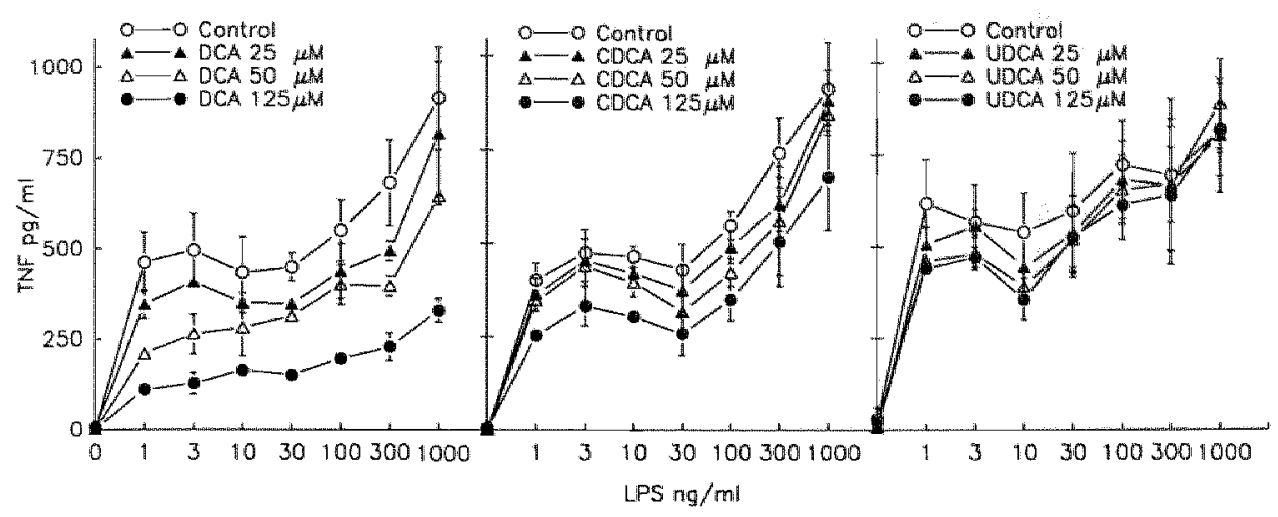

Figure 2. Influence of concentration and type of bile acids on the TNF production by monocyles stimulated with LPS. DCA, CDCA and UDCA were preincubated with LPS for 1 hour in the concentrations given. TNF production was assessed in the cell free culture supematants after 18 hours. Data are expressed as mean \pm S.D. (bars) of four values.

To test whether the inhibitory effect of bile acid was concentration dependent, DCA, CDCA and UDCA in concentrations of 25,50 and $125 \mu \mathrm{M}$ were incubated with a serial dilution of LPS and added to the monocytes; thereafter, TNF production was measured. The results are shown in Figure 2. DCA was the most competent inhibitor at all concentrations tested, reducing TNF production $90 \%$ at a concentration of $125 \mu \mathrm{M}(\mathrm{p}<0.001)$ and $40 \%$ at $25 \mu \mathrm{M}(\mathrm{p}<0.05)$. CDCA was less active $(125 \mu \mathrm{M}, \mathrm{p}<0.01 ; 25 \mu \mathrm{M}, \mathrm{NS})$, and UDCA did not cause a significant reduction of TNF release.

In order to assess whether the inhibitory effect of bile acids was reversible, monocytes were preincubated with DCA, CDCA and UDCA. After removal of the bile acids by exchanging CM, the monocytes were stimulated with LPS, and thereafter TNF release by the monocytes was measured (Figure 3). TNF release by monocytes preincubated with bile acids was found to be similar compared to control cells.

\section{Influence of bile acids on PMA-induced TNF release by monocytes}

To test whether bile acids also inhibit TNF production by monocytes activated with a stimulus other than endotoxin, the phorbol ester PMA was used. Cultured monocytes were incubated with PMA and combinations of PMA and bile acids. Stimulation of cultured monocytes with PMA resulted in high TNF production. The effect of bile acids on PMA-induced TNF release by mono- 


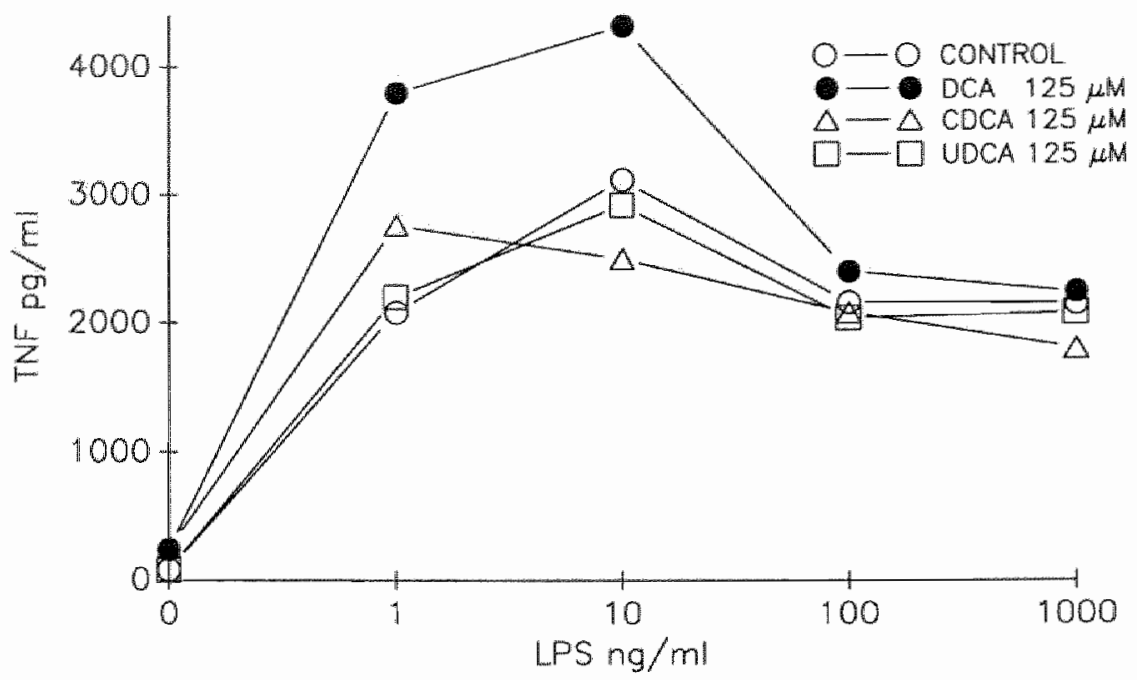

Figure 3. Effect of preincubation of monocytes with bile acids on the LPS-induced TNF release. Monocytes were incubated for 2 hours with DCA, CDCA and UDCA at $125 \mu \mathrm{M}$. Bile acids were removed by changing the culture medinm twice, after which LPS in CM in concentrations shown was added. TNF production was measured in cell-free culture supernatants after overnight incubation. Data of a representative experiment are shown which are the average of two values.

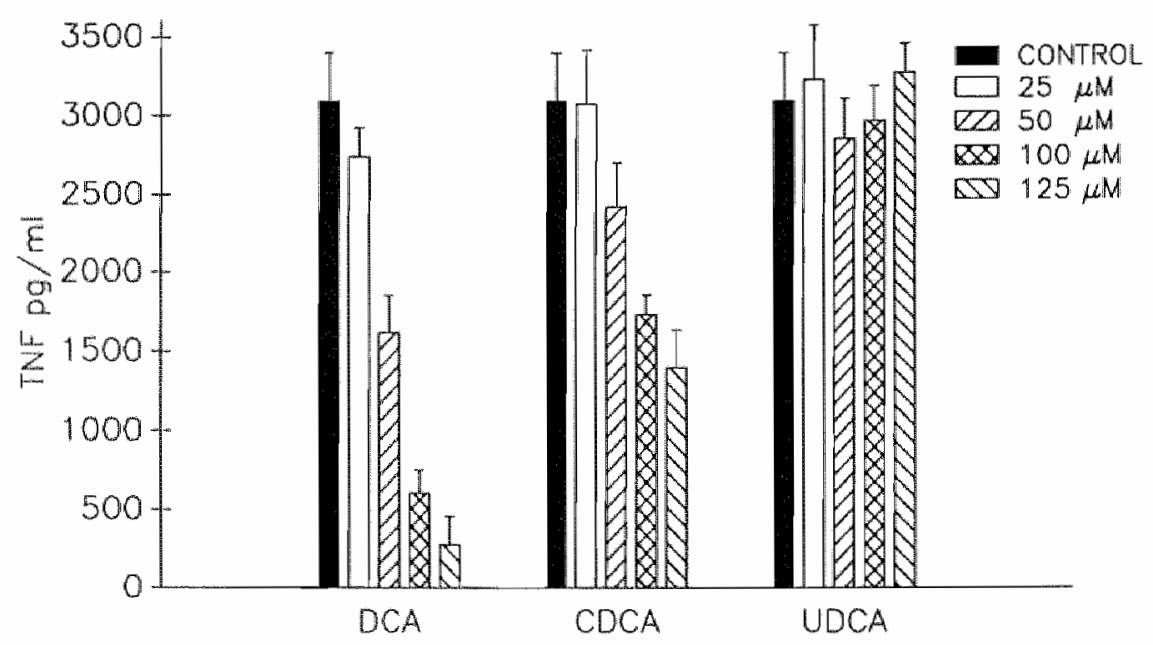

Figure 4. Effect of bile acids on PMA-mediated TNF production by monocytes.

PMA, $5 \mathrm{ng} / \mathrm{ml}$, was added together with given concentrations of DCA, CDCA and UDCA to monocyte cultures. TNF production was measured in the cell free supernatants after 18 hours culture. Each column represents mean \pm S.D. (bars) of eight values after deduction of TNF production by control, not stimulated, monocytes. 
cytes is summarized in Figure 4 . The inhibitory effect of bile acids on TNF release by monocytes stimulated with PMA was similar to the inhibition observed in the experiments with LPS. DCA reduced the TNF release by the monocytes, stimulated with $5 \mathrm{ng} / \mathrm{ml} \mathrm{PMA}$, by $90 \%$ at a concentration of $125 \mu \mathrm{M}$ and $10 \%$ at $25 \mu \mathrm{M}(\mathrm{p}<0.001$ and $\mathrm{p}<0.01$ vs. control). CDCA caused a significant reduction of TNF release only with concentrations of $125 \mu \mathrm{M}(\mathrm{p}<$ $0.001)$ and $100 \mu \mathrm{M}(\mathrm{p}<0.001)$, whereas UDCA did not significantly reduce TNF release at any of the concentrations used.

\section{Phagocytosis by monocytes}

Viability of monocytes used in the experiments described above was tested at the end of the incubation period by assessing the capacity of the cells to phagocytose latex beads. After removing the supernatant for TNF measurements, latex beads in fresh CM were added. After 2 hours more than $90 \%$ of the cells had engulfed latex beads, indicating that the cells were viable.

The effect of bile acids on phagocytosis by monocytes was determined with antibody coated SRBC. The results are summarized in Table 1. In presence of DCA at a concentration of $125 \mu \mathrm{M}$, phagocytosis of SRBC by monocytes was reduced by $52 \%$ as compared to controls. CDCA and UDCA at the same concentration caused a reduction of phagocytosis by $27 \%$ and $5 \%$, respectively. At $50 \mu \mathrm{M}$, a similar but less pronounced effect was seen.

Table 1. Influence of bile acids on phagocytosis of SRBC by monocytes.

\begin{tabular}{llrll} 
Concentration & DCA & \multicolumn{1}{l}{ CDCA } & UDCA & Control \\
\hline $50 \mu \mathrm{M}$ & $9.75 \pm 0.9$ & $12.6 \pm 0.6$ & $13.5 \pm 2.6$ & $13.6 \pm 2.6$ \\
$125 \mu \mathrm{M}$ & $6.5 \pm 2.8$ & $8.5 \pm 0.3$ & $12.9 \pm 1.9$ &
\end{tabular}

Monocytes, $2 \times 10^{6} / \mathrm{ml}$, were incubated with bile acids for 1 hour in given concentrations. Opsonized SRBC were added and monocytes were allowed to phagocytose for 30 minutes at $37^{\circ} \mathrm{C}$. Results are expressed as percentage of monocytes containing SRBC and are mean $\pm \mathrm{SD}$ of 4 observations. 


\section{Influence of bile acids on LPS}

The influence of bile acids on LPS was measured by incubating known concentrations of LPS with the three bile acids in different concentrations at $37^{\circ} \mathrm{C}$. After 1 hour, the remaining LPS was measured with the endotoxin assay. No difference was found between the effects of DCA, CDCA or UDCA (Table 2 ). The bile acids in the concentrations shown were equally ineffective to inactivate LPS as measured with the Limulus amoebocyte lysate assay. Only the measured amount of $200 \mathrm{pg}$ LPS/ml treated with $125 \mu \mathrm{M}$ UDCA was significantly lower $(\mathrm{p}<0.01)$ compared to control.

Table 2. Lack of effect of bile acids on LPS measured with a chromogenic Limulus amoebocyte lysate assay.

\begin{tabular}{lcccc}
\hline LPS pg/ml & DCA $125 \mu \mathrm{M}$ & CDCA $125 \mu \mathrm{M}$ & UDCA $125 \mu \mathrm{M}$ & Control \\
\hline 0 & 1 & 0 & 0 & 0 \\
50 & $79 \pm 4$ & $64 \pm 12$ & $72 \pm 7$ & $63 \pm 8$ \\
200 & $145 \pm 19$ & $151 \pm 10$ & $125 \pm 10$ & $154 \pm 14$ \\
\hline
\end{tabular}

LPS and bile acids were incubated for 1 hour at $37^{\circ} \mathrm{C}$ in the concentrations given. Solutions with only LPS or bile acid served as controls. Results expressed in pg LPS/ml are the average $\pm S$.D. of quadruplicates. In experiments the same batch of LPS was used for incubation with bile acids and preparation of the standard curve for the endotoxin assay.

\section{DISCUSSION}

TNF is an important mediator of endotoxin toxicity (17). In experiments with mice, a polyclonal anti-TNF antibody significantly reduced mortality after injection of a lethal dose of LPS (18). Similar results were observed in experiments with baboons in which an anti-TNF antibody reduced mortality after injection of Gram-negative bacteria (19). Complications in patients with obstructive jaundice are related to endotoxins $(3,5,6)$. Since endotoxin toxicity is mediated by TNF, this cytokine may also play a role in the pathogenesis of these complications. We therefore investigated the influence of bile acids on endotoxin toxicity by measuring changes of monocyte function and TNF release in vitro. 
Our results showed that the bile acids DCA, CDCA and UDCA in concentrations of up to $125 \mu \mathrm{M}$ did not inactivate endotoxins as measured with the Limulus amoebocyte lysate assay. In contrast, the production of the mediator of endotoxin toxicity, TNF, was significantly reduced by DCA and to a lesser extent by CDCA. UDCA did not have an inhibitory effect. This effect of bile acids was not due to a cytolytic effect on the monocytes since the inhibitory effect of the bile acids was shown to be reversible. Moreover, viability of the monocytes after the experiments was greater than $90 \%$ as tested with trypan blue exclusion and phagocytosis of latex beads. Bile acids also inhibited TNF production after stimulation with PMA, a nonspecific stimulator of monocytes, in a way similar to the reduction of the LPS-induced TNF production. The results indicate that DCA and CDCA inhibit TNF production of monocytes by a direct inhibitory effect on the cells. The observed reduction of phagocytosis by monocytes of opsonized SRBC after incubation with bile acids further demonstrates a direct effect of bile acids on the cells.

Our results are in agreement with data from two studies in which the effect of bile acids on lymphocyte function was tested. In an in vitro experiment by Gianni et al. (27), CDCA inhibited the lymphoproliferative response to mitogens significantly. In similar experiments by Keane and co-workers (28), it was shown that DCA and CDCA inhibited lymphocyte function, whereas UDCA was significantly less effective. It was also shown that bile acids in concentrations of up to $1,000 \mu \mathrm{M}$ in the first and $250 \mu \mathrm{M}$ in the latter study were not cytolytic to the cells, data which are supported by our results. With existing techniques it is difficult, however, to exclude a possible cytotoxic effect of bile acids on monocytes.

In contrast to our results, several studies showed that bile acids inactivate endotoxins (29-33). A direct effect of bile acids on endotoxin, as an explanation for their clinical effects, is, however, unlikely. The concentrations of bile acids needed to inactivate endotoxin in the above-mentioned in vitro and in vivo experiments were well above the concentrations of bile acids found in the clinical situation and the concentrations used in our experiments (maximum 125 $\mu \mathrm{M})(25,26)$. The minimal concentration of deoxycholate necessary to inactivate endotoxin in the in vivo experiments $(10 \mathrm{mM})$ was at least 80 times higher than the concentration used in the present study (29-31). In healthy subjects, concentrations of bile acids in feces may reach $5 \mathrm{mM}$, still clearly below those used in the experiments mentioned above $(34,35)$. Furthermore, it is unlikely that the clinically effective treatment of jaundiced patients with oral administration of deoxycholate (approximately a total of 4.5 mmoles per day) for three days results in concentrations in the bowel lumen or in serum high enough to actually inactivate endotoxins $(12,13)$. 
Another explanation for the clinical effect of bile acids is the reduced absorption of endotoxins from the gut, data which are, however, controversial. Preoperative oral administration of DCA in jaundiced patients reduced endotoxemia and prevented renal complications $(12,13)$. In contrast, oral administration of CDCA and UDCA appeared to reduce endotoxemia but did not have a beneficial clinical effect $(13,14)$. The clinical efficacy of the different bile acids correlates better with the inhibitory effect of these compounds observed in our study. DCA, the strongest inhibitor of TNF production by monocytes, reduced renal complications significantly. The clinically ineffective bile acids CDCA and UDCA were, respectively, less and not effective in reducing the production of the mediator of endotoxin toxicity.

Therefore, based on our experimental data, we postulate that orally administered bile acids could be effective through an inhibition of TNF release by mononuclear phagocytes. This seems contradictory to the high bile acid levels observed in serum of patients with obstructive jaundice. But since only the less inhibitory bile acids (e.g. CDCA and cholic acid) accumulate, no protection against the endotoxin induced TNF release by monocytes is to be expected in such patients $(25,26)$.

We conclude that bile acids do not inactivate endotoxins but rather inhibit the TNF production by mononuclear phagocytes, hence reducing the release of the mediator responsible for endotoxin toxicity. Despite similar physicochemical properties, DCA and CDCA differ greatly in their effect on monocytes. An explanation for this difference is not available. However, the difference in dispersing activities, possibly affecting cell wall integrity or receptor sites, as well as their different influence on calcium uptake by cells may be related to the observed effect $(28,36,37)$. More study is needed to locate the anatomical and physiological site of action of bile acids on mononuclear phagocytes. 


\section{REFERENCES}

1 Bailey ME. Endotoxin, bile salts and renal function in obstructive jaundice. Br J Surg 1976;63:774-778.

2 Pain JA, Cahill CJ, Bailey ME. Perioperative complications in obstructive jaundice:therapeutic considerations. Br J Surg 1985;72:942-945.

3 Wardle EN, Wright NA. Endotoxin and acute renal failure associated with obstructive jaundice. Br Med J 1970;4;472-474.

4 Pain JA, Bailey ME. Measurement of operative plasma endotoxin levels in jaundiced and non-jaundiced patients. Eur Surg Res 1987;19:207-216.

5 Wilkinson SP, Moody H, Stamatakis JD, Kakkar VV, Williams R. Endotoxaemia and renal failure in cirrhosis and obstructive jaundice. Br Med J 1976;2:1415-1418.

6 Hunt DR, Allison MEM, Prentice CRM, Blumgart LH. Endotoxemia, disturbance of coagulation, and obstructive jaundice. Am J Surg 1982;144:325-329.

7 Fletcher MS, Westwick J, Kakkar VV. Endotoxin, prostaglandins and renal fibrin deposition in obstructive jaundice. Br J Surg 1982;69:625-629.

8 Deventer van. SJH, Cate ten. JW, Tytgat GNJ. Intestinal endotoxemia. Gastroenterology 1988;94:825-831.

9 Kocksár LT, Bertók L, Várierész V. Effect of bile acids on the intestinal absorption of endotoxin in rats. J Bacteriol 1969;100:220-223.

10 Bertók L. Physico-chemical defense of vertebrate organisms: the role of bile acids in defense against bacterial endotoxins. Perspect Biol Med 1977;21:70-76.

11 Evans HJR, Torrealba $V$, Hudd C, Knight M. The effect of preoperative bile salt administration on postoperative renal function in patients with obstructive jaundice. $\mathrm{Br} J \mathrm{Surg}$ 1982;69:706-708.

12 Cahill CJ. Prevention of postoperative renal failure in patients with obstructive jaundice the role of bile salts. Br J Surg 1983;70:590-595.

13 Cahill CJ, Pain JA, Bailey ME. Bile salts, endotoxin and renal function in obstructive jaundice. Surg Gynecol Obstet 1987;165:519-522.

14 Thompson JN, Cohen J, Blenkharn JI, McConnell JS, Barr J, Blumgart LH. A randomized clinical trial of oral ursodeoxycholic acid in obstructive jaundice. Br J Surg 1986;73:634636.

15 Beutler B, Krochin N, Milsark IW, Luedke C, Cerami A. Control of cachectin (tumor necrosis factor) synthesis: Mechanisms of endotoxin resistance. Science 1986;232:977. 980.

16 Beutler B, Cerami A. Cachectin: More than a tumor necrosis factor. N Engl J Med 1987;316:379-385.

17 Beutler B, Cerami A. The endogenous mediator of endotoxin shock. Clin Res 1987; 35:192-197

18 Beutler B, Milsark IW, Cerami A. Passive immunization against cachectin/tumor mecrosis factor protects mice from lethal effect of endotoxin. Science 1985;229:869-871.

19 Tracey KJ, Fong Y, Hesse DG, et al. Anti-cachectin/TNF monoclonal antibodies prevent septic shock during lethal bacteriaemia. Nature 1987;330:662-664.

20 Lehman V, Freudenberg MA, Galanos C. Lethal toxicity of lipopolysaccharide and tumor necrosis factor in normall and d-galactosamine treated mice. J Exp Med 1987; 165:657-663. 
21 Graziano RF, Fanger MW. Fc-gamma-RI and Fc-gamma-RII on monocytes and granullocytes are cytotoxic trigger molecules for tumor cells, J Immunol 1987; 139:3536-3541.

22 Debets JHM, Linden v.d. CJ, Dieteren IEM, Leeuwenberg JFM, Buurman WA. Fc-receptor cross-linking induces rapid secretion of tumor necrosis factor (cachectin) by human peripheral blood monocytes. I Immunol 1988;141:1197-1201.

23 Olofsson $\mathrm{P}$. Application of a quantitative spectrophotometric endotoxin assay on lymph and plasma from the rat. Eur Surg Res 1986;18:112-121

24 Friberger $P$, Sörskog $L$, Nilsson $K, K$ nös. M. The use of a quantitative assay in endotoxin testing. Prog Clin Biol Res 1987;231:149-169

25 Neale $G$, Lewis $B$, Weaver $V$, Panveliwalla $D$. Serum bile acids in liver disease. Gut $1971 ; 12: 145-152$.

26 Pennington CR, Ross PE, Bouchier AD. Serum bile acids in the diagnosis of hepatobiliary disease. Gut 1977; 18:903-908.

27 Gianni L, Di Padova F, Zuin M, Podda M. Bile acid-induced inhibition of the lymphoproliferative response to phytohemagglutinin and pokeweed mitogen: An in vitro study. Gastroenterology 1980;78:231-235.

28 Keane RM, Gadacz TR, Munster AM, Birmingham W, Winchurch RA. Impairment of human lymphocyte function by bille salts. Surgery 1984;95:439-443.

29 Ribi E, Anacker RL, Brown R, et al. Reaction of endotoxin and surfactants I. Physical and biological properties of endotoxin treated with sodium deoxycholate. J Bacteriol 1966 ; 92:1493-1509.

30 Tarmina DF, Milner KC, Ribi E, Rudbach JA. Reaction of endotoxins and surfactants. Immunologic properties of endotoxins treated with sodium deoxycholate. J Immunol $1968 ; 100: 444-450$.

31 Tarmina DF, Milner KC, Ribi E, Rudbach JA. Modification of selected host-reactive properties of endotoxin by treatment with sodium deoxycholate. J Bacteriol 1968;96: $1611-1616$.

32 McIntire FG, Barlow GH, Sievert HW, Finley RA, Yoo AL. Studies on a lipopolysaccharide from Escherichia coli. Heterogeneity and mechanism of reversible inactivation by deoxycholate. Biochemistry 1969;8:4036-4067.

33 Shands JW, Chun PW. The dispersion of gram-negative lipopolysaccharide by deoxycholate. J Biol Chem 1980;255:1221-1226.

34 Faasen v. A, Bol J, Dokkum v. W, Pikaar NA, Ockhuizen T, Hermus RJJ. Bile acids, neutral steroids and bacteria in fieces as influenced by a mixed, a lacto-ovo-vegetarian and a vegan diet. Am J Clin Nutr 1987;46:962-967.

35 Nagengast FM, Hectors MPC, Buys WAM, Tongeren v.JHM. Inhibition of secondary bile acid formation in the large intestine by lactulose in healthy subjects of two different age groups. Eur J Clin Invest 1988;18:56-61.

36 Trias X, Strebel HM, Paumgartner G, Wiesmann UN. Effects of bile and bile acids on cultured human fibroblasts. Eur J Clin Invest 1977;7:189-94

37 Oelbeg DG, Dubinsky WP, Sackman JW, Wang L.B, Adock EW, Lester R. Bile salts induce calcium uptake in vitro by human erythrocytes. Hepatology $1987 ; 7: 245-52$ 


\section{Chapter 5}

\section{Lactulose inhibits endotoxin-induced tumour necrosis factor production by monocytes}

\section{An in vitro study}

J.W. Greve, D.J. Gouma, P.A.M. v. Leeuwen, W.A. Buurman.

Gut: 1990;31:198-203

\section{SUMMARY}

Preoperative oral treatment with lactulose is used to prevent complications after surgery in patients with obstructive jaundice. The effect is perhaps due to an inactivation of gut derived endotoxins, but the exact mechanism of action is, however, unknown.

Tumour necrosis factor (TNF) is an important mediator of endotoxin toxicity. The cytokine TNF is mainly produced by mononuclear phagocytes. In this study the effect of lactulose on the endotoxin-induced TNF release by monocytes was investigated. The direct effect of lactulose on endotoxin was tested in a chromogenic limulus amoebocyte lysate assay. Polymyxin B a known inactivator of endotoxin was used as control in both experiments.

Lactulose has a limited capacity to inactivate endotoxin as measured in the endotoxin assay. In contrast lactulose significantly reduced endotoxin-induced TNF production by monocytes.

It is concluded that lactulose inhibits TNF production by a direct inhibitory effect on monocytes, rather than by inactivation of endotoxin. Because TNF is an important mediator of endotoxin toxicity, this inhibitory effect could explain the beneficial effect of lactulose in obstructive jaundice. 


\section{INTRODUCTION}

Gut derived endotoxins are thought to be responsible for postoperative complications such as renal insufficiency, gastrointestinal bleeding and infections, in patients with obstructive jaundice $(1,2)$. This theory is supported by the high incidence of endotoxaemia reported in these patients and the correlation that was found between the presence of endotoxaemia and occurrence of complications (3-5).

Polymyxin B is a known anti-endotoxin agent (6-8), and reduces mortality in rats, with experimental biliary obstruction, challenged with intragastric endotoxin (9). Unfortunately, because of its renal toxicity, effective doses can not be given to jaundiced patients (10). Orally administrated bile acids have been used successfully to prevent endotoxin related complications after surgery in jaundiced patients $(11,12)$. Bile acids reduced absorption of endotoxins from the gastrointestinal tract resulting in a decrease of portal and systemic endotoxaemia and of post-operative renal complications.

Pre-operative oral treatment with lactulose was found to be equally effective in preventing post-operative renal complications in patients with obstructive jaundice (13). The effect of lactulose was explained by an inactivation of endotoxins from the gastrointestinal tract. Suggestive evidence for this hypothesis was the reduced limulus amoebocyte lysate activation by endotoxin in the presence of lactulose $(13,14)$. The mechanism through which lactulose reduces endotoxin toxicity, however, remains to be further clarified.

Tumour necrosis factor (TNF) is reported to be an important mediator of endotoxin toxicity (15-17). The cytokine TNF is mainly produced by mononuclear phagocytes in response to endotoxin $(18,19)$. These findings enabled us to develop an in vitro model to study the effect of different agents on the production of TNF as the mediator of endotoxin toxicity. Human peripheral blood monocytes were stimulated with endotoxin in presence of the compound to be tested and TNF production was measured with an enzyme linked immunosorbent assay (ELISA).

To analyse if and how lactulose prevents the toxic effects of endotoxin, this in vitro model was used. The direct effect of lactulose on endotoxin was evaluated with a modified chromogenic limulus amoebocyte lysate assay. As lactulose preparations used in clinical practice can be divided in two groups, a crystalline pure lactulose and lactulose syrup containing galactose and lactose besides lactulose, both preparations were tested. 


\section{MATERIALS AND METHODS}

\section{Chemicals and antibodies}

Lactulose syrup (Duphalac ${ }^{\circledR}$ ) was kindly provided by Duphar (Weesp, the Netherlands). Crystalline lactulose (Legendal ${ }^{3}$ ) was a gift from Inpharzam (Almere, The Netherlands). Lactitol was kindly provided by CGA biochemicals bv (Gorichem, The Netherlands). Lipopolysaccharide E. Coli O111:B4 (LPS) chromatographically purified, phorbol myristate acid (PMA), Polymyxin B sulphate $(8000 \mathrm{U} / \mathrm{mg})$, latex beads $(1.091 \mu \mathrm{m}$ diameter $)$, bovine serum albumin (BSA) and o-phenylenediamine (OPD) were obtained from Sigma Chemical Co. (St.Louis, MO). Human recombinant tumour necrosis factor ( $\mathrm{TTNF}$ ) was a gift of BASF/Knoll AG (Ludwigshaven, FRG). Monoclonal antibodies against rTNF were derived from hybridomas obtained by standard cell fusion procedures. Rabbit polyclonal antibodies against TNF were raised by immunizing rabbits with rTNF. Peroxidase-conjugated goat anti-rabbit IgG was purchased from Jackson Immunoresearch Laboratories (West Grove, PA).

\section{Mononuclear cells from human peripheral blood}

Peripheral blood mononuclear cells (PBMC) from buffy coats of healthy blood donors (kindly provided by the local blood bank) were purified by buoyant density centrifugation on Lymphoprep (Nycomed AS,Oslo, Norway). The interface layer was collected and washed twice in Hanks balanced salt solution. The PBMC were resuspended in culture medium (CM), consisting of RPMI 1640 (Gibco, Paisley, Scotland) supplemented with $10 \%$ bovine calf serum (BCS) (Hyclone, Logan, UT) and streptomycin $100 \mu \mathrm{g} / \mathrm{ml}$ penicilin 100 $\mathrm{IU} / \mathrm{ml}$ (Flow, Irvine, UK), at a concentration of $5 \times 10^{7} / \mathrm{ml}$. Monocytes were further isolated as described elsewhere (20). In short, the suspension was spun in polypropylene tubes at $20 \mathrm{rpm}, 4^{\circ} \mathrm{C}$ to induce monocyte clumping. The clumped monocytes were separated from lymphocytes by sedimentation on ice cold $\mathrm{BCS}$ for $20 \mathrm{~min}$. Monocytes were resuspended in $\mathrm{CM}$ at a concentration of $10^{5} / \mathrm{ml}$ and transferred to a 96 well tissue culture plate (Costar, Cambridge, MA) $100 \mu \mathrm{l} /$ well. The remaining cells consisted of more than $90 \%$ monocytes as evaluated by phagocytosis and indirect immunofluorescence (data not shown). 


\section{TNF enzyme-linked immunosorbent assay (ELISA)}

TNF concentrations in the cell free supernatants of the cell cultures were determined with a TNF specific ELISA as described previous (21). In short: 96 well immuno plates (Nunc, Roskilde, Denmark) were coated with a monoclonal anti-TNF antibody. Test samples were added to the plate and incubated for three hours at room teriperature. A standard titration curve was obtained by making serial dilutions of a known sample of rTNF. Next the plates were washed and sequentially incubated with rabbit anti-TNF immune serum and peroxidaseconjugated goat anti-rabbit IgG. After adding substrate (OPD $0.43 \mathrm{mg} / \mathrm{ml}$ ) the color reaction was stopped and light absorption (at $492 \mathrm{~nm}$ ) was measured with a microelisa autoreader (Flow, Irvine, UK). The ELISA has a lower detection limit of $10 \mathrm{pg} / \mathrm{ml}$. The TNF-assay was neither affected by both lactulose preparations nor by Polymyxin B. Extinctions as measured with the ELISA of different concentrations of rTNF as well as natural, monocyte derived, human TNF in presence of these compounds differed less than $5 \%$ from control values.

\section{Endotoxin assay}

Endotoxin was measured with a modified chromogenic limulus amoebocyte

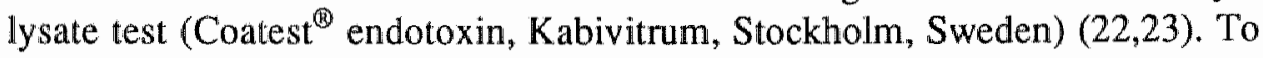
evaluate the direct inactivating effect of lactulose on endotoxin crystalline lactulose or lactulose syrup dissolved in pyrogen free water (NPBI, EmmerCompascuum, The Netherlands), at concentrations similar to those used in the cell culture experiments, were incubated for two hours at $37^{\circ} \mathrm{C}$ with different concentrations of LPS. As control Polymyxin B, a known inactivator of endotoxin, was incubated at a concentration of $25 \mu \mathrm{g} / \mathrm{ml}$ with LPS. After incubation the remaining endotoxin was measured with the LAL assay. All glassware used in the experiments was rendered endotoxin free by heating for three hours at $180^{\circ} \mathrm{C}$. Addition of lactulose or Polymyxin B just before to the limulus lysate or the substrate step of the LAL assay did not affect recovery of standard samples of LPS. This indicates that both the lysate reaction and the substrate activation are not influenced by both substances. 


\section{Cell culture experiments}

The isolated monocytes, as described above, were allowed to settle for two hours after which CM was replaced with CM to which combinations of LPS, PMA, crystalline lactulose, lactulose syrup, lactitol, and Polymyxin B were added. In the first series of experiments a serial dilution of LPS was preincubated for two hours with crystalline lactulose, lactulose syrup, lactitol, or Polymyxin B. In the second series of experiments different concentrations of crystalline lactulose, lactulose syrup and Polymyxin B were preincubated for two hours with a serial dillution of LPS. In the third series of experiments PMA was used to stimulate the TNF production of monocytes, again after preincubation for two hours with crystalline lactulose, lactulose syrup, lactitol, and Polymyxin B. In both experiments monocytes stimulated with LPS or PMA in $\mathrm{CM}$ served as positive controls whereas monocytes cultured in $\mathrm{CM}$ were used as negative controls. All cultures were performed at $37^{\circ} \mathrm{C}$ in a moist $8 \%$ carbon dioxide air atmosphere. Lactulose syrup, crystalline lactulose and lactitol used in the cell culture experiments were diluted in pyrogen free water in order to reach an osmolarity of 300 mosmol. Thereafter lactulose syrup was diluted in $\mathrm{CM}$ to obtain a concentration of $\pm 7 \mathrm{mg} / \mathrm{ml}$ of lactulose. Crystalline lactulose and lactitol were diluted in CM to a concentration of $\pm 10 \mathrm{mg} / \mathrm{ml}$. The difference in lactulose content between the two lactulose solutions is caused by the presence of the monosaccharides lactose and galactose which account for $30 \%$ of the osmolarity of undiluted lactulose syrup. In all experiments osmolarity and $\mathrm{pH}$ of $\mathrm{CM}$ after addition of the different compounds were determined. Osmolarity ranged from 300 to 320 mosmol, $\mathrm{pH}$ from 7.14 to 7.24 . The values of $\mathrm{CM}$ were 307 mosmol and $\mathrm{pH} 7.15$.

Experiments lasted for 16-18 hours after which cell free culture supernatants were harvested for analysis. The supernatants were assayed for presence of TNF directly or were stored at $-20^{\circ} \mathrm{C}$ until analysis. Experiments were performed in duplicate or quadruplicate as given below. All experiments were repeated at least three times using monocytes from different blood donors.

\section{Viability of monocytes}

Viability of the monocytes was examined after the experiments by trypan blue exclusion and by phagocytosis of latex beads. Latex beads were washed four times in PBS and a $0.01 \%(\mathrm{v} / \mathrm{v})$ suspension was made in CM. The latex beads were added to the monocytes. After incubation for two hours at $37^{\circ} \mathrm{C}$ remaining latex beads were removed and percentage phagocytosis was assessed 
by counting the monocytes containing two or more latex beads. The percentage trypan blue excluding, viable, cells was assessed by counting 200 cells per cell culture.

\section{RESULTS}

\section{Effect of lactulose and Polymyxin B on LAL activation by endotoxin}

The concentrations of both lactulose preparations used to inactivate endotoxin were similar to the concentrations used in the cell culture experiments. Lactulose syrup (Duphalac) inactivated low amounts of LPS significantly, however at increasing amounts of LPS this inactivating effect of lactulose decreased, being reduced to approximately $50 \%$ at an endotoxin concentration of $150 \mathrm{pg} / \mathrm{ml}$ (Table 1). The crystalline, $99 \%$ pure, lactulose (Legendal) did not inactivate LPS as measured with the LAL assay.

As a positive control Polymyxin B, a known inactivator of LPS, was used. In contrast with both lactulose preparations Polymyxin B inactivated the amount of LPS used in this experiment nearly completely.

TABLE 1. Effect of lactulose and Polymyxin B on endotoxin measured with the LAL assay.

A

B

$\mathrm{C}$

$\begin{array}{lrrr}\text { CONTROL } & 7.6 \pm 8.1 & 43.3 \pm 14.0 & 165 \pm 18.8 \\ \text { CRYSTALLINE LACTULOSE } & 20.2 \pm 13.4 & 72.3 \pm 8.6 & 149.8 \pm 20.9 \\ \text { LACTULOSE SYRUP } & 2.3 \pm 4.8 & 14.5 \pm 5.8 & 85 \pm 6.5 \\ \text { POLYMYXIN B } & 1.8 \pm 2.1 & 6.7 \pm 5.9 & 11.2 \pm 7.9\end{array}$

Endotoxins (in three concentrations $A, B, C$ ), dissolved in endotoxin free water, were incubated with lactulose syrup ( $7 \mathrm{mg}$ lactulose $/ \mathrm{ml}$ ), crystalline lactulose ( $10 \mathrm{mg}$ lactulose/ $\mathrm{ml}$ ) and Polymyxin B (25 $\mathrm{\mu g} / \mathrm{ml})$ for two hours at $37^{\circ} \mathrm{C}$. Untreated LPS dissolved in endotoxin free water served as control. Remaining endotoxin was measured with a modified chromogenic LAL assay. Results, expressed in pg LPS/ml, are mean \pm SD of 6 values. 


\section{Effect of lactulose, lactitol, and Polymyxin B on the TNF production by monocytes stimulated with endotoxin}

Stimulation of monocytes with endotoxin resulted in a high TNF release. Endotoxin dosages of $1 \mathrm{ng}$ LPS/ml caused TNF productions which were on average above $1000 \mathrm{pg} / \mathrm{ml}$ (Figures 1-3). The TNF production rapidly increased at higher LPS dosages reaching a plateau at 30-100 $\mathrm{ng}$ LPS/ml, after which a much slower increase of TNF production in relation to the LPS dose was found. Measuring TNF production by monocytes was a highly sensitive and reproducible way to detect the presence of biological active LPS.

Both lactulose preparations inhibited TNF production by monocytes after stimulation with endotoxin significantly (Figure 1). Lactulose syrup appeared to be a more effective inhibitor of TNF production, than crystalline lactulose. At 7 $\mathrm{mg}$ lactulose/ml lactulose syrup reduced LPS-induced TNF production by monocytes with $95 \%$ at all concentrations of LPS used, whereas crystalline lactulose

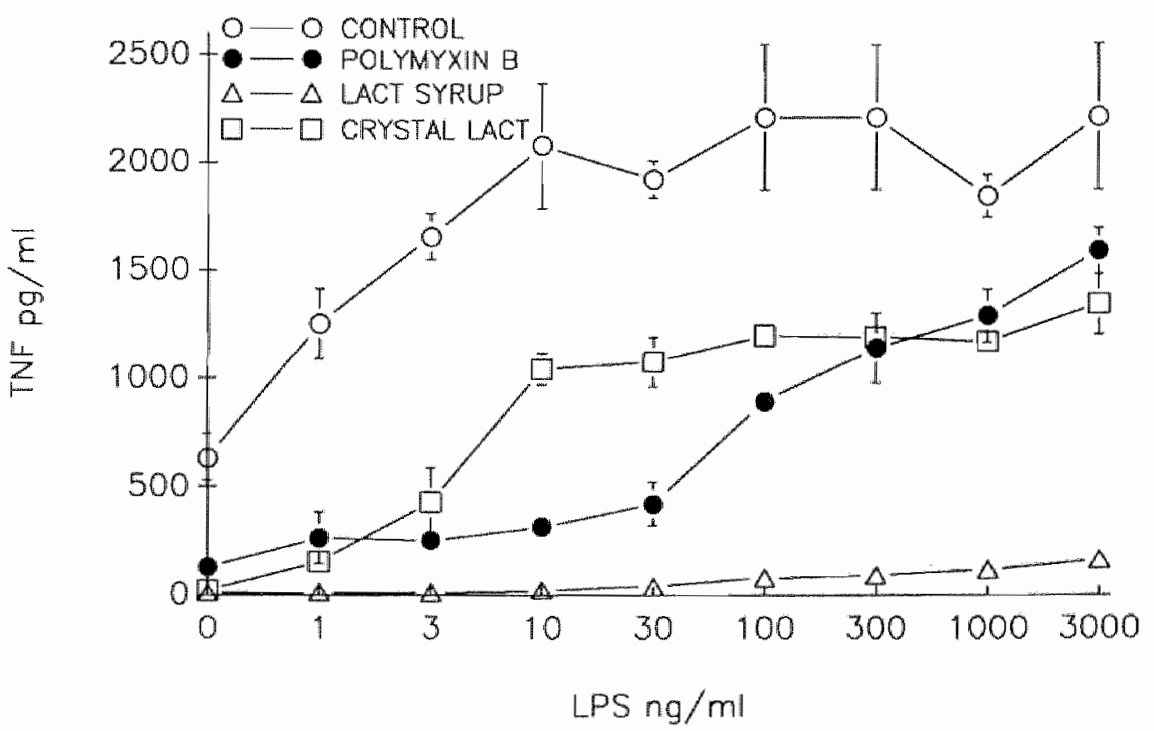

Figure 1. Inhibitory effect of lactulose syrup, crystalline lactulose and Polymyxin B on TNF production by monocytes stimulated with LPS. Human peripheral blood monocytes were incubated with a serial dilution of LPS and the same amounts of LPS after pre-incubation with lactulose syrup (7 mg lactulose/ $\mathrm{ml}$ ), crystalline lactulose ( $10 \mathrm{mg}$ lactulose/ml) and Polymyxin B $(25 \mu \mathrm{g} / \mathrm{ml})$. TNF production was measured in cell free culture supernatant with an ELISA. Data points represent mean $\pm S D$ of 4 values. 


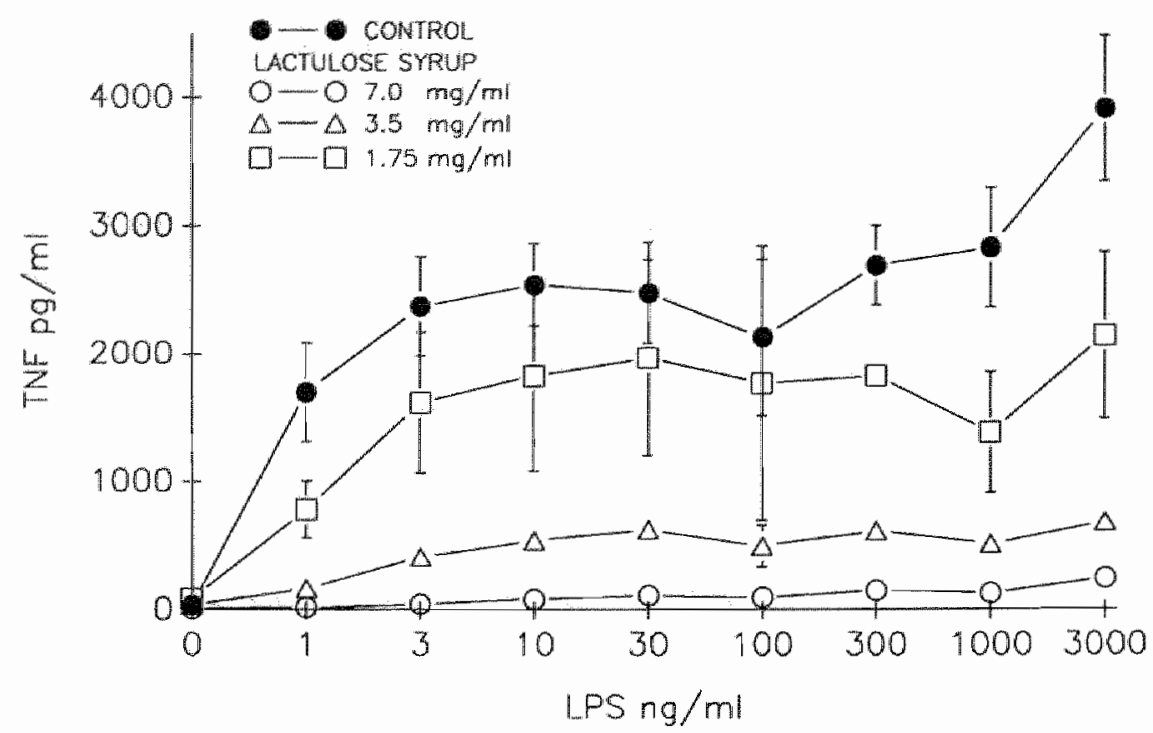

Figure 2. Effect of different concentrations of lactulose syrup on LPS-induced TNF production by monocytes. Monocytes were incubated with a serial dilution of LPS pre-incubated with lactulose syrup in concentrations of $7,3.5$ and $1.75 \mathrm{mg}$ lactulose $/ \mathrm{ml}$. Untreated LPS served as control. TNF production was measured in cell free culture supernatants with an ELISA. Data points represent mean $\pm S D$ of 4 values.

in similar concentrations reduced TNF production with 15-20\%. Lactitol at 10 $\mathrm{mg} / \mathrm{ml}$ did not inhibit endotoxin-induced TNF production by monocytes (data not shown in figure).

As expected Polymyxin B, a proven inactivator of endotoxins, inhibited TNF production by monocytes after stimulation with endotoxins. With $25 \mu \mathrm{g}$ Polymyxin $\mathrm{B} / \mathrm{ml}$ on average $30 \mathrm{ng} \mathrm{LPS} / \mathrm{ml}$ was inactivated.

The effect of both lactulose preparations and Polymyxin B on the endotoxininduced TNF production by monocytes was further studied by testing different concentrations of these agents. Crystalline lactulose and lactulose syrup inhibited concentration dependent the LPS-induced TNF production by monocytes (Figures 2,3). Lactulose syrup reduced LPS-induced TNF production at 7, 3.5 and $1.75 \mathrm{mg}$ lactulose $/ \mathrm{ml}$ with 95,75 and $30 \%$ respectively. Crystalline lactulose reduced LPS-induced TNF production with approximately 25,15 and $0 \%$ at concentrations of 10,5 and $2.5 \mathrm{mg}$ lactulose $/ \mathrm{ml}$. This inhibitory effect of both lactulose preparations was independent from the concentration of endotoxin used. Polymyxin B also reduced concentration dependent the TNF production of monocytes stimulated with endotoxin. With concentrations of 25 , 5 and $1 \mu \mathrm{g}$ Polymyxin $\mathrm{B} / \mathrm{ml}$ the effect of 30,10 and $1 \mathrm{ng}$ LPS/ml was inhibited. 


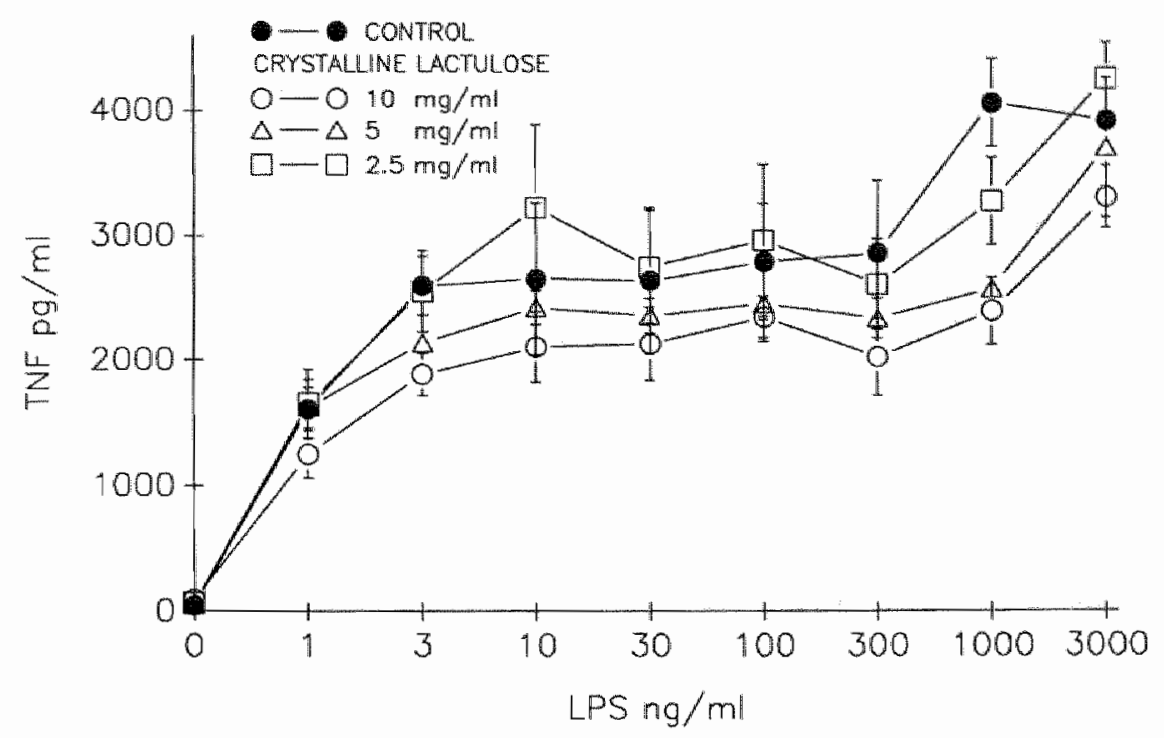

Figure 3. Effect of different concentrations of crystalline laculose on LPS-induced TNF production by monocytes. Monocytes were incubated with a serial dilution of LPS pre-incubated with crystalline lactulose in concentrations of 10,5 and $2.5 \mathrm{mg}$ lactulose/ml. TNF production was measured in cell free culture supernatants with an ELISA. Data points represent mean \pm SD of 4 values.

In contrast to lactulose, however, this inhibitory effect was limited to a maximum dose of endotoxin, after which TNF production of Polymyxin B treated cells paralleled that of control monocytes (Figure 4).

\section{TNF production by monocytes after stimulation with PMA, effect of lactulose, lactitol, and Polymyxin B}

To further analyse the effect of both lactulose preparations, lactitol and Polymyxin B on TNF production by monocytes, the PMA-induced TNF production by monocytes was studied. PMA induces TNF production by an activation of the intracellular messenger protein kinase $C$.

After stimulation with PMA monocytes produced high amounts of TNF. Crystalline lactulose and lactulose syrup in concentrations shown, significantly reduced PMA-induced TNF production by monocytes (Figure 5). This reduction was equivalent to the inhibitory effect of both crystalline lactulose and lactulose syrup on endotoxin-induced TNF production by monocytes. Lactitol did not inhibit PMA-induced TNF production. 


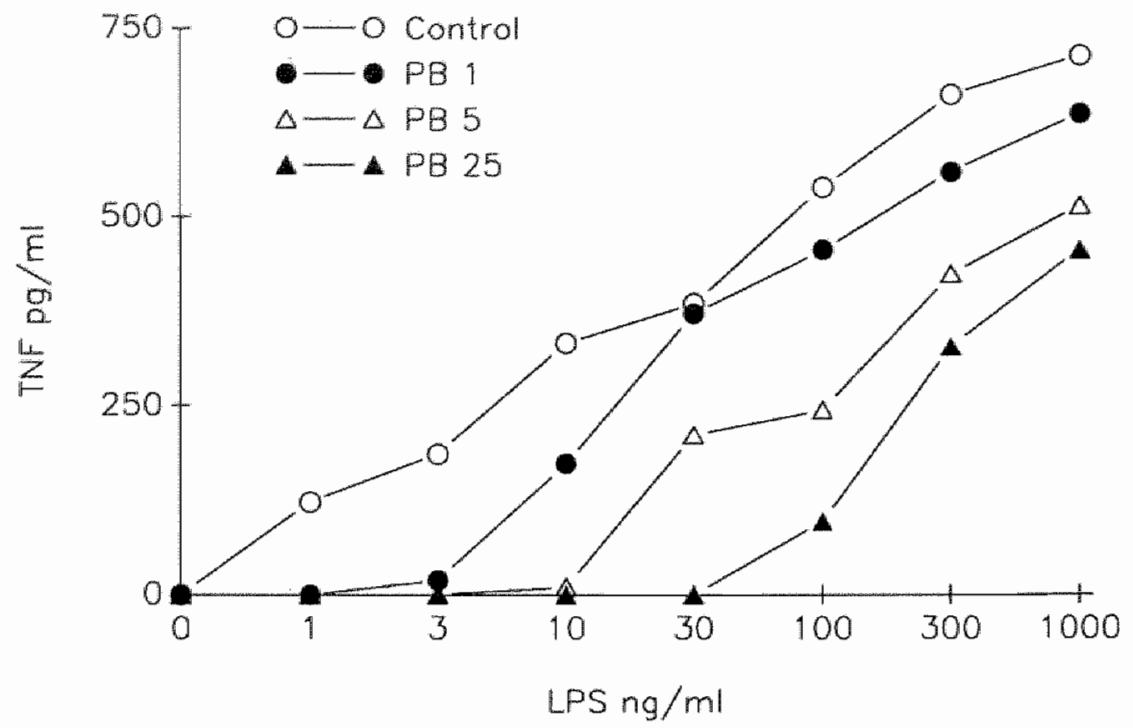

Figure 4. Effect of different concentrations of Polymyxin B on LPS-induced TNF production by monocytes. Monocytes were incubated with a serial dilution of LPS pre-incubated with Polymyxin B in concentrations of 25,5 and $1 \mu \mathrm{g} / \mathrm{ml}$. TNF production was measured in cell free culture supernatants with an ELISA. Results from a representative experiment are shown.

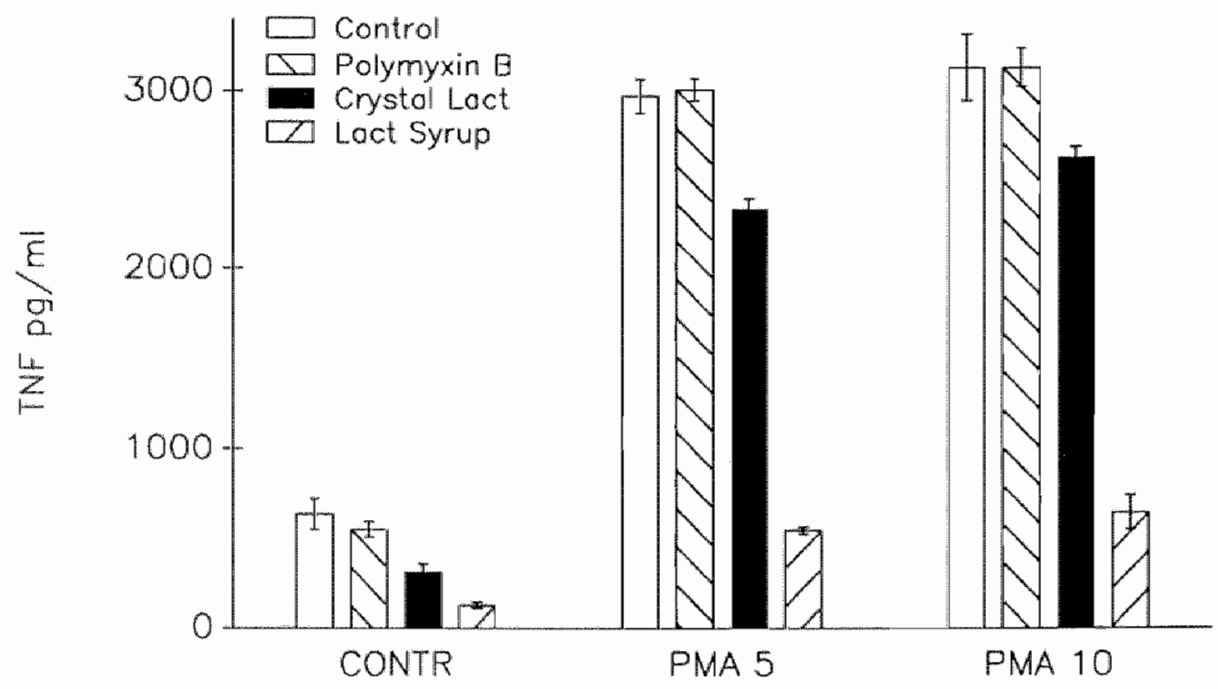

Figure 5. Effect of both lactulose preparations and Polymyxin B on the PMA-induced TNF production by monocytes. Monocytes were incubated with PMA in concentrations of 5 and 10 $\mathrm{ng} / \mathrm{ml}$ in the presence of lactulose syrup $(7 \mathrm{mg}$ lactulose $/ \mathrm{ml})$, crystalline lactulose (10 $\mathrm{mg}$ lactulose $/ \mathrm{ml}$ ) and Polymyxin B $25 \mu \mathrm{g} / \mathrm{ml}$. Unstimulated monocytes and monocytes stimulated with PMA served as control. Bars represent mean \pm SD of 6 values. 
Polymyxin B did not affect PMA-induced TNF production by monocytes, this in contrast to the endotoxin-induced TNF production.

\section{Viability of the monocytes after the experiments}

After the cell culture experiments the viability of the monocytes was tested by trypan blue exclusion and phagocytosis of latex beads. Directly after removing supernatants for TNF measurements trypan blue solution or latex beads in CM were added to the cell cultures. Trypan blue exclusion was greater than $85 \%$ in all experiments. Phagocytosis of latex beads was clearly delayed, but not significantly reduced, after incubation with lactulose syrup whereas preincubation with crystalline lactulose or Polymyxin B did not affect phagocytosis as compared with control cells.

\section{DISCUSSION}

The results of our experiments show that crystalline lactulose (Legendal) did not inactivate endotoxin as determined with the LAL assay. Lactulose syrup (Duphalac) did inactivate low amounts of LPS, this effect decreased with increasing LPS concentrations.

Both lactulose syrup and crystalline lactulose inhibited TNF production of monocytes stimulated with LPS significantly. Polymyxin B also inhibited TNF production by monocytes after stimulation with endotoxin but the kinetics were clearly different from the inhibition caused by lactulose. TNF production of the monocytes stimulated with Polymyxin B treated LPS parallelled that of control cells when a maximum amount of LPS was passed. Apparently Polymyxin B could only inactivate a certain amount of endotoxin related to the amount of Polymyxin B used. In contrast both lactulose preparations inhibited TNF production by monocytes independent from the concentration of endotoxin used. These data indicate that where Polymyxin B was effective by actually inactivating endotoxin, both lactulose preparations probably prevented the production of the mediator of endotoxin toxicity by a direct effect on the cells. The inhibitory effect of both lactulose preparations or Polymyxin B in the experiments could not be explained by a cytolytic effect on the cells as the viability of monocytes was not affected. Lactitol a disaccharide clinically used for similar indications as lactulose did not reduce TNF production by monocytes, indicating that the observed inhibitory effect is specific for lactulose. 
Experiments with PMA, a direct stimulator of TNF production by monocytes which acts through activation of the intracellular messenger protein kinase $C$, supplied further evidence for a direct inhibitory effect of lactulose on monocytes. Both lactulose preparations inhibited the PMA-induced TNF production by monocytes in a fashion similar to the inhibition of LPS-induced TNF production. In contrast Polymyxin B, as expected, did not reduce TNF production by monocytes stimulated with PMA.

The data show that both lactulose preparations inhibit LPS-induced as well as PMA-induced TNF production by monocytes. In all cell culture experiments, however, lactulose syrup was more effective than similar amounts of crystalline lactulose in reducing TNF production by monocytes.

The effect of Polymyxin B as described in our experiments is similar to results of a study by Duff et al (24). In these experiments the effect of Polymyxin $B$ on production of endogenous pyrogen by monocytes after stimulation with endotoxin was studied. They found that LPS-induced production of endogenous pyrogen was inhibited by polymyxin B, whereas production of endogenous pyrogen after stimulation of monocytes with killed Staphylococci could not be reduced by polymyxin B. This indicated that Polymyxin B inactivated LPS but did not affect the monocytes. The inhibitory effect of Polymyxin B on LPS but not on cells was further supported by results of Spear et all, who used Polymyxin B to inactivate contaminating LPS in mixed lymphocyte reactions and found that Polymyxin B did not affect $\left[{ }^{3} \mathrm{H}\right]$ thymidine incorporation (25). Polymyxin B was used successfully as an anti-endotoxin drug in a number of in vivo experiments, but its high toxicity severely limits its clinical use (6-10). In contrast with Polymyxin B little is known of the anti-endotoxin effect of lactulose.

Orally administrated lactulose prevented endotoxin-related complications after surgery in jaundiced patients (13). Moreover galactosamine-induced liver necrosis, caused by endotoxins from the gastrointestinal tract, was prevented by oral pretreatment with lactulose (14). Both studies reported a strongly reduced activation of the LAL assay by endotox in in presence of lactulose, but these data differ from our observations. We found that lactulose inactivates only small amounts of endotoxin. The results of our study indicate, however, that the efficacy of lactulose can be explained by a direct effect on mononuclear phagocytes resulting in a reduced production of the mediator of endotoxin toxicity (TNF). Lehman et al showed that TNF appeared to be a central mediator of endotoxin mediated mortality in mice treated with D-galactosamine and endotoxin (19). These results indicate that inhibition of TNF production can prevent endotoxin-induced complications. 
That lactulose treatment not only causes an acidification and/or hyperosmolarity of the bowel lumen, but can also have an effect on metabolism of bacteria and different cells in the bowel wall was suggested by a number of studies on lactulose treatment of hepatic encephalopathy in patients with liver cirrhosis. Diminished ammonia production after lactulose treatment was explained by alteration of bacterial flora in the gut, by changes of bacterial metabolism and recently by an effect of lactulose on metabolism of crypt and villus cells of the bowel wall (26-30).

Lactulose under normal conditions is only absorbed in small amounts from the gastro-intestinal tract (approximately $1.5 \%$ of the administrated oral dose is excreted in urine) (31). In situations of mucosal damage, stress, or infection, however, the absorption of lactulose from the bowel is greatly increased (3234). It is in these situations where substantial amounts of lactulose penetrate the bowel wall that it is probably most effective. Our observations show that lactulose can have a direct effect on cell function. Lactulose inhibited the release of TNF, the mediator of endotoxin toxicity, by an inhibitory effect on mononuclear phagocytes. The effect of lactulose could not be explained by an inactivation of endotoxin. Hypothetically this inhibitory effect of lactulose on the production of TNF may explain the beneficial effect of lactulose as supportive pre-operative treatment in jaundiced patients. 


\section{REFERENCES}

1 Pain JA, Cahill CJ Bailey ME. Perioperative complications in obstructive jaundice:therapeutic considerations. Br J Surg 1985;72:942-5.

2 Deventer $\vee \mathrm{SJH}$, Cate $\mathbb{J W}$, Tytgat GNJ. Intestinal endotoxemia. Gastroenterology 1988:94:825-31.

3 Wardle EN, Wright NA. Endotoxin and acute renal failure associated with obstructive jaundice. Br Med J 1970;4:472-4.

4 Wilkinson SP, Moody $H_{*}$ Stamatakis JD, Kakkar VV, Williams R. Endotoxaemia and renal failure in cirrhosis and obstructive jaundice. Br Med J 1976;2:1415-8.

5 Pain JA, Bailey ME. Measurement of operative plasma endotoxin levels in jaundiced and non-jaundiced patients. Eur Surg Res 1987;19:207-16.

6 Corrigan JJ, Kiemat JF. Effect of polymyxin B sulfate on endotoxin activity in a gramnegative septicemia model. Pediat Res 1979;13:48-51.

7 From AHL, Fong JSC, Good RA. Polymyxin B sulfate modification of bacterial endotoxin: effects on the development of endotoxin shock in dogs. Infect Immun 1979; 23:660-4.

8 Nolan JP, Leibowitz All. Endotoxin and the liver III. Modification of acute carbon tetrachloride injury by polymyxin B an antiendotoxin. Gastroenterology 1978;75:445-9.

9 Ingoldby $\mathrm{CJH}$. The value of polymyxin B in endotoxaemia due to experimental obstructive jaundice and mesenteric ischaemia. Br J Surg 1980;67:565-7.

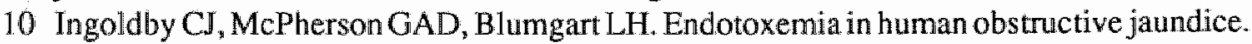
Effect of Polymyxin B. Am J Surg 1984;147:766-71.

11 Cahill CJ. Prevention of postoperative renal failure in patients with obstructive jaundice-the role of bile salts. Br J Surg 1983;70:590-5.

12. Bailey ME. Endotoxin, bile salts and renal function in obstructive jaundice. Br J Surg $1976 ; 63: 774-8$.

13 Pain JA, Bailey ME. Experimental and clinical study of lactulose in obstructive jaundice. Br J Surg 1986;73:775-8.

14 Liehr H, Englisch G, Rasenack U. Lactulose-A drug with antiendotoxin effect. Hepatogastroenterology 1980;27:356-60.

15 Beutler B, Krochin N, Milsark IW, Luedke C, Cerami A. Control of cachectin (tumor necrosis factor) synthesis:Mechanisms of endotoxin resistance. Science 1986;232:977-80.

16 Beutler B, Milsark IW, Cerami A. Passive immunization against cachectin/tumor necrosis factor protects mice from lethal effect of endotoxin. Science 1985;229:869-71.

17 Tracey KJ, Fong Y, Hesse DG et al. Anti-cachectin/TNF monoclonal antibodies prevent septic shock during lethal bacteriaemia. Nature 1987;330:662-4.

18. Beutler B, Cerami A. Cachectin: More than a tumor necrosis factor. $\mathrm{N}$ Engl J Med 1987;316:379-85.

19 Lehman V, Freudenberg MA, Galanos C. Lethal toxicity of lipopolysaccharide and tumor necrosis factor in normal and d-galactosamine-treated mice. J Exp Med 1987;165:657-63.

20 Graziano RF, Fanger MW. Fc-gamma-RI and Fc-gamma-RII on monocytes and granulocytes are cytotoxic trigger molecules for tumor cells. J Immunol 1987;139:3536-41.

21 Debets JHM, Linden w.d. CJ, Dieteren IEM, Leeuwenberg JFM, Buurman WA. Fc-receptor cross-linking induces rapid secretion of tumor necrosis factor (cachectin) by human peripheral blood monocytes. J Immunol 1988;141:1197-1201. 
22 Friberger $P$, Sörskog L, Nilsson $K$, Knös $M$. The use of a quantitative assay in endotoxin testing. Prog Clin Biol Res 1987;231:149-69.

23 Olofsson P. Application of a quantitative spectrophotometric endotoxin assay on lymph and plasma from the rat. Eur Surg Res 1986;18:112-21.

24 Duff GW, Atkins $E$. The inhibitory effect of polymyxin $B$ on endotoxininduced endogenous pyrogen production. J Immunoll Methods 1982;52:333-40.

25 Spear GT, Teodorescu M. Enhancement of human MLR by very low concentrations of lipopolysaccharide and blocking of this enhancement by polymyxin B. J Immunol Methods 1984;73:321-7.

26 Bircher J, Muller J, Guggenheim $\mathbb{P}$, et al Treatment of chronic portalsystemic encephalopathy with lactulose. Lancet 1966;1:890-893

27 Vince AJ, Burridge SM. Ammonia production by intestinal bacteria: the effects of lactose, lactulose and glucose. J Med Microbiol 1980;13:177-91.

28 Vince $A$, Killingley $M$, Wrong OM. Effect of lactulose on ammonia production in a fecal incubation system. Gastroenterology 1978;74:544-9.

29 Leeuwen v. PAM, Janssen MA, Soeters PB, Jonge d. H. Metabolic characteristics of villus and crypt cells of conventional and germ-free rats and the influence of Neomycin and Lactulose. Eur Surg Res 1985;17,S1:77

30 Huhtanen CN, Parrhish FW, Hicks KB. Inhibition of bacteria by lactulose preparations. Appl Environ Microbiol 1980;40:171-3.

31 Delhunty $T$, Hollander $D$. Acomparison of intestinal permeability between humans and three common laboratory animals. Comp Biochem Physiol 1987;86A,565-7

32 Nathavitharana KA, Lloyd DR, Raafat F, Brown GA, McNeish AS. Urinary mannitoll:lactulose excretion ratios and jejunal mucosal structure. Arch Dis Child 1988;63,1054-9

33 Turner MW, Boulton $P$, Shields JG, et al. Intestinal hypersensitivity reactions in the rat $I$. Uptake of intact protein, permeability to sugars and their correlation with mucosal mast-cell activation. Immunology 1988;63,119-24

34 Ziegler TR, Smith RJ, O'Dwyer ST, Demling RH, Wilmore DW. Increased intestinal permeability associated with infection in burn patients. Arch Surg 1988;123,1313-9 



\section{Chapter 6}

\section{Increased sensitivity to endotoxemia by tissue}

necrosis

J.G. Maessen, J.W. Greve, and W.A. Buurman

Submitted for publication

\section{SUMMARY}

In this study the interaction of endotoxemia and ischemic organ injury was investigated in a rat model. Animals received LPS to induce endotoxemia, and were simultaneously subjected to renal ischemia. If only renal ischemia was induced moderate azotemia occurred and all animals survived. LPS treatment neither caused renal failure nor mortality. However, rats with both endotoxemia and renal ischemia showed severe azotemia and $50 \%$ of the animals died within 48 hours. The observed mortality was unlikely to be related to renal failure as bilaterally nephrectomized animals did not die within 48 hours following treatment with LPS.

To further exclude the role of renal failure in the enhanced effect of endotoxemia, experiments were performed in which ischemic kidneys were excised from littermates and were placed in the abdomen of LPS treated animals. A similar effect was observed: $50 \%$ of the animals died within 48 hours. Azotemia did not occur.

Since tumor necrosis factor (TNF) is an important cytokine involved in endotoxemia induced morbidity and mortality, we studied the role of TNF in our model. Plasma levels of TNF were increased during endotoxemia. Concomitant renal ischemic injury did not influence the concentration of TNF. When animals were treated with recombinant TNF and were subsequently subjected to renal ischemic injury, again a fifty percent mortality was observed, similar as in LPS treated animals. 


\section{INTRODUCTION}

Extensive tissue necrosis or ischemia-reperfusion associated tissue injury is related to the development of multiple organ failure and shock. The local involvement of inflammatory mechanisms in ischemia induced tissue damage has been described (1). Recent studies demonstrated that ischemic tissue injury elicits an inflammatory response which may have negative side effects that locally enhance the eventual damage in the ischemic area $(2,3)$. However, the importance of inflammatory mechanisms in the development of systemic effects following ischemia induced tissue damage has not yet been established.

Endotoxemia is associated with the induction of extensive inflammatory reactions (4). In previous studies it was shown that the enhancement of inflammatory reactions by endotoxemia, as in gram-negative sepsis, exacerbates the local effect of preexisting ischemic tissue injury (5). In the present study we tested the hypothesis that ischemic tissue damage in combination to changes in the inflammatory response, by endotoxemia, induces a systemic effect leading to an increase in morbidity and mortality. Such a mechanism might explain the development of multiple organ failure and shock following extensive tissue necrosis.

Fever usually accompanies ischemic tissue damage (e.g. in myocardial infarction). This sign suggests the induction of an inflammatory reaction. The macrophage-derived cytokine tumor necrosis factor (TNF) is a pyrogen and has been shown to play a central role in endotoxemia related morbidity and mortality (6). Treatment with monoclonal antibodies against TNF has been successfully used to inhibit the development of lethal complications as well as damage to organs during gram-negative sepsis $(7,8)$. We therefore studied whether TNF is involved in the supposed systemic effects of ischemic tissue damage in combination with endotoxemia.

In the present experimental study in rats evidence is provided that ischemic tissue damage affects the host response to endotoxemia and increases mortality. It is shown that TNF is likely to play a role in this phenomenon. 


\section{MATERIALS AND METHODS}

\section{Animals}

Male Sprague Dawley rats weighing 200-250 g were obtained from Charles River Breeding Laboratories. They were maintained on a standard laboratory diet and were allowed free access to water.

\section{Reagents}

Escherichia coli 055:B5 lipopolysaccharide (LPS) was obtained from Sigma Co. (St. Louis,MO) and suspended in sterile pyrogen-free saline. Human recombinant tumor necrosis factor was kindly provided by Cell Tech (Slough, UK). Before use, stock solutions were diluted in pyrogen-free saline.

\section{Surgical procedures}

Animals were anesthetized with ether. Surgery was performed on a temperature controlled watermattress. After making a midline abdominal incision both kidneys were dissected from surrounding tissues. The renal vessel pedicles, including the ureter, were clamped with soft tip, vascular clamps to induce renal ischemia. During the ischemic interval the abdomen was closed. Immediately following removal of the clamps to reinstall renal blood flow, the abdomen was closed. Nephrectomy was performed with a ligature around the vessel pedicle and complete removal of all renal tissue.

In other experiments a bilateral nephrectomy was performed in littermates of experimental animals. Two of these devascularised ischemic, kidneys were implanted in the peritoneal cavity of experimental animals. In all experiments blood samples were collected by puncture of the retrobulbar venous plexus.

\section{Experimental design}

All experimental groups consisted of 6 to 7 animals. In a first series of experiments the interaction of endotoxemia and tissue damage was studied. Tissue damage was induced by either clamping of the vessel pedicle of both kidneys during 30 or 60 minutes, or by implanting two syngeneic, devascu- 
larised kidneys in the peritoneal cavity. Endotoxemia was induced by administration of LPS at either $0.75 \mathrm{mg}$ per $100 \mathrm{~g}$ body weight or $1.5 \mathrm{mg}$ per $100 \mathrm{~g}$ body weight. LPS was given in two injections, the first one subcutaneously just before the release of the vessel clamps and the second one intraperitoneally 30 minutes after the release of the clamps or the implantation of two kidneys.

In a second series of experiments the effect of rTNF administration in stead of LPS was studied by injecting a single dose of $110 \mu \mathrm{g}$ per $100 \mathrm{~g}$ body weight in the penile vein prior to the onset of reperfusion after 30 minutes of ischemia.

In control experiments LPS and rTNF injections were administered in the same way as in the other groups, however, without clamping of the renal vessel pedicle. In an additional control group LPS injections were given in animals without renal ischemia but after bilateral nephrectomy. All injections were given in a volume of $1.0 \mathrm{ml}$. Blood samples for measurement of circulating TNF levels were taken before surgery and 1,2 , and 4 hours after surgery. Blood urea nitrogen levels were determined after 24 and 48 hours. Suriving animals were sacrificed after 5 days.

\section{Assay}

TNF activity in plasma was determined in a biological assay based on L929 mouse cells as described before (9). In short L929 cells were cultured and brought on 96 well tissue culture plates (Greiner, Nuertingen, FRG) in $100 \mu 1$ culture medium (RPMI 1640 (Gibco, Paisley, Scotland), 10\% bovine calf serum (Hyclone, Cogan, Utah), penicillin $100 \mathrm{IU} / \mathrm{ml}$ and streptomycin $100 \mu \mathrm{g} / \mathrm{ml}$ (Flow, Irvine, UK)).TNF values were calculated based on the values of a standard serial dilution of human recombinant TNF and expressed in pg per $\mathrm{ml}$.

\section{Data analysis}

All data are mean \pm SE of 6 or 7 values. Statistical analysis was performed with the Wilcoxon rank-sum test or the Mann-Whitney U test. Probality (P) values less than 0.05 were considered significant. 


\section{RESULTS}

\section{LPS treatment}

Animals received LPS either or not in combination with ischemic renal tissue damage. When animals were injected with $0.75 \mathrm{mg}$ LPS / $100 \mathrm{~g}$ no significant increase of the blood urea nitrogen level was observed. Doubling of this dose resulted in a small increase of these levels at 24 and 48 hours (Table 1). The latter group of animals showed moderate signs of illness (lethargy, rough fur). Lethality was not observed (Figure 1).

Blood urea nitrogen levels in animals with billateral renal ischemia ( 30 minutes) doubled during the first 24 hours of reperfusion but returned almost completely to normal within 48 hours. Simultaneous treatment of these rats with LPS $(0.75 \mathrm{mg})$ induced a significant further increase of the blood urea nitrogen levels both after 24 and 48 hours. The high dose of LPS (1.5 mg) in combination with renal ischemia ( $30 \mathrm{~min}$ ) caused a sharp increase of BUN after 24 hours.

Table 1. Blood urea nitrogen levels (mmol/l) after various treatments

\begin{tabular}{lrr}
\hline Group & $24 \mathrm{~h}$ & \multicolumn{1}{c}{$48 \mathrm{~h}$} \\
\hline control & $7 \pm 0.2$ & $7 \pm 0.1$ \\
LPS 0.75 & $8 \pm 0.4$ & $8 \pm 0.5$ \\
LPS 1.50 & $10 \pm 0.3$ & $9 \pm 0.5$ \\
RIS 30' & $15 \pm 0.3$ & $8 \pm 0.2$ \\
RIS 30' + LPS 0.75 & $24 \pm 1.5$ & $14 \pm 1.4$ \\
RIS 30' + LPS 1.50 & $58 \pm 5.1$ & $41 \pm 4.0$ \\
RIS 60' & $44 \pm 4.0$ & $41 \pm 4.2$ \\
RIS 60' + LPS 0.75 & $57 \pm 5.1$ & $51 \pm 9.3$ \\
TNF & $8 \pm 0.2$ & $7 \pm 0.3$ \\
RIS 30' + TNF & $47 \pm 4.3$ & $30 \pm 3.9$ \\
Bilat. Nephrectomy & $67 \pm 2.0$ & $113 \pm 2.3$ \\
DKS & $8 \pm 0.3$ & $8 \pm 0.4$ \\
DKS + LPS 1.50 & $9 \pm 0.4$ & $9 \pm 0.5$ \\
\hline
\end{tabular}

Abbreviations are: RIS, bilateral renal ischemia; DKS, devascularised syngeneic kidneys; LPS, lipopolysacharide; TNF, tumor necrosis factor. 

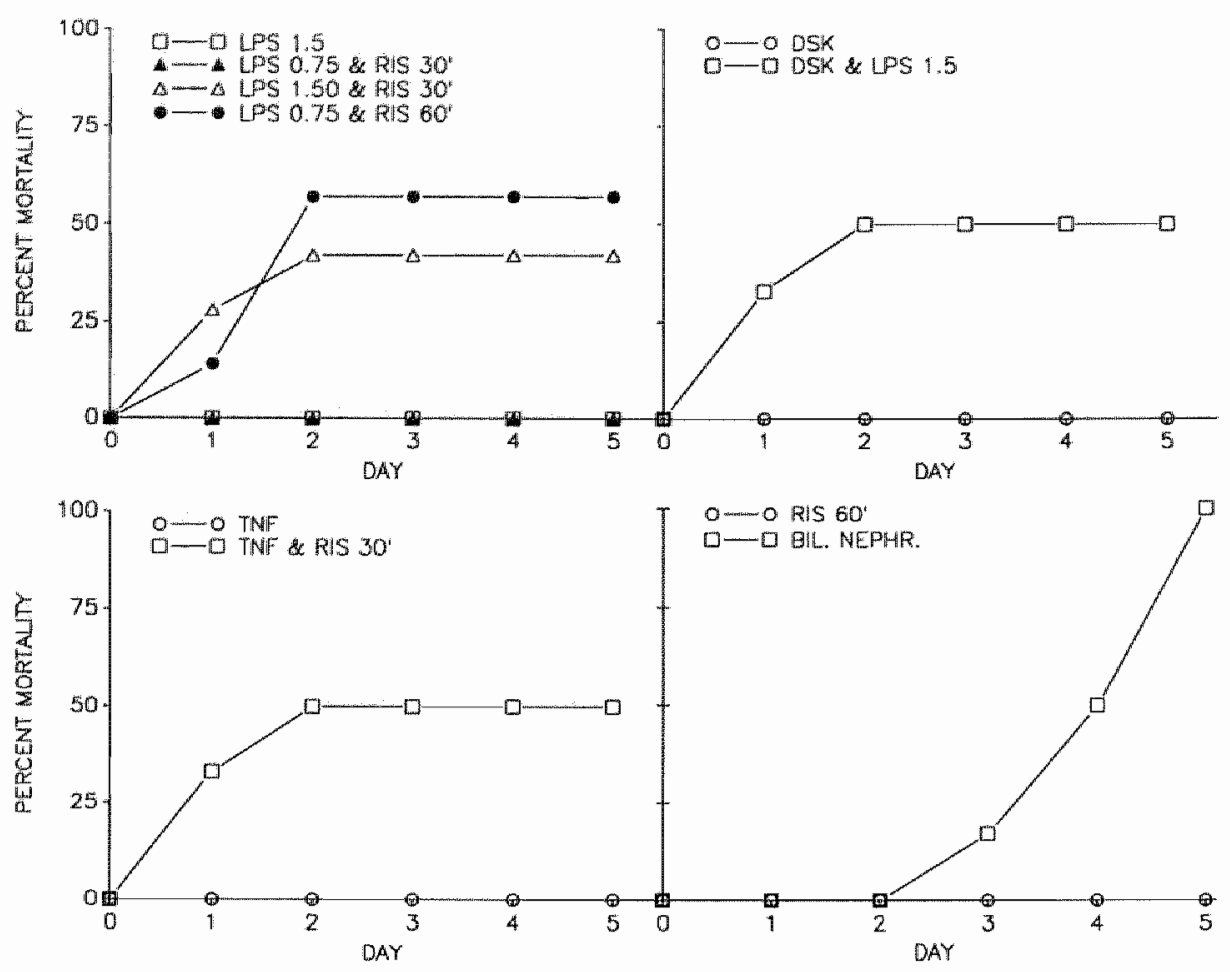

Figure 1. Cumulative mortality of rats. Upper left: effect of renal ischemia in combination to LPS treatment. Upper right: effect of implantation of two devascularised, syngeneic kidneys (DSK) in combination to LPS treatment. Bottom left: effect of renal ischemia in combination to human recombinant TNF treatment. Bottom right: effect of renal ischemia and bilateral nephrectomy. Single treatment with LPS at a dose of $0.75 \mathrm{mg}$ did not induce mortality nor did thirty minutes of bilateral renal ischemia (data not shown). All groups consisted of 6 or 7 rats.

During the next 24 hours only a small reduction of the increased blood urea nitrogen levels was observed (Table 1). The animals in this group with 30 minutes of ischemia and $1.50 \mathrm{mg} / 100 \mathrm{~g}$ body weight LPS, were severely ill with symptoms of diarrhoea and blood stained fluid exudation around the eyes. Three out of seven animals died within 48 hours (Figure 1).

When animals were subjected to 60 minutes of bilateral renal ischemia similar results were obtained at the low dose of LPS. Blood urea nitrogen levels were almost maximally raised and four out of seven animals died within 48 hours. Sixty minutes of ischemia without LPS treatment did not induce lethality. Notably, following bilateral nephrectomy most animals died between 48 and 120 hours (Figure 1). 


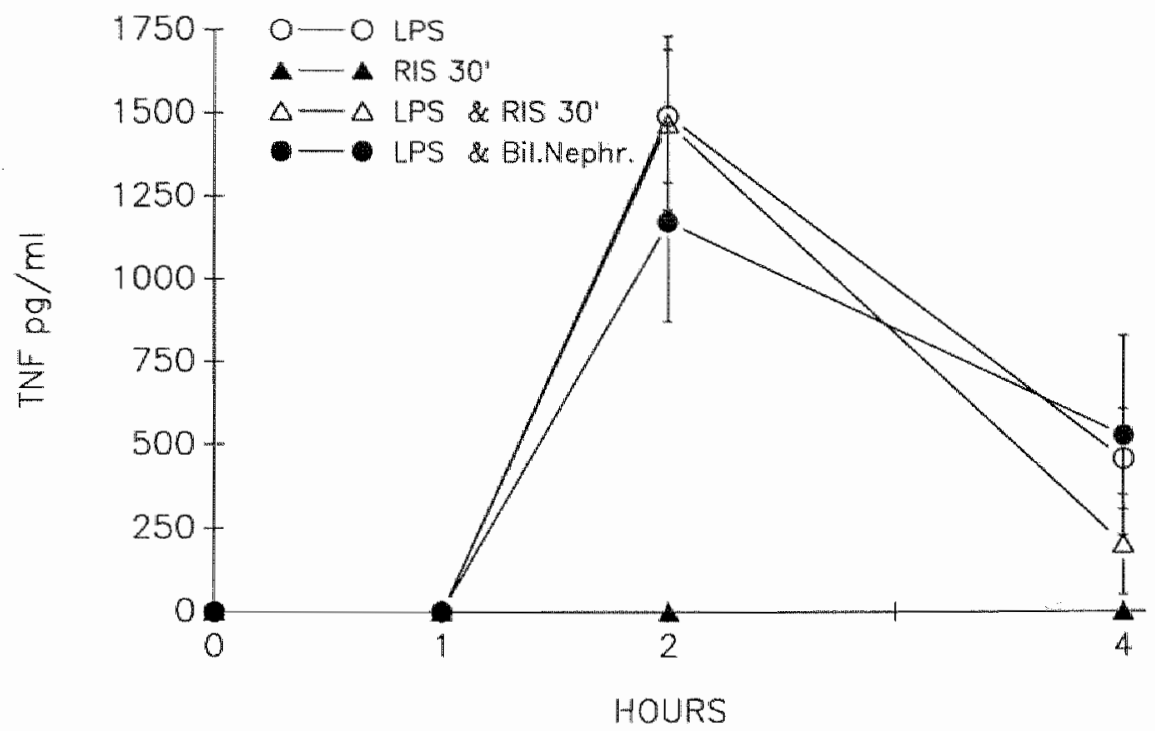

Figure 2. Plasma TNF levels in response to LPS treatment in normal rats, in bilaterally nephrectomized rats, and in rats with bilateral ischemia.

In the next experiments the stimulus of ischemic tissue was changed. Kidneys from experimental animals remained undamaged, however, two additional, devascularised kidneys were placed in the peritoneal cavity. No azotemia developed within 48 hours. Thus, in this model the effect of endotoxemia and tissue damage could be studied without the influence of renal failure and postischemic reperfusion. Following LPS treatment $(1.5 \mathrm{mg}$ per $100 \mathrm{~g}$ body weight) blood urea levels did not increase (Table 1). However, three out of six animals died within 48 hours, similar as in animals with 30 minutes of bilateral renal ischemia and LPS (Figure 1).

\section{Human recombinant TNF treatment}

The combination of bilateral renal ischemia during 30 minutes and recombinant TNF treatment $(110 \mu \mathrm{g} / 100 \mathrm{~g})$ induced a profound increase in blood urea nitrogen levels which was significantly higher in comparison to the increase following either single TNF treatment or renal ischemia. The increase was also significantly higher than the sum of the increases that were obtained with single treatment. In the combined treatment group three out of six animals died within 
48 hours. The other animals survived definitively ( 5 days). After single recombinant TNF treatment, none of the animals died and only moderate symptoms of illness were observed.

\section{Circulating plasma TNF levels}

When animals were injected with LPS high levels of circulating plasma TNF were found one hour after injection. Peak values were reached after two hours. TNF levels gradually dropped to reach nadir levels within six hours (data not shown). This pattern did not significantly change if before LPS treatment, a bilateral nephrectomy was performed. Renal ischemia either or not in combination to LPS treatment did not increase plasma TNF levels (Figure 2).

\section{DISCUSSION}

The eventual extent of organ damage that results from an ischemic insult is in part determined by inflammatory processes which are elicited by tissue injury (10). The clinical impact of this hypothesis has been increased as recent studies demonstrated a remarkable reduction of the extent of ischemic injury with therapeutic interventions directed against inflammatory reactions. Particularly inhibition of neutrophil involvement has been found to be successful. Depletion of circulating neutrophils can significantly reduce myocardial infarct size $(1,2)$. Prevention of neutrophil activation with monoclonal antibodies directed against a neutrophil adherence molecule also markedly attenuates the extent of organ injury following hemorrhagic shock (11). On the effector side of the response, blocking neutrophil production of reactive oxygen metabolites has been successful, leading to a profound reduction of postischemic reperfusion injury $(12,3)$.

The interactions of inflammatory mechanisms and ischemic organ damage may also be considered in an opposite way. Stimulation of inflammatory mechanisms might exacerbate the local effect of ischemic tissue injury. This mechanism is likely to exist as it has been demonstrated that the response of the inflammatory system is regulated by the severity of the initial ischemic injury (2). Pertinent to this assumption are findings in the present study as well as in previous studies (5) suggesting that renal ischemic injury is exacerbated by systemic stimulation with LPS. From clinical experience it is known that sepsis by Gram-negative infections is related to the development of acute renal failure with severe tubular necrosis whilst only mild hypotension is present (13). In the 
present study we showed that following occlusion of renal vessels during 30 minutes the development of renal failure is markedly enhanced by simultaneous injections of LPS, in a dose-dependent manner. LPS treatment without renal vessel occlusion does not affect renal function. These data provide direct evidence that inflammatory mechanisms have an important role among factors that determine the extent of ischemia induced tissue injury.

In addition to effects in the ischemic target organ we present evidence in this study that ischemic tissue injury in combination to inflammatory mechanisms can lead to systemic complications. Again from clinical experience we know that in certain conditions following acute renal failure general complications develop inducing failure of multiple organ systems and death (13). In the present experimental study we show that following 60 minutes of renal vessel occlusion, leading to severe but reversible renal failure, treatment with LPS appears to induce lethality. Animals die between 24 and 72 hours following surgery indicating that their death is unrelated to renal failure since most bilateral nephrectomized animals survive for at least 3 days. It is thus suggested that the lethal effects of endotoxemia are enhanced by the concomitant presence of renal failure.

So far our data are in line with clinical information indicating that renal failure in combination to gram negative infections leads to general complications involving multiple organ systems. However, the results of additional experiments suggest that failure of renal function per se is not essential for this mechanism to occur. If in our experiments two additional, ischemically damaged and devascularised kidneys are implanted in experimental animals with otherwise normal renal function a similar lethal effect in combination to LPS is obtained. Thus the presence of ischemic tissue necrosis rather than acute renal failure appears to be responsible for the enhancement of the general effect of endotoxemia.

Recently, possibly related, mechanisms have been reported combining endotoxemia with a second stimulus. Treatment of mice with D-Galactosamine which is a hepatotoxic agent induces a remarkable sensitization to lethal effects of small doses of LPS. Treatment with either of these substances has no effect on the viability of mice (14). This phenomenon has been related to the Shwartzman reaction in which two stimuli with endotoxin at an interval of 24 hours elicit a fulminant inflammatory reaction leading to death (15). A number of cytokines including TNF, interleukin 1 , and gamma interferon have been shown to be able to replace part of the original endotoxin stimuli (15). It is tempting to speculate that the two stimuli concept according to Shwartzman is involved in the interaction of endotoxemia and ischemic tissue necrosis (16). The clinically observed failure of multiple organ systems following extensive tissue necrosis 
might thus be explained by the interaction of the tissue necrosis and high serum levels of endotoxins due to increased absorption of endotoxins from the gut (17, 18).

Recent studies dealing with endotoxemia mediated inflammatory reactions attribute an important intermediate role to TNF. In experimental as well as in clinical studies high levels of circulating TNF have been found in response to endotoxemia (4). Recently, inhibition of lethal shock following gram-negative sepsis has been established by previous administration of TNF neutralizing antibodies (7). Furthermore, some effects of LPS treatment can be mimicked with TNF treatment (19). In this view we examined whether TNF might play a role in the observed combined effect of ischemic tissue injury and endotoxemia. It was found that the effect of systemic treatment with non-lethal doses of TNF with or without renal ischemia showed important similarities with the effect of LPS treatment. Within 48 hours half of the animals died in the combined treatment group.

In a study on the kinetics of circulating TNF it has been suggested that the kidneys are involved in the clearance of TNF (20). Hence, one might argue that the interaction of the stimulated inflammatory response and ischemic tissue injury is a rather kidney specific phenomenon since renal failure might lead to accumulation of circulating amounts of TNF. We therefore measured circulating plasma TNF levels following LPS stimulation with and without concomitant renal failure. It was observed that the characteristic changes of plasma TNF levels upon LPS treatment was not influenced by the absence of normal renal function. Apparently, other mechanisms than renal function were responsible for the clearance of TNF.

In the present study we show interactions between endotoxemia and ischemic tissue necrosis. A phenomenon is observed which implicates both exacerbation of damage to ischemic organ damage as well as enhancement of general septic complications. The possibility of circulating immunosuppressive and/or inflammation stimulating factors as a result of tissue necrosis must be further examined. 


\section{REFERENCES}

1. Romson $\mathrm{IL}$, Hook BG, Kunkel SL, Abrams GD, Lucchesi BR. Reduction of the extent of ischemic myocardial injury by neutrophil depletion in the dog. Circulation $1983 ; 67: 1016$ 1023.

2 Engler RL, Dahlgren MD, Peterson MA, Dobbs A, Schmid-Schonbein GW. Accumullation of polymorphonuclear leukocytes during $3-\mathrm{h}$ experimental myocandial ischemia. Am I Physiod 1986;251:H93 H100.

3 Farber NE, Pieper GM, Thomas JP, Gross GJ. Benificial effects of iloprost in the stunned myocardium. Circ Res 1988;62: 204-215.

4 Old LJ. Another chapter in the long history of endotoxin. Nature 1987;330:602-603.

5 Zager RA. Escherichia coli endotoxin injections potentiate experimental ischemic renal injury. Am J Physiol 1986;251:F988-F994.

6 Kettelhut IC, Fiers W, Goldberg AL. The toxic effects of tumor necrosis factor in vivo and their prevention by cyclooxygenase inhibitors. Proc Narl Acad Sci 1987;84:4273-4277.

7 Beutler B, Milsark IW, Cerami AC. Passive immunization against cachectin / tumor necrosis factor protects mice from lethal effect of endotoxin. Science 1985;229:869-871.

8 Tracey KJ, Fong Y, Hesse DG, Manogue KR, Lee AT, Kuo GC, Lowry SF, Cerami A. Anti-cachectin/TNF monoclonal antibodies prevent septic shock during lethal bacteriaemia. Nature 1987;330:662-664.

9 Ruff MR, Gifford GE. Rabbit tumor necrosis factor: mechanism of action. Infect Immun 1.981;31:380-384.

10 Henson PM, Johnston RB. Tissue injury in inflammation. J Clin Invest 1987;79:669-674.

11 Vedder NB, Winn RK, Rice CL, Chi EY, Arfors KE, Harlan JM. A monoclonal antibody to the adherence-promoting leukocyte glycoprotein, $\mathrm{CD} 18$, reduces organ injury and improves survival from hemorrhagic shock and resuscitation in rabbits. J Clin Invest 1988;81:939-944.

12 Hernandez LA, Grisham MB, Twohig B, Arfors KE, Harlan JM, Granger DN. Role of neutrophils in ischemia-reperfusion-induced microvascular injury. Am J Physiol 1987; 253:H699-H703.

13 Shock:causes and management of circulatory collapse 38-63. In: Textbook of Surgery- The biological basis of modem surgical practice, Sabiston DC, WB Saunders Co, 13 th edition 1988.

14 Lehmann V, Freudenberg MA, Galanos C. Lethal toxicity of lipopolysaccharide and tumor necrosis factor in normal and d-Galactosamine treated mice.J Exp Med 1987; 165:657-663.

15 Biliau A. Gamma-interferon: the match that lights the fire? Immunology Today 1988;9:3740

16 Demling RH, Lalonds C, Liu Y, Zhu D. The lung inflammatory response to thermal injury: relationship between physical and histological changes. Surgery 1989;106:52-59.

17 Deventer SJH van, Cate JW ten, Tytgat GNJ. Intestinal Endotoxemia, Clinical Significance. Gastroenterology 1988:94:825-831.

18 Ziegler TR, Smith RJ, o'Dwyer ST, Demling RH, Wilmore DW. Increased intestinal permeability associated with infection in burn patients. Arch Surg 1988;123:1313-1319.

19 Revhang A, Michi HR, Manson JM, Watters JM, Dinarello CA, Sheldon MW, Wilmore DW. Inhibition of cyclo-oxygenase attenuates the metabolic response to endotoxin in humans. Arch Surg 1988;123:162-170. 
20 Pessina GP, Pucini A, Bocci V, Maioli E, Naldini A. Studies on tumor necrosis factor (TNF): II Metabolic fate and distribution of human recombinant TNF. Lymphokine research 1987;6:35-44. 


\section{Chapter 7}

\section{Prevention of postoperative complications in jaundiced rats}

\section{Internal biliary drainage versus oral lactulose}

J.W. Greve, J.G. Maessen, T. Tiebosch, W. A. Buurman and D. J. Gouma Annals of Surgery Accepted for publication

\section{ABSTRACT}

In an experiment mimicking a severe surgical trauma by deliberate renal ischemia the postoperative outcome in jaundiced rats was studied. Intervention studies were performed with preoperative oral lactulose (to reduce endotoxin toxicity) or preoperative internal biliary drainage.

Compared to control, obstructive jaundice in rats significantly reduced survival time $(p<0.001)$ and enhanced renal impairment $(p<0.001)$ after renal ischemia. Preoperative supportive therapy of jaundiced rats with oral lactulose increased survival time $(\mathrm{p}<0.01)$ but did not reduce deterioration of renal function. Preoperative internal biliary drainage proved to be superior, with a significant reduction of renal impairment $(p<0.001)$ and an improved survival time $(\mathrm{p}<0.001)$.

Our experiments provide further evidence that obstructive jaundice enhances the complication rate following major surgical procedures. Based on our results in rats we suggest that in obstructive jaundice preoperative internal biliary drainage is the supportive therapy of choice. However, if adequate drainage is not possible, oral treatment with lactulose may attribute to reduce postoperative complications. 


\section{INTRODUCTION}

Surgery in jaundiced patients is associated with a mortality rate of approximately $16 \%$ (1). Mortality is to a large extend caused by acute renal failure (1). Clinical and experimental studies indicated that endotoxins play an important role in postoperative complications in obstructive jaundice (2-5). Moreover ischemic renal injury is exacerbated by endotoxins (6) and endotoxemia in combination with ischemic tissue damage results in a high mortality (7).

Preoperative orally administered bile acids or lactulose have been shown to reduce endotoxin toxicity $(8,9)$ and thus to prevent postoperative complications in jaundiced patients and in rats with experimental biliary obstruction (10-13). However, both lactulose and bile acids predominantly interfere with endotoxin related complications whereas other side effects of impaired liver function remain untreated.

Drainage of the obstructed biliary tract was also suggested as preoperative supportive therapy. However preoperative external biliary drainage did not improve postoperative outcome as was shown in several prospective clinical trials (14-16). In a study with rats internal biliary drainage improved survival after intra-abdominal sepsis significantly (17). A positive effect of preoperative internal biliary drainage was also suggested in a large clinical study on patients with pancreatic carcinoma (18). In spite of these findings so far prospective randomized clinical studies confirming these results have not been reported. Moreover a trial to compare the different supportive therapies was not performed.

In our experiments a model, using bilateral renal ischemia as a severe surgical trauma, was used to study the enhanced complication rate in rats with experimental biliary obstruction. Furthermore, the effect of preoperative internal biliary drainage on the outcome of this surgical trauma was compared to the effect of a preoperative anti-endotoxin treatment with oral lactulose. Parameters were nutritional status, renal function and mortality. Moreover plasma tumor necrosis factor (TNF), being a proven mediator of endotoxin toxicity (19-21), was measured to evaluate the role of endotoxins in the enhanced morbidity and mortality of surgically treated jaundiced animals. 


\section{Chemicals and antibodies}

Lactulose (Duphalac) was kindly provided by Duphar (Weesp, The Netherlands). The monoclonal anti-mouse TNF (TN3) was a kind gift of drs Sheehan and Schreiber via Celltech (Slough, UK) (22). The following reagents were purchased: r-murine-TNF and anti-mouse TNF antibodies (Genzyme, Boston, MA), O-phenylenediamine (Sigma Co., St.Louis, MO), peroxidase-conjugated IgG (Jackson, West Grove, PA), bilirubin-kit and triglyceride-kit (Roche, Mijdrecht, The Netherlands), BUN-kit (Bio Merieux, Charbonierres les Bains, France).

\section{Experimental design}

Male Wistar rats (Winkelmann, Borchen, FRG) weighing 200-250 g were used. The rats were allowed free access to water and rat chow. The rats were divided in 5 experimental groups (Table 1). Control groups consisted of bile duct ligation (BDL), sham operation (SHAM) and bile duct ligation with sham renal ischemia (BDL-SI). The treated groups were: 1) bile duct ligation and biliary drainage (BDL-DRAIN), 2) bile duct ligation and oral lactulose (BDLLACT). Each group except the BDL-SI group $(n=4)$ consisted of 10 rats. After two weeks all groups, except the BDL-DRAIN group, were exposed to renal ischemia. The BDL-DRAIN group was treated by biliary drainage after two weeks and exposed to renal ischemia three weeks later. The BDL-LACT group was treated for three days with oral lactulose $(2 \mathrm{ml} 30 \%$ lactulose syrup in water) three times a day prior to renal ischemia. All other groups were given 2 $\mathrm{ml}$ saline solution orally using a similar schedule.

Blood was taken by orbital puncture on day one and directly prior to renal ischemia. In the BDL-DRAIN group blood was also sampled prior to biliary drainage. Following renal ischemia blood was sampled after 2 and 4 hours and on days $1,2,3,5$ and 7 . Body weights of all rats were recorded weekly and on the third day after renal ischemia. Mortality of the rats was recorded during one week after renal ischemia, thereafter surviving rats were sacrificed to obtain blood and to take renal biopsies. 


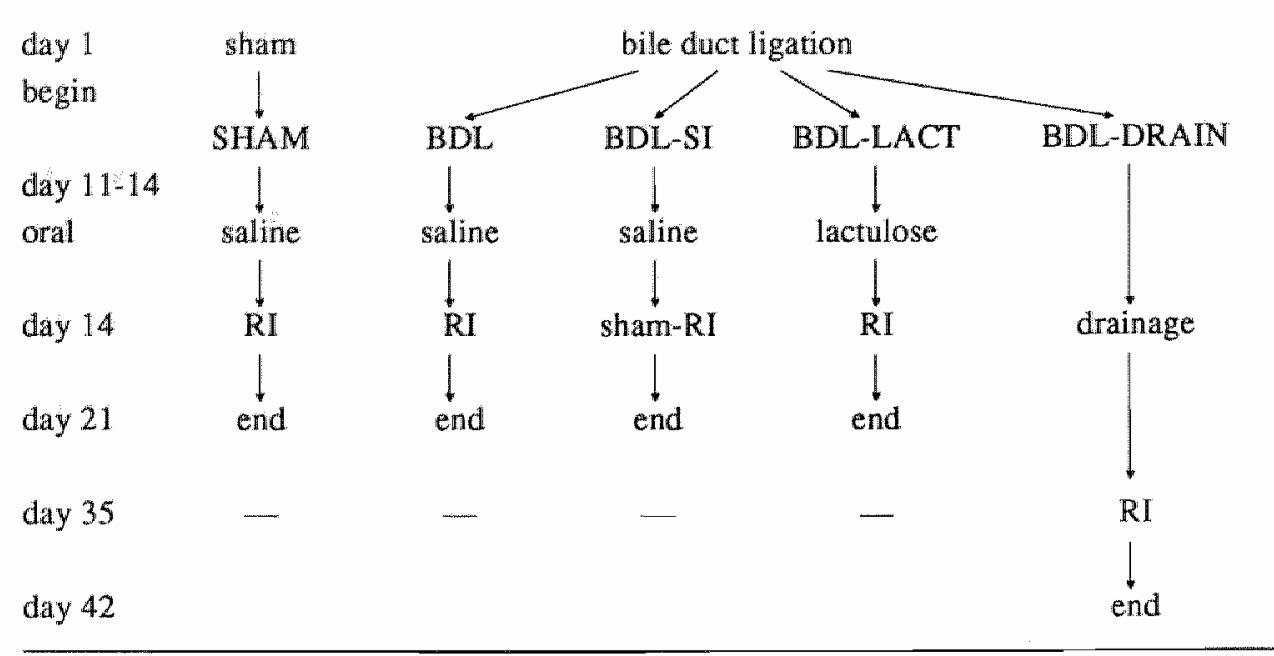

$\mathrm{BDL}=$ bile duct ligation, SHAM = sham operation, $\mathrm{BDL}-\mathrm{SI}=$ bile duct ligation and sham renal ischemia, BDL-LACT = bile duct ligation and oral lactulose, BDL-DRAIN = bile duct ligation and internal biliary drainage, $\mathrm{RI}=$ renal ischemia

\section{Surgical procedures}

All surgical procedures were performed under ether anaesthesia. Bile duct ligation was performed by ligature of the common bile duct with silk 4-0 sutures after which it was divided. In the SHAM group the common bile duct was dissected from the hepatoduodenal ligament but not ligated.

Drainage of the biliary tract was performed by placing a cuffed silastic tube ( $0.3 \mathrm{~mm}$ inner, $0.65 \mathrm{~mm}$ outer diameter) in the dilated common bile duct which was inserted in the duodenum through a small stab wound. To prevent leakage the duodenum was fixed on the common bile duct with three 6.0 silk sutures. Technical failure caused biliary leakage and death in 5 rats. These rats were excluded from the study.

Renal ischemia was performed in all rats except the BDL-SI group. The entire renal pedicle was dissected and clamped on both sides. In the BDL-SI group the renal pedicle was dissected but not clamped. After control of vascular occlusion the abdomen was closed and the rats were allowed to awake. Rats were kept under an infrared lamp to maintain a constant body temperature. After 45 minutes the occlusion clamps were removed. Reperfusion of the kidneys was checked macroscopically. 


\section{Laboratory tests}

All determinations were performed with a Cobas Bio (Hoffman La Roche, Basle, Switzerland). Albumin was measured as described (23). Blood urea nitrogen (BUN) was determined in all blood samples. Bilirubin levels were determined in blood samples of day one, prior to, and on day 7 after renal ischemia. Albumin levels were determined on day 1 and 7 , one day prior to and 3 and 7 days after renal ischemia. Plasma triglycerides and TNF were determined on day one, prior to renal ischemia, and 2 hours, 4 hours and 1,2,3,5 and 7 days after renal ischemia. TNF was measured with a sandwich ELISA as described previously (24). TNF levels of the samples were determined by calculation against a standard curve obtained with a serial dilution of recombinant murine TNF. All samples were measured in duplicate. The lower detection limit of the ELISA was approximately $150 \mathrm{pg} \mathrm{TNF} / \mathrm{ml}$.

\section{Determination of ischemic damage to the kidneys}

Renal biopsies were obtained within 12 hours of death or immediately after sacrifice. Biopsies were snap frozen in liquid nitrogen. Frozen tissue was postfixed in $4 \%$ buffered formalin. Histological examination was performed double blind using a qualitative grading system. Tubular regeneration was considered present if anisonucleosis or increased mitotic activity was observed.

\section{Statistical analysis}

Student's T' test for unpaired data was used for statistical analysis. Results are expressed as mean \pm SD unless otherwise indicated. $P$ values less than 0.05 were considered to be statistically significant. 
Experimental biliary obstruction enhances mortality and morbidity after renal ischemia in rats.

The increased susceptibility of jaundiced rats to postoperative complications was studied by subjecting rats with experimental biliary obstruction to renal ischemia. Both BDL and BDL-SI rats were deeply jaundiced after 2 weeks (Table 2). The nutritional parameters body weight and serum albumin were not different between BDL and BDL-SI rats 2 weeks after bile duct ligation. Compared to SHAM rats a significant weight loss was observed in the jaundiced rats 1 week after bile duct ligation which partly recovered during the second week (Figure 1). Two weeks after bile duct ligation serum albumin levels were significantly lower in BDL and BDL-SI rats compared to SHAM $(\mathrm{p}<0.001)$ (Table 3). Renal ischemia induced a dramatic weight loss and a reduction of serum albumin in all experimental groups, no significant difference between SHAM, BDL and BDL-SI was observed.

After renal ischemia SHAM rats showed a sharp rise in BUN levels which recovered after $1-3$ days (Figure 2 ). In BDL rats rise of BUN was significantly higher during the first 24 hours (change of BUN in mmol/l: SHAM $41.6 \pm 6.7$ vs BDL $54.7 \pm 4.2, \mathrm{p}<0.001$ ). Thereafter BUN in BDL rats did not recover but increased. Sham ischemia in BDL-SI rats did not affect BUN (data not given).

Post renal ischemia mortality was recorded during 7 days, thereafter remaining rats were sacrificed (Figure 3). Following renal ischemia in SHAM rats, 4 out of 10 rats died resulting in a survival time of $134 \pm 49$ hours. No BDL rat survived after renal ischemia, the survival time of $54 \pm 35$ hours was significantly lower compared to SHAM rats $(p<0.001)$. BDL-SI rats all survived the 7 day observation period after sham renal ischemia.

\section{Preoperative supportive therapy reduces the occurrence of postoperative complications}

Following bile duct ligation changes of bilirubin levels (Table 2), serum albumin (Table 3 ) and body weight (Figure 1) of BDL-LACT and BDL-DRAIN rats were not significantly different from BDL rats. Internal biliary drainage resulted in a rapid decrease of clinical jaundice and after 3 weeks bilirubin levels had returned to normal (Table 2). 
Table 2. Serum bilirubin levels in bile duct ligated rats:

\begin{tabular}{lllccl}
\hline Group & Begin & Drainage & RI & End & \\
\hline SHAM & $2.6 \pm 0.5$ & - & $2.4 \pm 0.7$ & $3.2 \pm 0.2$ & $(n=6)$ \\
BDL & $2.6 \pm 0.5$ & - & $117 \pm 39$ & - & $(n=0)$ \\
BDL-SI & $2.8 \pm 0.5(n=4)$ & - & $101 \pm 37(n=4)$ & $60 \pm 19$ & $(n=4)$ \\
BDL-LACT & $2.5 \pm 1.0$ & - & $132 \pm 23$ & $208 \pm 55$ & $(n=4)$ \\
BDL-DRAIN & $2.7 \pm 0.6$ & $114 \pm 22$ & $2.5 \pm 0.5$ & $2.8 \pm 0.8$ & $(n=9)$
\end{tabular}

Bilirubin levels are given in $\mu \mathrm{M} / 1 /$ and are the mean $\pm S D$ of 10 rats unless indicated in the Table. Exact timetable of the different observation points in each individual experimental group is given in Table 1 . (RI = renal ischemia)

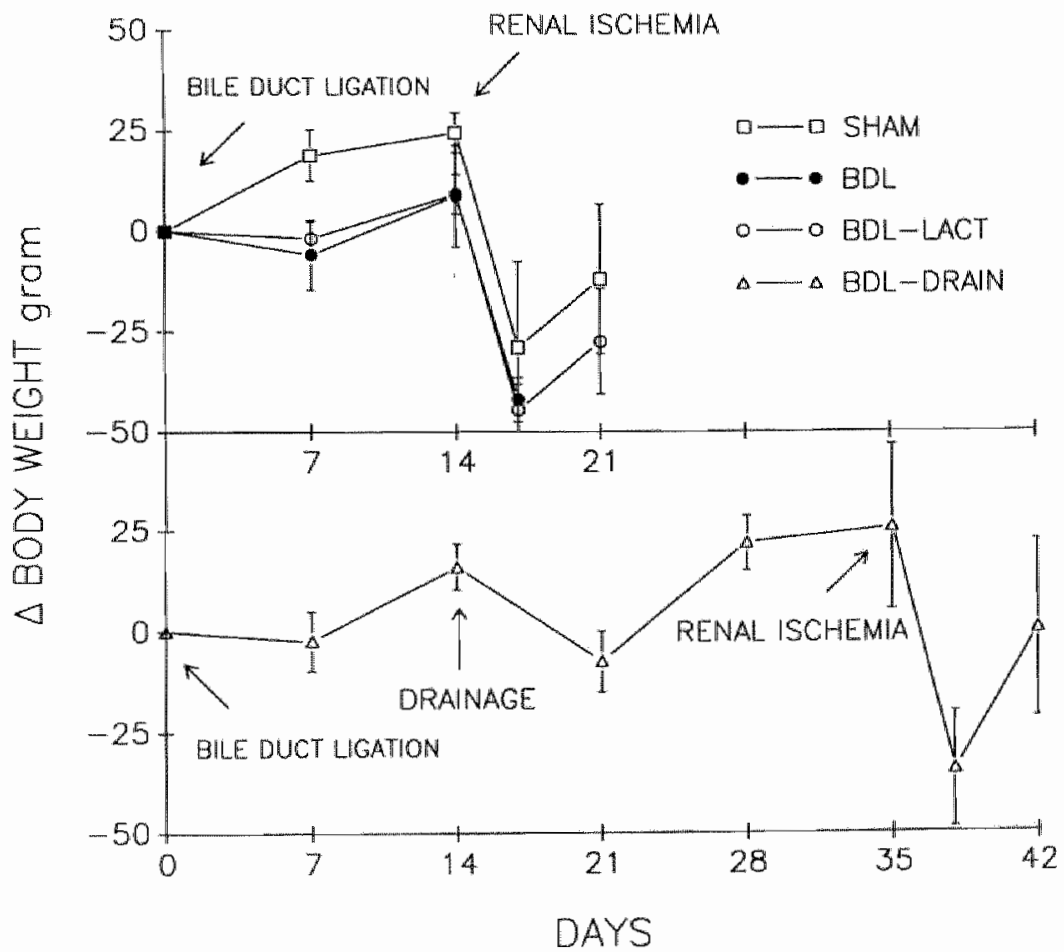

Figure 1. Changes of body weight of the rats during the experiments in the different experimental groups. Body weight of each individual rat was recorded weekly. Vallues shown are mean $\pm \mathrm{SD}$. In the upper part weight changes of SHAM, BDL, and BDL-LACT rats are shown. In the lower part weight changes of BDL-DRAIN rats before and after internal biliary drainage are presented. 


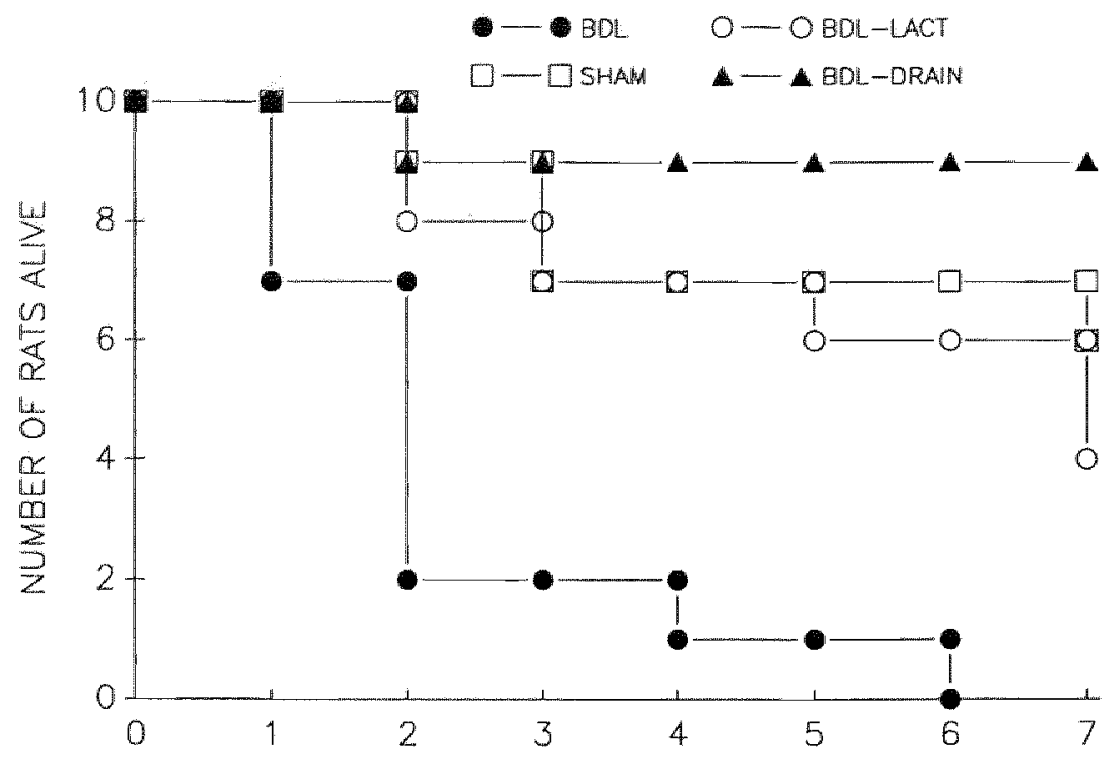

DAYS AFTER RENAL ISCHEMIA

Figure 3. Survival of rats after a severe surgical trauma, effect of preoperative treatment. After renal ischemia survival was observed during 7 days. Thereafter remaining rats were sacrificed. Preoperative treatment consisted of oral lactulose during 3 days prior to the trauma in the BDL-LACT group or internal biliary drainage 3 weeks prior to renal ischemia in the BDLDRAIN group.

\section{Relation of TNF and trigly cerides to postoperative complications in jaundiced rats}

Plasma TNF measurements were performed to study the role of endotoxin in occurrence of complications. The mediator of endotoxin toxicity TNF was measured rather than endotoxin itself since plasma endotoxin determinations are difficult and most of all because in vivo plasma endotoxin appears intermittent making single daily samples unreliable.

Substantial amounts of TNF were found in plasma from BDL and BDLLACT rats following renal ischemia (Table 4). In plasma from SHAM, BDL-SI and BDL-DRAIN rats no detectable TNF was measured. Plasma TNF levels did not correlate with mortality.

Plasma triglyceride levels were determined to further study the role of endotoxins in postoperative complications in jaundiced rats. In SHAM, BDL-SI and BDL-DRAIN rats triglyceride levels remained within the normal range. After renal ischemia in BDL rats a significant rise of triglyceride levels was 
Table 4. Plasma TNF levels after renal ischemia.

\begin{tabular}{|c|c|c|c|c|c|c|}
\hline GROUP & \multicolumn{2}{|c|}{ SHAM } & $\mathrm{BDL}$ & BDL-SI & BDL-LACT & BDL-DRAIN \\
\hline 1 & - & * & $3350 *$ & - & $-\ldots$ & $-*$ \\
\hline 2 & - & $*$ & $--\quad *$ & - & $1038 *$ & - \\
\hline 3 & 677 & * & - * & - & $220 *$ & - \\
\hline 4 & - & & - * & - & 640 & - \\
\hline 5 & - & & $230^{*}$ & & - & - \\
\hline 6 & - & & - * & & $557 *$ & - \\
\hline 7 & - & & $569 *$ & & $590 *$ & - \\
\hline 8 & - & * & $2120 *$ & & - & - \\
\hline 9 & - & & - & & - & - \\
\hline 10 & - & & — $*$ & & 8263 & - \\
\hline
\end{tabular}

Plasma TNF levels were measured with an ELISA and are expressed in $\mathrm{pg} / \mathrm{ml}$. Values are the average of duplicate determinations. The highest TNF values of each individual rat after renal ischemia are shown. Deceased rats are marked with an asterisk.

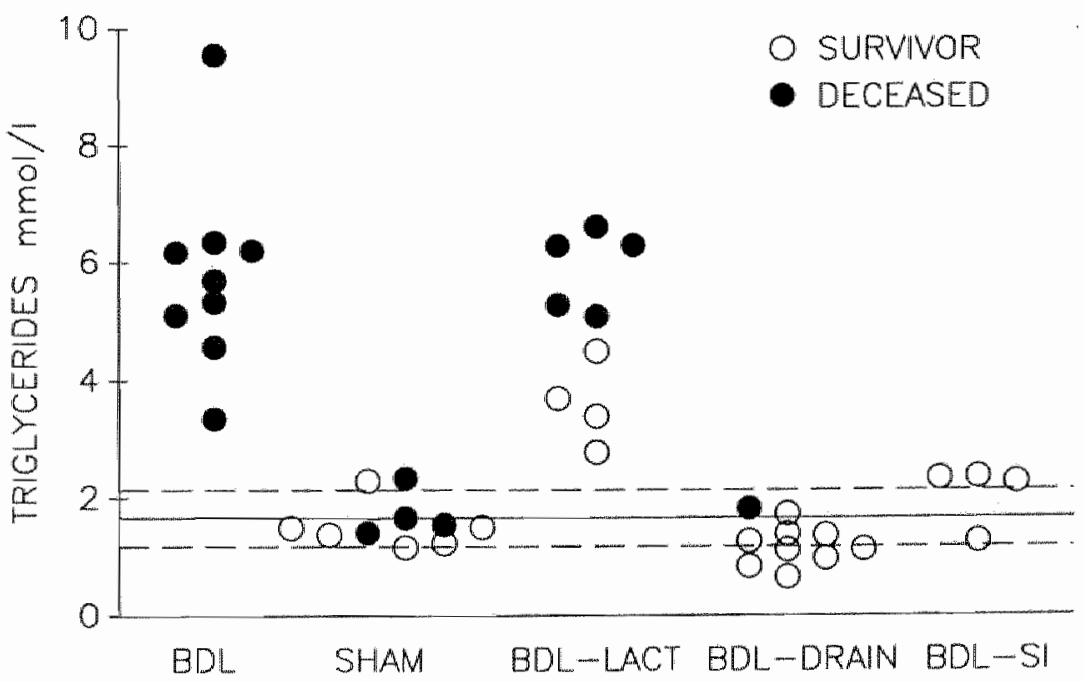

Figure 4. Correlation of serum triglycerides with mortality in jaundiced rats. Triglycerides were measured in all rats as an indirect parameter of TNF activity and consequently of endotoxin toxicity. The highest triglyceride level of each individual rat following renal ischemia is shown. The BDL-SI group underwent sham renal ischemia. Solid line and dashed line represent mean $\pm \mathrm{SD}$ of triglyceride levels in control rats. 
observed (Figure 4). Triglyceride levels of surviving BDL-LACT rats were significantly lower compared to deceased $B D L-L A C T$ rats $(3.6 \pm 0.6 \mathrm{mmol} / \mathrm{l}$ vs $5.9 \pm 0.6 \mathrm{mmol} / \mathrm{l}, \mathrm{p}<0.001)$. Moreover mean plasma triglyceride levels of surviving jaundiced rats (from the BDL-LACT and BDL-SI groups) were significantly lower compared to plasma triglyceride levels from jaundiced rats which died (from the BDL and BDL-LACT groups) (surviving jaundiced rats $2.8 \pm 0.9 \mathrm{mmol} / \mathrm{l}$ vs deceased jaundiced rats $5.9 \pm 1.3 \mathrm{mmol} / \mathrm{l}, \mathrm{p}<0.001$ ).

\section{Renal histology}

Differences in the grade of ischemic damage between the left and the right kidney of each rat were not observed, indicating that vascular occlusion had been effective. BDL rats showed severe cortical necrosis. Biopsies from BDLSI rats were normal. Renal tissue from deceased SHAM, BDL-LACT and BDL-DRAIN rats showed moderate to severe cortical necrosis and in most samples signs of tubular regeneration. In surviving SHAM, BDL-LACT and BDL-DRAIN rats cortical necrosis was moderate or absent with or without signs of tubular regeneration.

\section{DISCUSSION}

In our experiments bilateral renal ischemia was used as a severe surgical trauma to study postoperative morbidity and mortality in rats with obstructive jaundice. In BDL rats renal impairment was significantly increased and survival time was significantly decreased compared to SHAM rats following renal ischemia. These results are supported by previous experimental studies in which obstructive jaundice in rats significantly increased mortality after intraabdominal sepsis (17) and after renal ischemia $(25,26)$.

We also found that experimental biliary obstruction caused a decrease of serum albumin, which is in agreement with the results of previous studies in rats $(5,27)$. Low serum albumin levels were related to a high complication rate in several studies on risk factors related to postoperative outcome in jaundiced patients (28-30).

Besides low serum albumin, gut derived endotoxins were suggested to play an important role in the occurrence of complications in patients with obstructive jaundice $(2-4,10)$. In a previous study however we were not able to measure 
substantial amounts of endotoxin in plasma of jaundiced rats (5). Nevertheless a clear relation was shown between endotoxin and suppression of cellular immunity (5).

Endotoxin toxicity is mainly mediated by TNF $(20,21)$, therefore we studied plasma TNF levels of all rats in our experiments. However, like endotoxin measurements, plasma TNF determinations in vivo turned out to be very difficult and unpredictable. TNF has a very short half live time and it was found that in patients treated with continuous infusions of TNF the previously measured plasma TNF levels disappeared despite clinical evidence of its effects (21).

One of the clinical effects of TNF is the inhibition of lipoprotein lipase resulting in a hypertriglyceremia (31). Moreover it was recently shown that TNF stimulates a de novo synthesis of triglycerides in the liver (32). Since plasma triglycerides remain elevated for at least 17 hours following TNF stimulation (32), they offer an indirect way to further study the possible involvement of endotoxins and/or TNF.

Serum TNF measurements could not confirm the role of endotoxins in the observed morbidity and mortality after renal ischemia rats. Only in jaundiced rats substantial amounts of TNF could be measured and no correlation was found between TNF levels and mortality. However after renal ischemia in jaundiced rats a highly significant relation between raised serum triglyceride levels and mortality was found. This suggests that TNF and consequently endotoxin may be involved.

The effect of most clinically used preoperative treatments to prevent complications in jaundiced patients are still disappointing (1). Intravenous mannitol was suggested to prevent postoperative renal complications, however the results of early studies on mannitol have recently been disputed $(25,26,33)$. Preoperative external biliary drainage after initial hopeful reports (34-36) was also found to be ineffective (14-16). In our experiments preoperative intervention with lactulose or internal biliary drainage significantly reduced postoperative complications in jaundiced rats.

Lactulose significantly increased survival time after renal ischemia. In previous studies it was suggested that lactulose was effective by reducing endotoxin toxicity (13) or by reducing the release of its mediator TNF (8). This correlates well with the significant relation of serum triglycerides (related to TNF) and postoperative mortality in jaundiced rats as observed in our study. Lactulose treatment however did not improve liver function nor nutritional status.

Internal biliary drainage not only significantly increased postoperative survival time but also significantly reduced renal impairment following renal ischemia. An explanation of the difference with lactulose treatment could be 
that internal biliary drainage did improve liver function and nutritional status, and also reestablished bile flow to the intestine thus reducing endotoxin toxicity. The latter was suggested by our results of an in vitro study in which bile acids reduced endotoxin-induced TNF production by monocytes (9). The good results of internal biliary drainage are in accordance with the observation by Trede et al that preoperative interal biliary drainage decreased postoperative complications in patients with pancreatic carcinoma (21). A safe internal biliary drainage procedure is however mandatory for successful preoperative intervention. Moreover biliary drainage must last for at least several weeks as was reported previously (37).

In conclusion we suggest that, although the effect of internal biliary drainage in patients still has to be studied, the preoperative supportive therapy of choice in obstructive jaundice is internal biliary drainage. However, in cases were surgical intervention is acutely indicated or if complete drainage of the billiary tract is not possible, short term preoperative treatment with oral lactulose may attribute to improve postoperative outcome. 


\section{REFERENCES}

1 Wait RB, Kahng KU. Renal failure complicating obstructive jaundice. Am I Surg 1989;157:256-263.

2 Wardle EN, Wright NA. Endotoxin and acute renal failure associated with obstructive jaundice. Br Med J 1970;4:472-474.

3 Wilkinson SP, Moody H, Stamatakis JD, Kakkar VV, Williams R. Endotoxaemia and renal failure in cirrhosis and obstructive jaundice. Br Med J 1976;2:1415-1418.

4 Pain JA, Cahill CJ, Bailey ME. Perioperative complications in obstructive jaundice:therapeutic considerations. Br J Surg 1985;72:942-945.

5 Greve JW, Gouma DJ, Soeters PB, Buurman WA. Suppression of cellular immunity in obstructive jaundice is caused by endotoxins: A study in germfree rats. Gastroenterology 1990;98:478-485.

6 Zager RA. Escherichia coli endotoxin injections potentiate experimental ischemic renal injury. Am J Physiol 1986;251:F988-F994.

7 Maessen JG, Greve JW, Buurman WA, Kootstra G. Sensitivity of ischemically damaged kidneys to inflammatory reactions. Transplant proc 1989;21:1261-1262.

8 Greve JW, Gouma DI, van Leeuwen PAM, Buurman WA. Lactulose inhibits endotoxininduced tumour necrosis factor production by monocytes. An in vitro study. Gut 1990;31:198-203.

9 Greve JW, Gouma DJ, Buurman WA. Bile acids inhibit endotoxin induced tumor necrosis factor production by monocytes: An in vitro study. Hepatology 1989;10:454-458.

10 Bailey ME. Endotoxin, bile salts and renal function in obstructive jaundice. Br J Surg 1976;63:774-778.

11 Evans HJR, Torrealba V, Hudd C, Knight M. The effect of preoperative bile salt administration on postoperative renal function in patients with obstructive jaundice. $\mathrm{Br} J$ Surg 1982;69:706-708.

12 Cahill CJ, Pain JA, Bailey ME. Bile salts, endotoxin and renal function in obstructive jaundice. Surg Gynecol Obstet 1987;165:519-522.

13 Pain JA, Bailey ME. Experimental and clinical study of lactulose in obstructive jaundice. Br J Surg 1986;73:775-778.

14 Hatfield ARW, Terblanche J, Fataar S, et al. Preoperative external biliary drainage in obstructive jaundice: A prospective controlled clinical trial. Lancet 1982;II:896-899.

15 McPherson GAD, Benjamin IS, Hodgson HJF, Bowley NB, Allison DJ, Blumgart LH. Pre-operative percutaneous transhepatic biliary drainage:the results of a controlled clinical trial. Br J Surg 1984;71:371-375.

16 Pitt HA, Gomes AS, Lois JF, Mann LL, Deutsch LS, Longmire WP. Does preoperative percutaneous biliary drainage reduce operative risk or increase hospital cost? Ann Surg 1985;201:545-553.

17 Gouma DJ, Coelho JCU, Schegel JF, Li YF, Moody FG. The effect of preoperative interna! and external biliary drainage on mortality of jaundiced rats. Arch Surg 1987;122:731-734.

18 Trede M, Schwall G. The complications of pancreatectomy. Ann Surg 1988;207:39-47.

19 Beutler B Cerami A. Cachectin: More than a tumor necrosis factor. N Engl J Med 1987;316:379-385. 
20 Beutler B, Krochin N, Misark IW, Luedke C, Cerami A. Control of cachectin (tumor necrosis factor) synthesis: Mechanisms of endotoxin resistance. Science 1986:232:977980.

21 Michie HR, Spriggs DR, Manogue KR, et al. Tumor necrosis factor and endotoxin induce similar metabolic responses in human beings. Surgery 1988;104:280-286.

22 Sheehan KCF , Ruddle NH, Schneiber RD. Generation and characterization of hamster monoclonal antibodies that neutralize murine tumor necrosis factors. J Immunol 1989; $142.3884-3893$

23 Doumas BT, Watson WA, Biggs HG. Albumin standards and the measurements of albumin with bromcresol green. Clin Chim Acta 1971;31:87-96

24 Dentener MA ${ }_{*}$ Greve JW, Maessen $\mathrm{JG}_{*}$ Buurman WA. Role of tumor necrosis factor in the phenomenon of the enhanced sensitivity of animals to endotoxin after exposure to lead. Immunopharmacology and immunotoxicology 1989;11:321-334.

25 Dawson JL. Jaundice and anoxic renal damage: protective effect of mannitol. Br Med J $1964 ; 1: 810-811$.

26 Dawson JL. Post-operative renal function in obstructive jaundice: effect of a mannitol diuresis. Br Med J 1965;1:82-86.

27 Gouma DJ, Roughneen PT, Kumar S, Moody FG, Rowlands BJ. Changes in nutritional status associated with obstructive jaundice and biliary drainage in rats. Am J Clin Nutr $1986 ; 44: 362-369$

28 Pitt HA, Cameron IL, Postier RG, Gadacz TR. Factors affecting mortality in biliary tract surgery. Am J Surg 1981;141:66-71.

29 Blamey SL, Fearon $\mathrm{KCH}_{3}$ Gilmour WH, Osborne DH, Carter DC. Prediction of risk in biliary surgery. Br J Surg 1983;70:535-538.

30 Little JM. A prospective evaluation of computerized estimates of risk in the management of obstructive jaundice. Surgery 1987;102:473-476.

31 Beutler B, Mahony J, Le Trang N, Pekala P, Cerami A. Purification of cachectin, a lipoprotein lipase-suppressing hormone secreted by endotoxin induced raw 264.7 cells. I Exp Med 1985; 161:984-995.

32 Feingold KR, Serio MK, Adi S, Moser AH, Grunfeld C. Tumor necrosis factor stimulates hepatic lipid synthesis and secretion. Endocrinology 1989;124:2336-2342.

33 Gubern JM, Sancho JJ, Simo J, Sitges-Serra A. A randomized trial on the effect of mannitol on postoperative renal function in patients with obstructive jaundice. Surgery 1988; 103:39-44.

34 Denning DA, Ellison EC, Carey LC. Preoperative percutaneous transhepatic biliary decompression lowers operative morbidity in patients with obstructive jaundice. Am J Surg $1981 ; 141: 61-65$.

35 Norlander A, Kalin B, Sundblad R. Effect of percutaneous transhepatic drainage upon liver function and postoperative mortality. Surg Gynecol Obstet 1982;155:161-166.

36 Gundry SR, Strodel WE, Knol JA, Eckhauser E, Thompson NW. Efficacy of preoperative biliary tract decompression in patients with obstructive jaundice. Arch Surg 1984;119: 703-708.

37 Koyama K, Takagi Y, Kenji I, Sato T. Experimental and clinical studies an the effect of biliary drainage in obstructive jaundice. Am J Surg 1981;142:293-299 


\section{Chapter 8}

\section{General conclusion}

\section{GENERAL CONCLUSION}

Complications after surgery in obstructive jaundice are caused by multiple factors. Possible etiologic factors were extensively studied resulting, when all data are combined, in a complex network of suggested relations between cause and defect (Figure A, Chapter 2). Until now no unifying cause could be identified. This may explain why so far preventive treatments, which have been reported, have limited success.

The review of the literature did reveal that endotoxins were suggested to be related with nearly every complication studied. Moreover, a more sensitive and reliable endotoxin assay to detect endotoxins became recently available, and the detection of the mediator of endotoxin toxicity, tumor necrosis factor, facilitated further studies on the pathophysiologic mechanism underlying endotoxin related complications. For these reasons the experiments presented in this thesis were directed to the role of endotoxins in obstructive jaundice.

The results of the first experiments showed, in contrast to conventional rats, that bile duct ligation in germ-free, endotoxin "free", rats, did not lead to suppression of cellular immunity. Moreover, peritoneal macrophages from conventional jaundiced rats were significantly activated, as concluded from the increased spontaneous TNF release. This activation correlated clearly with the observed suppression of cellular immunity. The results indicated, although no endotoxins could be detected in serum of conventional bile duct ligated rats, that endotoxins are responsible for the observed suppression of cellular immunity.

The in vitro experiments with bile acids or lactulose provided further evidence that endotoxins are involved in postoperative complications in jaundiced patients. Both compounds were suggested to reduce endotoxin related complications in jaundiced patients. Deoxycholic acid significantly reduced the production of TNF, the mediator of endotoxin toxicity, whereas chenodeoxycholic 
acid was less effective and ursodeoxycholic acid did not have any effect. These results correlated clearly with the efficacy of these bile acids in clinical studies. Similar results were obtained with lactulose. The data suggest that bile acids as well as lactulose are effective by inhibiting endotoxin-induced TNF production by the effector cell, the mononuclear phagocytes, of endotoxin toxicity.

The role of endotoxins with respect to renal impairment was studied in conventional rats. Administration of endotoxin or TNF in control rats did not result in renal impairment and did not cause mortality. Renal ischemia by itself caused a reversible azotemia. The experiments showed that the combination of ischemic tissue damage with endotoxins had a synergistic effect on renal impairment. Similar results were obtained with TNF which suggests that endotoxins do not have to be present in the circulation but that their effect can be mediated by TNF. Furthermore mortality was significantly increased when endotoxemia was combined with tissue damage, a situation possibly present during or following operative treatment of jaundiced patients.

Bilateral renal ischemia in jaundiced rats resulted in acute renal failure and $100 \%$ mortality within 7 days. This was significantly different from not jaundiced control rats. Treatment with oral lactulose prior to renal ischemia significantly reduced mortality and reduced renal impairment, however the latter was not statistically significant. Internal biliary drainage significantly reduced both renal impairment and mortality. No correlation was found between mortality and plasma TNF levels. In jaundiced rats however, a statistically significant relation was found between plasma triglyceride levels, as indicator for TNF activity, and mortality. The results show that an anti-endotoxin treatment (e.g. lactulose) can reduce the complication rate. This, in combination with the results from the previous experiment, suggests that endotoxins are involved in the etiology of renal impairment. The best results were obtained with internal biliary drainage. Internal biliary drainage probably rehabilitates the optimal natural defence against endotoxins by restoring bile flow to the gut and by reestablishing normal liver function, which is important for detoxification of endotoxins.

The experiments provide evidence that endotoxins are involved in the suppression of cellular immunity, and are related to postoperative renal impairment and mortality. In vitro experiments resulted in a possible explanation of the mechanism through which bile acids and lactulose reduce endotoxin toxicity. Experiments on the prevention of complications showed that anti-endotoxin treatment (e.g. lactulose) is effective, however superior results were obtained with internal biliary drainage. Based on these data a decision tree for treatment of jaundiced patients can be proposed (Figure B), which of course has to be validated by prospective randomized clinical studies. 


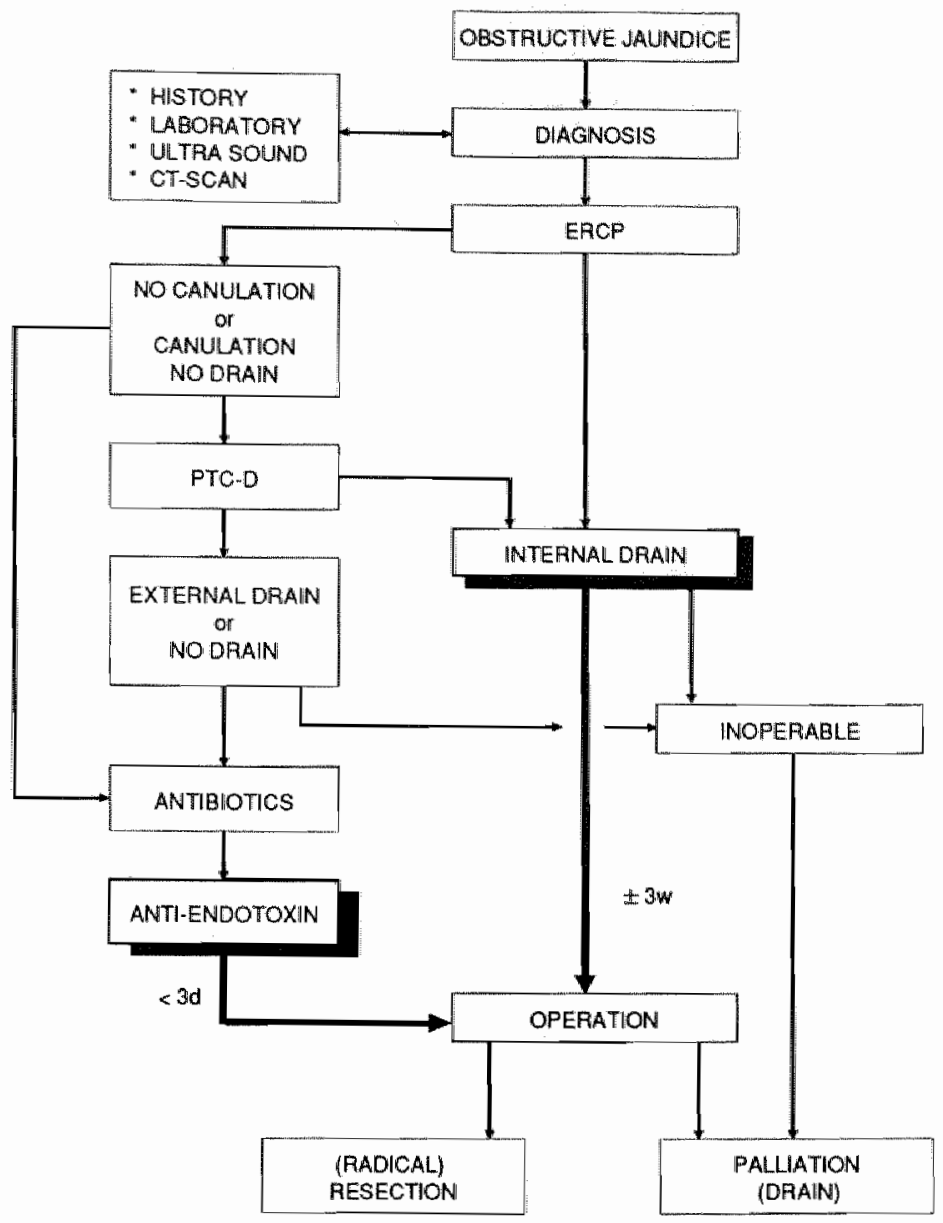

Legend to Figure B. Proposed decision tree for supportive preoperative therapy. The preventive treatments are shown in relation with the means to obtain them. Shadow-boxes show the desired supportive therapies. ERCP, endoscopic retrograde cholangiom pancreaticography (drainage). PTC-D percutaneous transhepatic cholangiography (drainage).

The proposed schedule can only be recommended if a safe (internal) drainage procedure is available which provides adequate decompression of the entire biliary tract, this to prevent the frequent occuring biliary drainage related cholangitis. The biliary drainage must be of sufficient duration in order to allow optimal recovery of the impaired organ systems. Anti-endotoxin treatment can be used as additional support or should be applied when preoperative biliary drainage is not possible. 


\section{Chapter 9}

\section{Summary / Samenvatting}

\section{SUMMARY}

The etiology of complications after surgery in patients with obstructive jaundice is multicausal and largely unknown. Many preoperative measures to reduce these complications have been suggested. The majority of treatments, however, is unfortunately not effective. The aim of this thesis was to study the etiology of the high morbidity and mortality associated with obstructive jaundice. In the first part of the thesis the etiology of the complications is studied. The second part is devoted to studies on prevention of the many postoperative complications in obstructive jaundice.

In Chapter 1 an overview of the literature is presented. Studies on complications rates after surgery in jaundiced patients show consistently a high morbidity and mortality. Recent publications suggest improvement, but the results of the studies are difficult to compare. Despite many experimental studies no unifying causative factor has been identified so far. Studies on toxic effects of bile acids and bilirubin did not provide consistent data. Malnutrition was suggested as a possible factor involved in the high complication rates but evidence was not sustained. Impairment of the immune system was convincingly shown, both experimentally and clinically, which correlates with the frequent septic complications. However, no direct etiologic mechanism was found for the impaired immune functions.

Renal impairment, another complication related to obstructive jaundice, was also extensively investigated. Renal impairment was clearly related to alterations of renal and systemic circulation. Again no convincing causative mechanism was revealed, however in some studies a relation between renal insufficiency and endotoxemia was found. 
Endotoxemia was also mentioned in relation with postoperative hemorrhage. In clinical studies endotoxemia was related to disseminated intravascular coagulation and postoperative mortality. This and the observation that preoperative treatment with anti-endotoxin agents, in animals as well as in the clinical situation, can prevent postoperative complications in obstructive jaundice, suggests that endotoxins are involved in the etiology of some complications.

Finally, on theoretical grounds, preoperative biliary drainage is the most physiologic preventive treatment. Clinical studies with external biliary drainage were however disappointing. Experimental studies suggest that internal biliary drainage offers greater benefit and this has to be explored further.

A description of the aim of this thesis and a short introduction to the experiments are provided in Chapter 2. The techniques used to measure endotoxins and the mediator of endotoxin toxicity, TNF, are discussed. Unfortunately both endotoxin and TNF are difficult to determine in plasma, due to the intermittent and often short duration of their presence. Therefore triglycerides, a more stable factor reflecting TNF activity, were measured in the in vivo experiments.

Experiments to investigate the role of endotoxins in the etiology of complications in obstructive jaundice are presented in Chapter 3. Germ-free, endotox in poor, rats were used to study the effects of biliary obstruction on cellular immunity and nutritional status in presence of very small amounts of endotoxins. In contrast to conventional rats, cellular immunity in germ-free rats was not suppressed following biliary obstruction. No differences were observed with respect to the nutritional status of germ-free and conventional jaundiced rats. A relation was found between the activation of peritoneal macrophages (measured by spontaneous TNF release, indicative for toxic effects of endotoxins) and the suppression of cellular immunity in jaundiced rats. The results strongly indicate that endotoxins cause the observed suppression of cellular immunity in jaundiced rats.

In Chapters 4 and 5 experiments are reported that study the mechanism through which "anti-endotoxin" agents such as bile acids and lactulose are active. Both studies were in vitro experiments. The model used was based on the TNF production by monocytes after stimulation with endotoxins. It was shown that bile acids and lactulose, agents used in clinical studies to prevent endotoxin related complications, significantly inhibit the production of the mediator of endotoxin toxicity. Deoxycholic acid was a strong inhibitor of TNF release whereas chenodeoxycholic acid was less and ursodeoxycholic acid was 
not effective. These results correlate clearly with the results of these bile acids in jaundiced patients. In contrast to previous reports no direct effect of the bile acids and lactulose on endotoxin as measured with the endotoxin assay was found. The results suggest that bile acids and lactulose are effective by a direct inhibitory effect on the effector cell of endotoxin toxicity.

Experiments on the role of endotoxin and tumor necrosis factor on the occurrence of complications are presented in Chapter 6. Experimental renal ischemic damage was aggravated with concomitant administration of endotoxins or TNF. The observed effect was synergistic rather than additive. Not only deterioration of renal function but also mortality was significantly increased. These results indicated that in a compromised host, such as the jaundiced patients, in which circulating endotoxins and subsequently TNF possibly are chronically present a minor ischemic trauma may be sufficient to induce renal impairment and even worse mortality.

In order to study the effect of preventive treatments on postoperative complications the described renal ischemia model was used in jaundiced rats. The results are reported in Chapter 7 . Renal ischemia in jaundiced rats resulted in a significantly increased renal impairment and mortality. Anti-endotoxin treatment with oral lactulose significantly reduced this mortality but not renal impairment, whereas internal biliary drainage significantly improved both. Increased triglyceride levels in jaundiced rats correlated significantly with "postoperative" (post renal ischemia) mortality. The latter suggested indirectly that endotoxin and subsequently TNF were involved in the observed morbidity and mortality.

It is concluded in Chapter 8 that endotoxins are related with renal impairment and suppression of cellular immunity. Furthermore anti-endotoxin treatments, e.g. oral lactulose or internal biliary drainage, can prevent these complications. Based on the results of the experiments a decision tree for the use of supportive preoperative therapy in jaundiced patients is proposed.

Internal biliary drainage is the preoperative preventive treatment of choice in jaundiced patients. The anti-endotoxin (lactulose) treatment may be used supplementary. Support can be provided by oral lactulose in cases where adequate, safe and complete drainage of the biliary tract is not possible. 
De chirurgische behandeling van patiënten met een obstructie icterus gaat gepaard met een onevenredig hoog aantal complicaties. Het overlijdens risico is in vergelijking met gelijkwaardige operaties in niet icterische patiënten significant hoger. De oorzaak van deze verhoogde vatbaarheid voor postoperatieve complicaties is grotendeels onbekend. Ter voorkoming van deze complicaties werden in de literatuur een aantal preoperatieve behandelingen voorgesteld en klinisch getest. De meeste therapieën bleken echter weinig effect te hebben.

Het doel van dit onderzoek was meer inzicht te krijgen in de etiologie en de pathofysiologie van de complicaties die optreden bij obstructie icterus. Een onderzoek naar de oorzaken die hieraan ten grondslag liggen vormt het eerste deel van deze thesis. (Hoofdstuk 3,6) In het tweede gedeelte wordt een aantal preventieve behandelingen bestudeerd (Hoofdstuk 4,5,7).

In Hoofdstuk 1 wordt een overzicht gegeven van de literatuur met betrekking tot postoperatieve complicaties bij patiënten met een obstructie icterus. Hieruit blijkt dat er de laatste decennia nauwelijks enige verbetering is opgetreden. De sterfte cijfers en het aantal complicaties blijven onveranderd hoog, waarbij met name infecties, bloedingen en een verslechterde nierfunctie een rol spelen.

Uit zowel experimenteel als klinisch onderzoek zijn een aantal mogelijke oorzaken van deze complicaties naar voren gebracht. Er werd onder andere gesuggereerd dat toxische effecten van galzuren en/of bilirubine een rol spelen. De experimentele gegevens zijn echter controversieel. Hetzelfde geldt voor de slechte voedingstoestand die in relatie werd gebracht met de verhoogde kans op infecties en de slechte wondgenezing. Doorbloedingsstoornissen van de nier van systemische of lokale aard zouden een rol spelen in het optreden van nierinsufficiêntie, maar ook hiervoor kon geen definitieve verklaring worden vastgesteld.

In een aantal publikaties werd een relatie beschreven tussen de endotoxinemie en het onstaan van acute nierinsufficièntie. In andere studies werd de endotoxinemie gerelateerd aan het optreden van postoperatieve bloedingen, gedissemineerde intravasale stolling en aan de verhoogde mortaliteit. De preventieve behandeling tegen endotoxine, met oraal lactulose of orale galzuren, bleek in enkele klinische studies met icterische patiënten effectief te zijn (minder nierfunctie stoomissen). Deze observaties suggereren dat endotoxinen een rol spelen in de pathofysiologie van complicaties die kunnen optreden bij icterische patiënten. 
Op theoretische gronden is preoperatieve drainage van de afgesloten galwegen de preventieve behandeling van keuze. In de praktijk bleek echter dat de, aanvankelijk gebruikte, uitwendige galwegdrainage geen vermindering geeft van het percentage complicaties. Resultaten van dierexperimentele studies suggereren dat inwendige galwegdrainage, met herstel van de enterohepatische kringloop, wel effectief zou zijn. Dit laatste dient nader onderzocht te worden.

Hoofdstuk 2 bestaat uit een introductie van de experimenten beschreven in dit proefschrift. Het doel van de studie wordt hierin naar voren gebracht. Een belangrijk deel van de experimenten heeft direct of indirect te maken met endotoxinen. Met name de rol van endotoxinen in het ontstaan van complicaties en het effect van preventieve behandelingen gericht tegen deze endotoxinen werden bestudeerd. Voor de bepaling van endotoxinen werd een recent gemodificeerde chromogene limulus amoebocyte lysate (LAL) test gebruikt. In plasma is het meten van endotoxinen, met name door de korte halfwaarde tijd, zeer gecompliceerd. Vandaar dat ook de belangrijkste mediator van endotoxine, tumor necrosis factor (TNF), werd gemeten. Hiervoor werd een zeer gevoelige en specifieke ELISA (enzyme linked immuno sorbent assay) gebruikt. Helaas bleek ook de plasmakinetiek van TNF onvoorspelbaar te zijn. Daarom werden in de laatste experimenten serum triglyceriden gemeten, die mogelijk direct gerelateerd zijn aan TNF en dus ook indirect aan endotoxine.

De rol van endotoxine in de etiologie van complicaties ten gevolge van galwegobstructie werd bestudeerd in kiemvrije ratten. De resultaten zijn beschreven in Hoofdstuk 3. In de kiemvrije en dus praktisch endotoxinevrije ratten werd het effect van galwegobstructie op cellulaire immuniteit en voedingsstatus bestudeerd. In tegenstelling tot de conventionele rat was de cellulaire immuniteit in de kiemvrije rat niet onderdrukt na experimentele galwegobstructie. De voedingstoestand van de icterische kiemvrije rat was niet verschillend van die van de conventionele icterische rat. In conventionele ratten met galwegobstructie werd een relatie gevonden tussen de activiteit van peritoneaal macrofagen (bepaald aan de hand van spontane TNF produktie) en de beschreven onderdrukking van de cellulaire immuniteit. De resultaten suggereren dat de onderdrukking van de cellulaire immuniteit in icterische ratten wordt veroorzaakt door endotoxinen.

In de Hoofdstukken 4 en 5 worden de resultaten weergegeven van een onderzoek naar het werkingsmechanisme van galzuren en lactulose die als "anti-endotoxine" middel klinisch zijn gebruikt. In de proefopstelling werd gebruik gemaakt van het feit dat monocyten TNF, de mediator van endotoxine 
toxiciteit, produceren wanneer ze worden gestimuleerd met endotoxine. Het effect wan de genoemde stoffen kon worden bepaald aan de hand van hun invlloed op de door endotoxine geinduceerde TNF productie. Tevens werd met behulp van de LAL test het rechtstreekse effect van deze stoffen op endotoxine gemeten. Bij de gebruikte concentraties bleken zowel lactulose als de galzuren niet in staat endotoxine direct te inactiveren, dit in tegenstelling tot eerdere publikaties. Toch verminderde het galzuur deoxycholzuur en in mindere mate chenodeoxycholzuur de produktie van de mediator van endotoxine toxiciteit (TNF) significant. Ursodeoxycholzuur had geen effect op de TNF produktie van de monocyten gestimuleerd met endotoxine. Deze resultaten komen overeen met de effectiviteit van deze gallzuren in de klinische studies. Ook lactulose veroorzaakte een significante vermindering van de TNF produktie na stimulatie met endotoxine. De resultaten van deze experimenten geven een duidelijke aanwijzing dat zowel galzuren als lactulose effectief de toxiciteit van endotoxine verminderen doordat $z i j$ de effectorcel van de endotoxine toxiciteit, de mononucleaire fagocyten, rechtstreeks remmen.

De rol van endotoxine en TNF bij het ontstaan van complicaties werd verder bestudeerd in experimenten beschreven in Hoofdstuk 6 . In een rattenmodel werd het effect van endotoxine en TNF in combinatie met nierischemie op de nierfunctie en de mortaliteit gemeten. Beide stoffen bleken de nierbeschadiging door ischemie significant te verergeren. Het gemeten effect was daarbij synergistisch en niet additief. Ook bleek de mortaliteit ten gevolge van nierischemie in combinatie met endotoxine of TNF significant verhoogd te zijn. De resultaten suggereren dat bij patiënten in een matige toestand, zoals de icterische patiënt, waarin lage hoeveelheden endotoxine en mogelijk ook TNF in het plasma aanwezig zijn, slechts een beperkte weefsel beschadiging voldoende kan zijn om een acute nierinsufficiëntie of zelfs mortaliteit te veroorzaken.

In Hoofdstuk 7 werd het effect van preventieve behandelingen in een rattenmodel getest. Het nierischemie model werd hiervoor gebruikt in ratten met een experimentele galwegobstructie. Het effect van preoperatieve behandeling met lactulose werd vergeleken met het effect van preoperatieve inwendige galwegdrainage. Nierischemie in icterische ratten resulteerde in een significant verhoogde nierinsufficiëntie en verhoogde mortaliteit in vergelijking met niet icterische controle ratten. De "anti-endotoxine" behandeling met lactulose verminderde de mortaliteit na nierischemie in de icterische rat significant. De nierinsufficiëntie leek wel verminderd maar het verschil was niet statistisch significant. Inwendige galwegdrainage gaf een significante vermindering van zowel de nierinsufficiëntie als de mortaliteit. Verhoogde triglyceriden spiegels 
in icterische ratten correleerden significant met postoperatieve mortaliteit. Dit suggereert indirect dat TNF en dus ook endotoxinen een rol spelen in het ontstaan van complicaties bij obstructie icterus.

In hoofdstuk 8 wordt een algemene conclusie van de experimenten weergegeven. Endotoxinen lijken verantwoordelijk voor zowel de nierfunctiestoornissen als de verminderde cellulaire immuniteit. Het effect van "anti-endotoxine" behandeling met galzuren en lactulose kan worden verklaard door een remmend effect op TNF productie door mononucleaire fagocyten. In vivo blijkt lactulose ook effectief te zijn. Het preventieve effect van de inwendige galwegdrainage was echter superieur.

Op basis van de experimentele bevindingen wordt aan de hand van een beslisboom een voorstel gedaan voor het preoperatieve belleid bij patiënten met een galwegobstructie. De resultaten geven aan dat een veilige inwendige galwegdrainage de preventieve behandeling van keuze is. Blijkt om technische redenen een adequate drainage van de galwegen niet mogelijk dan kan een preventieve behandeling met lactulose ondersteuning geven. 


\section{Acknowledgements}

When a thesis has passed its final test, the author receives all the congratulations. However, the effort necessary to accomplish a thesis can only be the result of successful teamwork. I would like to emphasize here that I am indebted to everybody who has been a member of the team and that a major part of the appreciation should be directed to them.

I am specially grateful to Dr. Dirk Gouma who turned me from a passive bystander into a enthusiastic "researcher". His never ending drive and his great experience in the field of basic research on obstructive jaundice formed the basis of this thesis.

Dr. Wim Buurman, without your astonishing insight of all aspects of research, your capacity to analyze the whirlpool of data resulting from experiments and your ability to mould them into logic results, I would still be trying to write my first paper. You are able to gently lead the blind into the land of the seeing, and I was one of those.

I thank Prof. Dr. Co Greep for his critical review of the manuscript, which was greatly improved by his suggestions.

I am indebted to Prof. Dr. Peter Soeters and to Prof. Dr. Huug Obertop who both provided financial and mental back-up when it counted most.

Jos Maessen your contribution to this thesis has been substantial. Without your always available help, many of the experiments performed during the last strenuous month in the Biomedical Center would not have been accomplished. Ton Tiebosch saved me from the heavy burden of preparing and assessing the necessary tissue biopsies, for which I am obliged.

I greatly appreciated the help and never ending patience of Trudy Jeunhomme, Ilse Dieteren, Jet Leeuwenberg and Marielle van der Linden from our laboratory in which the experimental work was performed. Many of the standard laboratory tests were meticulously performed by Mieke Jansen for which I am thankful. Math Hazen was responsible for bacterial cultures and put great effort in bile acid determinations. I am grateful to the personnel of the Depart- 
ment of experimental animal facilities (head Dr. T. van den Bogaard), especially Eep van Dam, Frans Weekers and Peter Kelderman, for all their help. Further it is impossible to mention everybody, but I am indebted for all the kind support I received from fellow researchers and from co-workers of the microbiology, pathology and virology laboratories in the Biomedical Center.

The staff of the surgical department (head: Prof. Dr. Co Greep and Prof. Dr. Gouke Kootstra) gawe me the opportunity to perform the experiments for which I am much obliged. I am indebted to all residents and junior surgeons who had to work a little harder because of my absence.

$I$ thank Dr. Karly Hamulyak and the personnel of the laboratory of hematology, and Dr. Degenaar and the personnel of the laboratory of clinical chemistry for their pleasant cooperation.

II thank Prof. Dr. Flendrig, Prof. Dr. Arends, Prof. Dr. Brombacher, Prof. Dr. Obertop and Prof. Dr. Tytgat for reviewing the final version of this thesis.

I look back with respect and admiration on the support I received from my late father Prof. Dr. Leo Greve, he was and always will be my greatest example. Unfortunately he was only allowed to witness the first stages of my experimental work. He would have been so proud.

The ever present backing of my father in law and especially my mother was invaluable for me to be able to accomplish this thesis. My appreciation of this was not always appropriately shown, but be sure that it was there.

Chantal by now all words to express gratitude have been used several times in this acknowledgement. These words are, however, insufficient to depict the admiration and gratitude I have for your achievements which have at least surpassed mine. While I was working on this humble thesis, you not only gave birth to our daughter Charlotte but allso finished your Law study. Besides that you were able to keep our little family running and were always there to support me in the difficult hours. I really thank you for everything. 


\section{Curriculum Vitae}

Jan Willem Greve was born on February $22^{\text {nd }} 1956$ in Utrecht, The Netherlands. He attended high school in Roermond, Bisschoppelijk College (Atheneum B). In 1974 he went to Medical School at the Catholic University of Leuven, Belgium and graduated in 1981. In April 1982 he started his surgical residency at the Surgical Department of the Academic Hospital, University of Limburg, Maastricht (Head: Prof. Dr. J.M. Greep, and Prof. Dr. G. Kootstra). From April 1986 till September 1988 he was research fellow at the Laboratory of the Department of Surgery, Biomedical Center, University of Limburg. He was registered as a surgeon April 1989 and presently works as "junior" surgeon at the Surgical Department, Academic Hospital, University of Limburg, The Netherlands. 